\title{
Metal-Free Hydropyridylation of Thioester-Activated Alkenes via Electroreductive Radical Coupling
}

\author{
Hehuan Xu, ${ }^{*}$ Jiayu Liu, Feiyun Nie, Xiaowei Zhao, Zhiyong Jiang*
}

Contents

1. Cyclic Voltammetry Studies

2. Computational Details

3. NMR Spectra of Radical Coupling Products

4. NMR Spectra of New Olefin Substrates

5. High-Resolution Mass Spectrum of Product 48

6. References
Page

S2

S3

S4

$\mathbf{S 4 0}$

S65

S66 


\section{Cyclic Voltammetry Studies}

The cyclic voltammograms (Figure S1) were recorded in an electrolyte solution of $\mathrm{Et}_{4} \mathrm{NBF}_{4}(0.1 \mathrm{M})$ in $\mathrm{DMSO} / \mathrm{MeOH}$ (1:1) using a glassy carbon disk working electrode (diameter, $3 \mathrm{~mm}$ ), a Pt wire auxiliary electrode and an $\mathrm{Ag} / \mathrm{AgCl}$ reference electrode. The scan rate was $50 \mathrm{mV} / \mathrm{s}$.

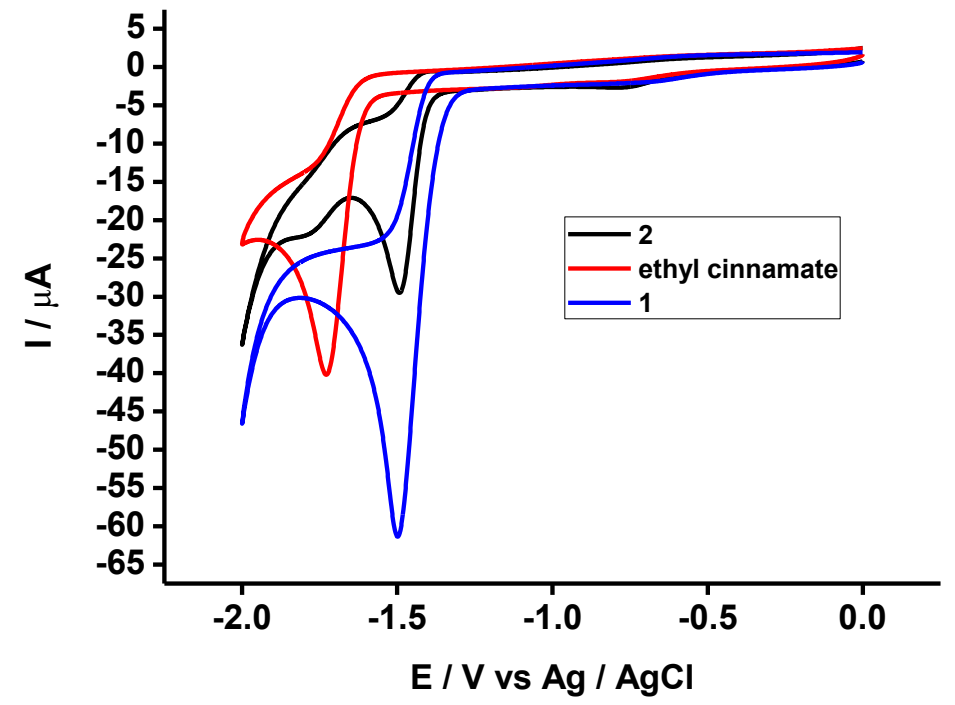

Figure S1. Cyclic voltammograms. a) $1(2.5 \mathrm{mM}), 2(2.5 \mathrm{mM})$, ethyl cinnamate $(2.5 \mathrm{mM})$ in $\mathrm{DMSO} / \mathrm{MeOH}(10 \mathrm{~mL}, 1: 1)$.

The cyclic voltammograms (Figure S2) were recorded in an electrolyte solution of $\mathrm{Et}_{4} \mathrm{NBF}_{4}(0.1$ $\mathrm{M}$ ) in DMSO using a glassy carbon disk working electrode (diameter, $3 \mathrm{~mm}$ ), a Pt wire auxiliary electrode and an $\mathrm{Ag} / \mathrm{AgCl}$ reference electrode. The scan rate was $50 \mathrm{mV} / \mathrm{s}$.

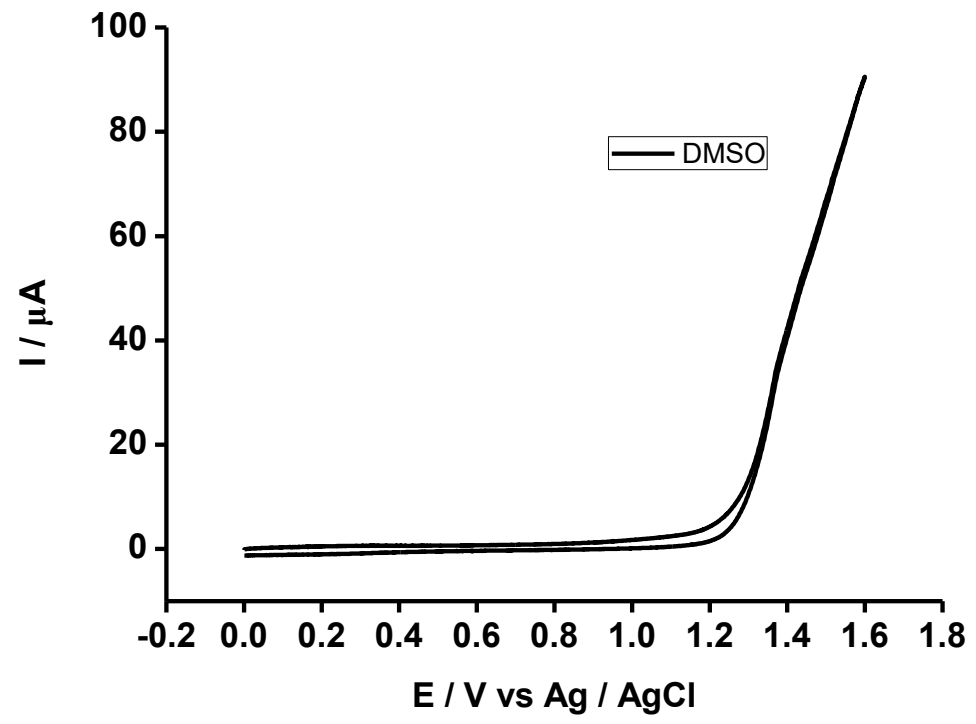

Figure S2. Cyclic voltammogram of DMSO. $\mathrm{Et}_{4} \mathrm{NBF}_{4}(0.1 \mathrm{M})$ in DMSO $(10 \mathrm{~mL})$. 


\section{Computational Details}

All spin-unrestricted DFT calculations were performed by Gaussian 16 program. ${ }^{1}$ The hybrid exchangecorrelation functional B3LYP and $6-311+\mathrm{G}(\mathrm{d}, \mathrm{p})$ basis set was employed to optimize all structures of the ground states. Frequency calculations showed that the optimized structures have the minimum energy states on the potential energy surfaces. All the energies were calculated at $298.15 \mathrm{~K}$ and corrected by considering zero-point energies.

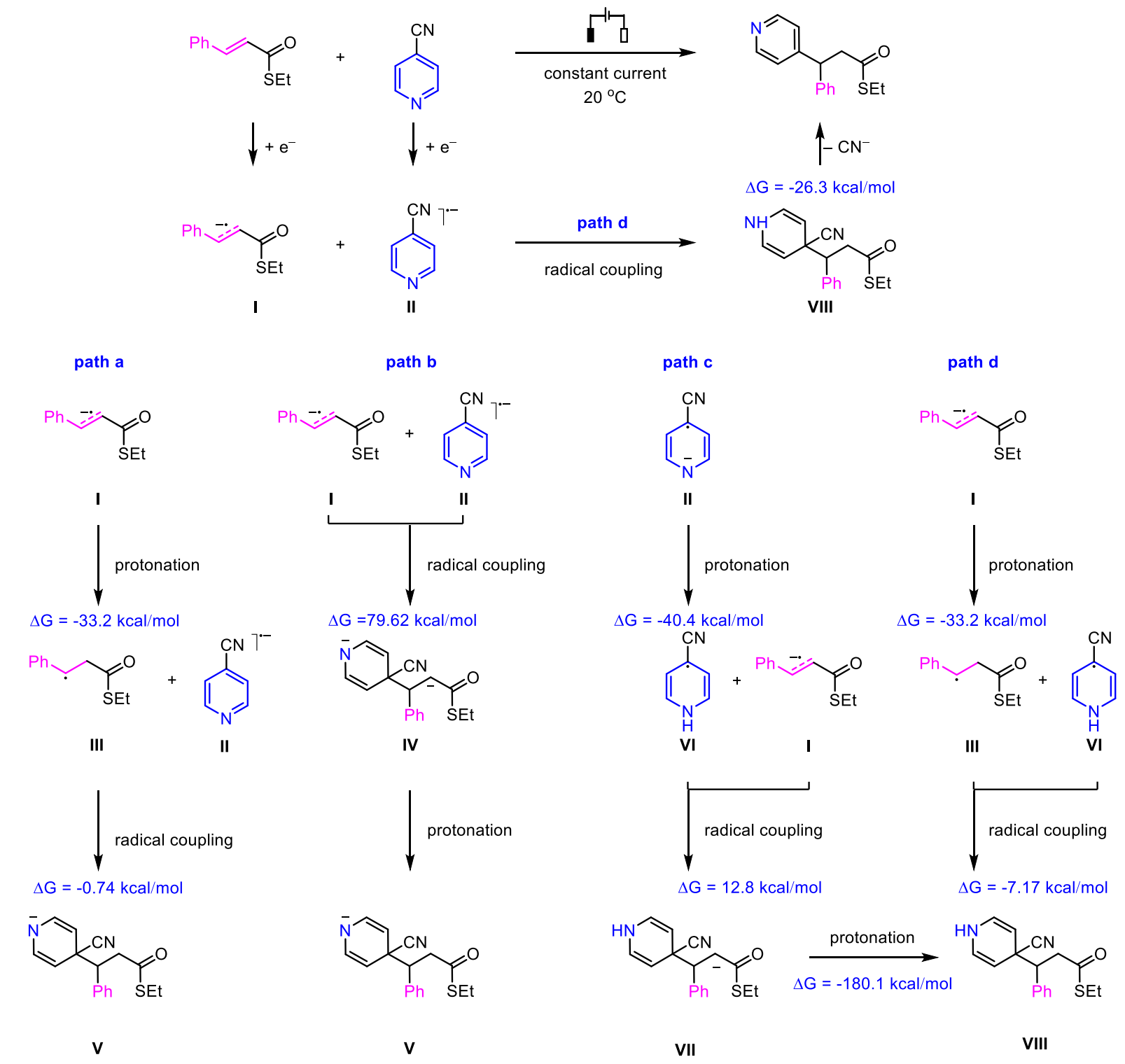

Figure S3. Computational Details. 


\section{NMR Spectra of Radical Coupling Products}
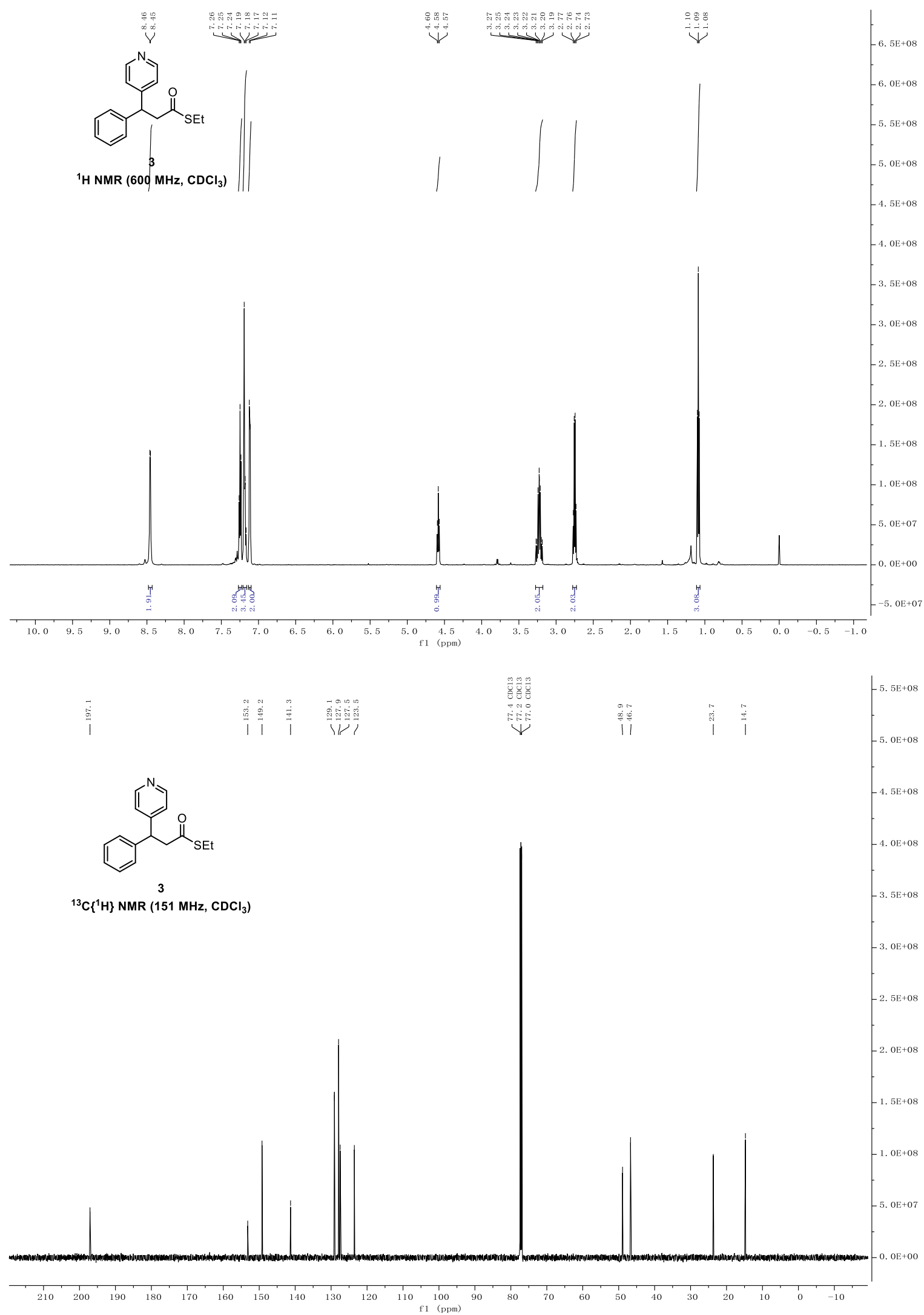


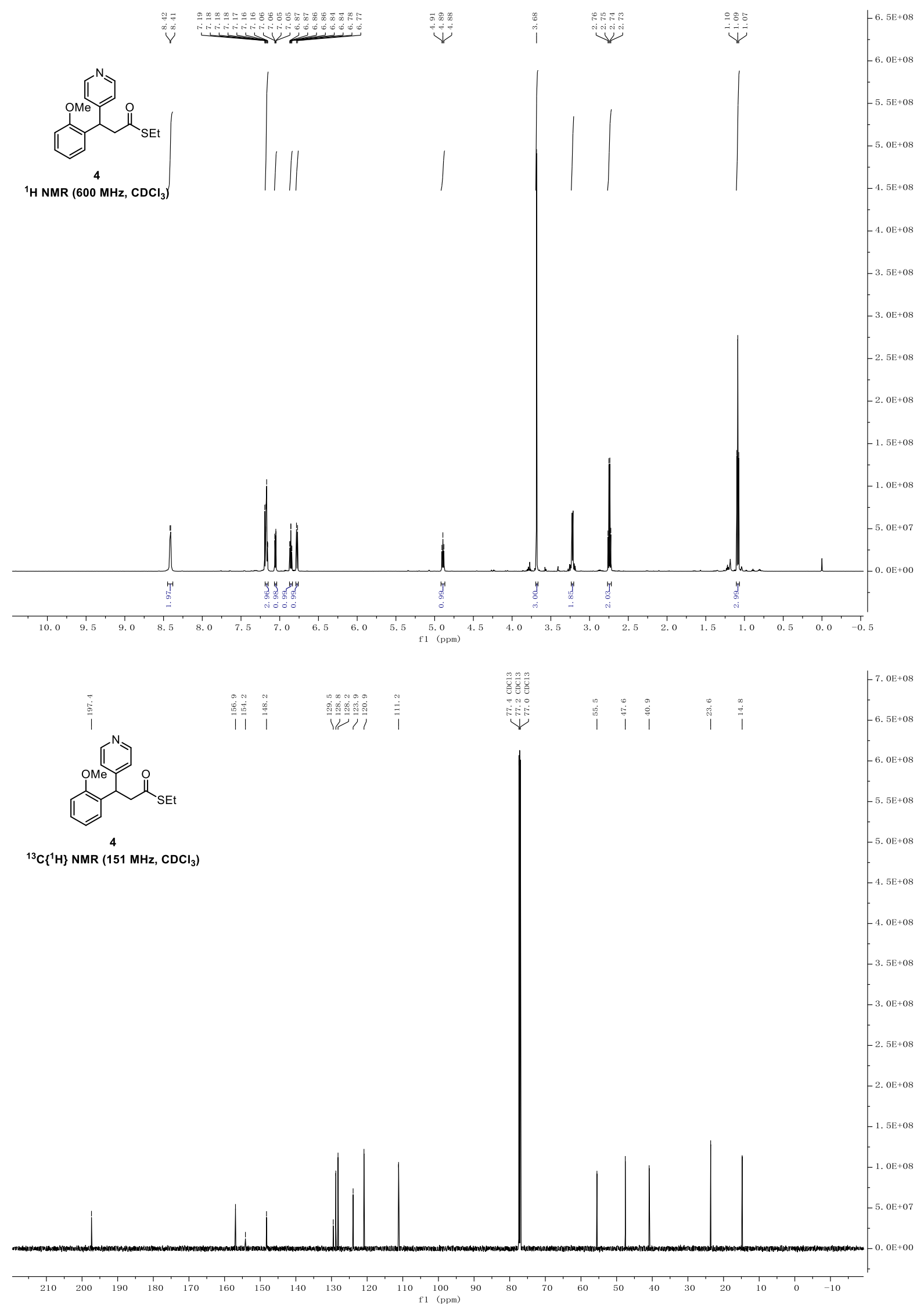




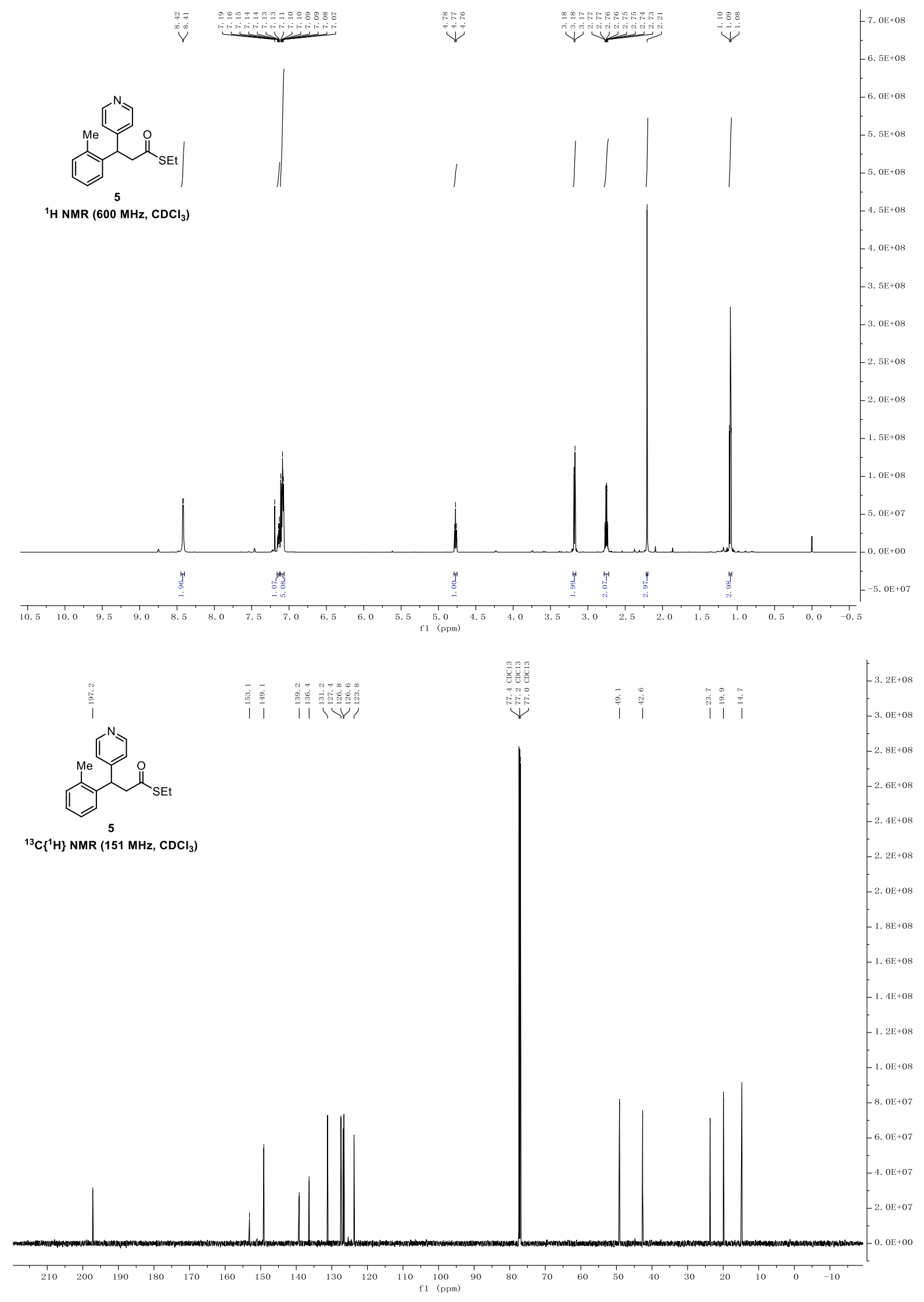




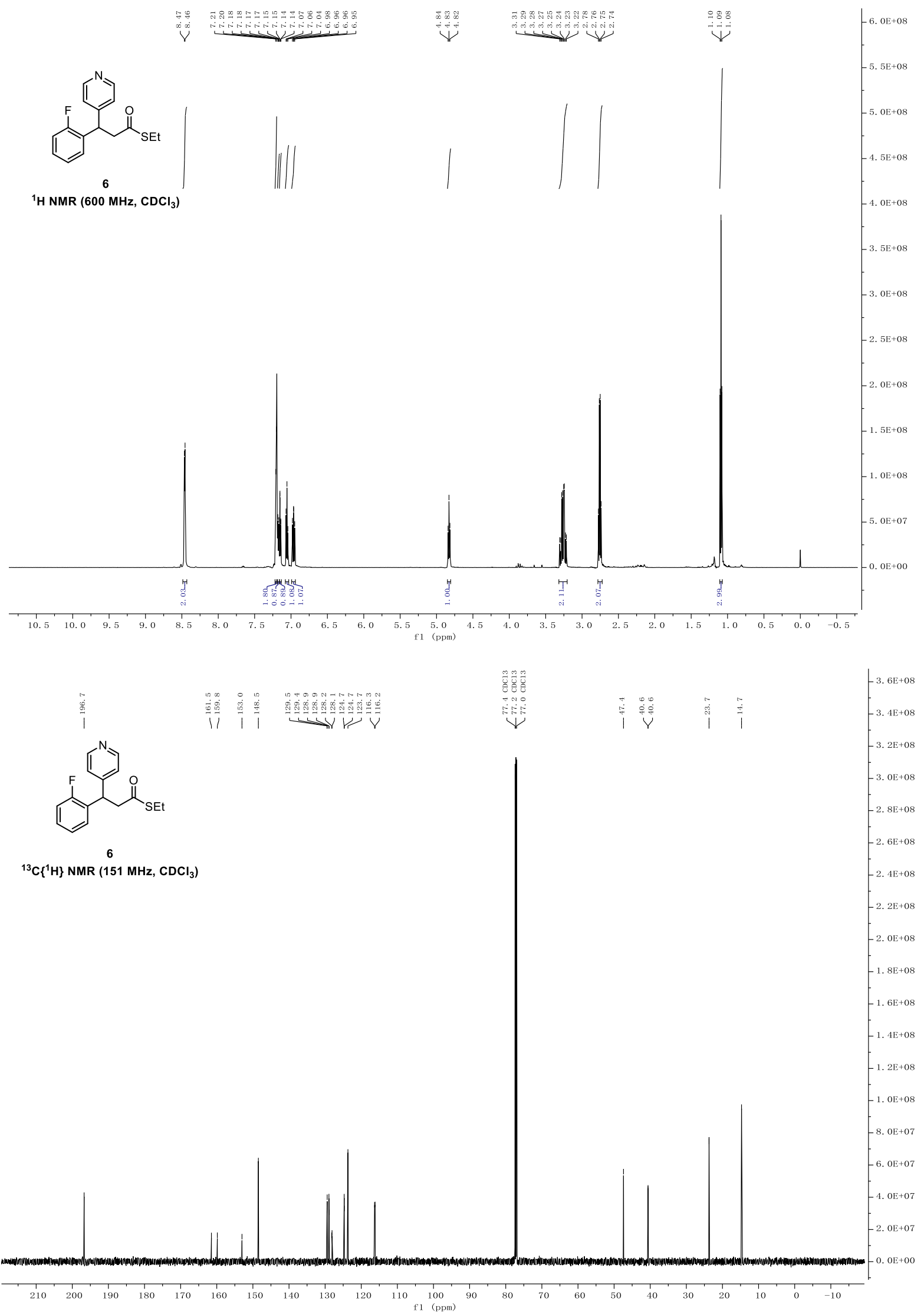




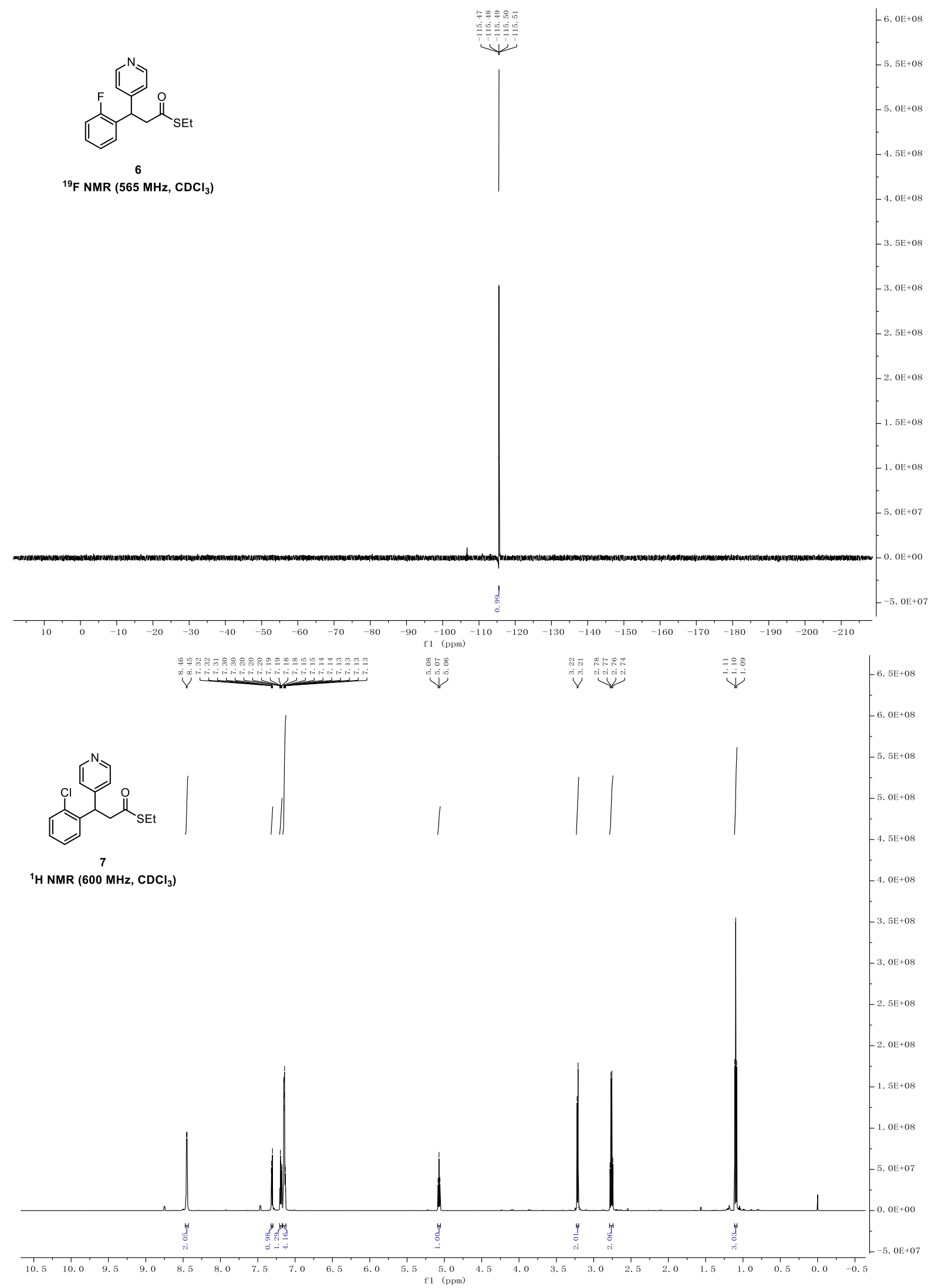




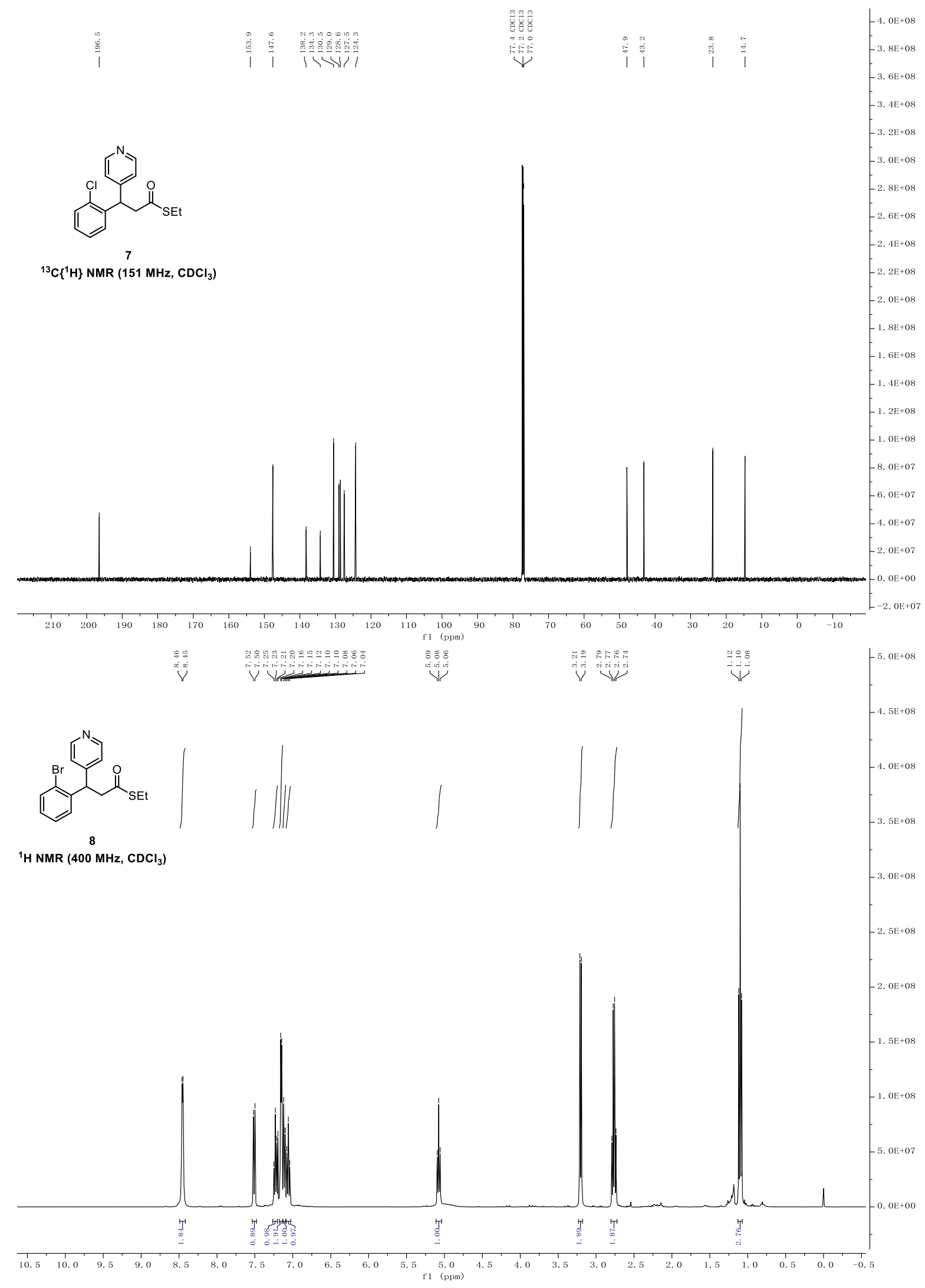




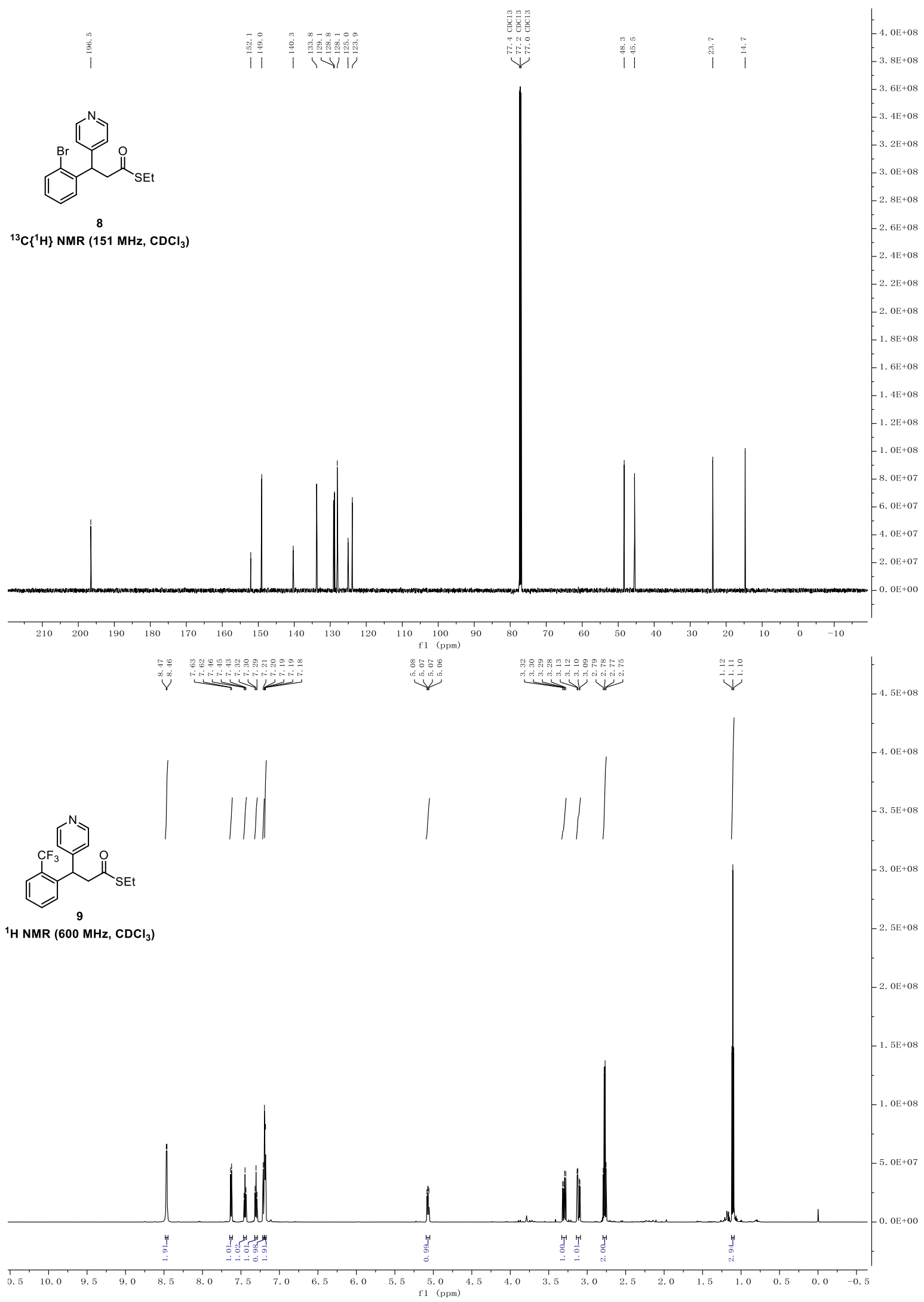




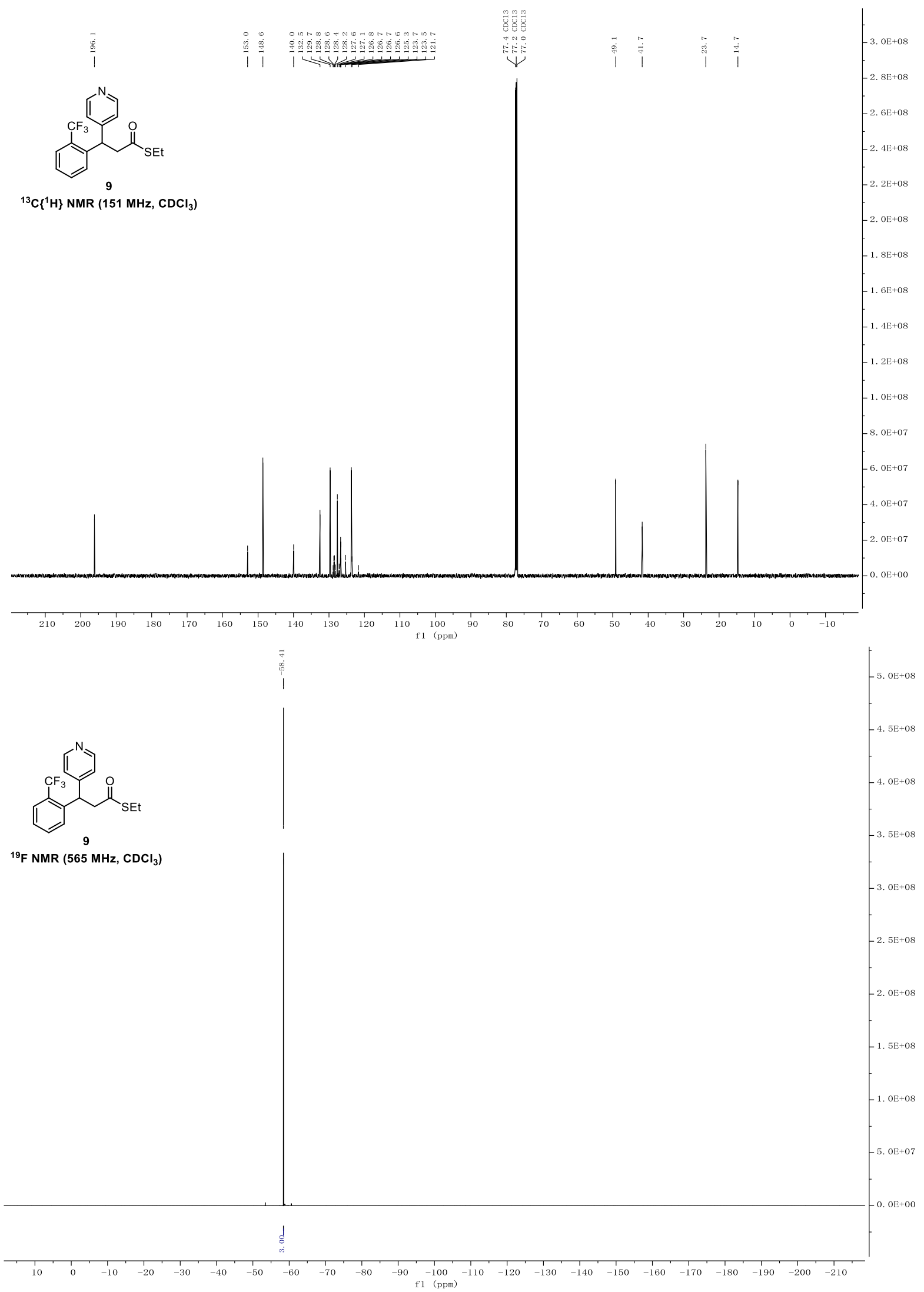




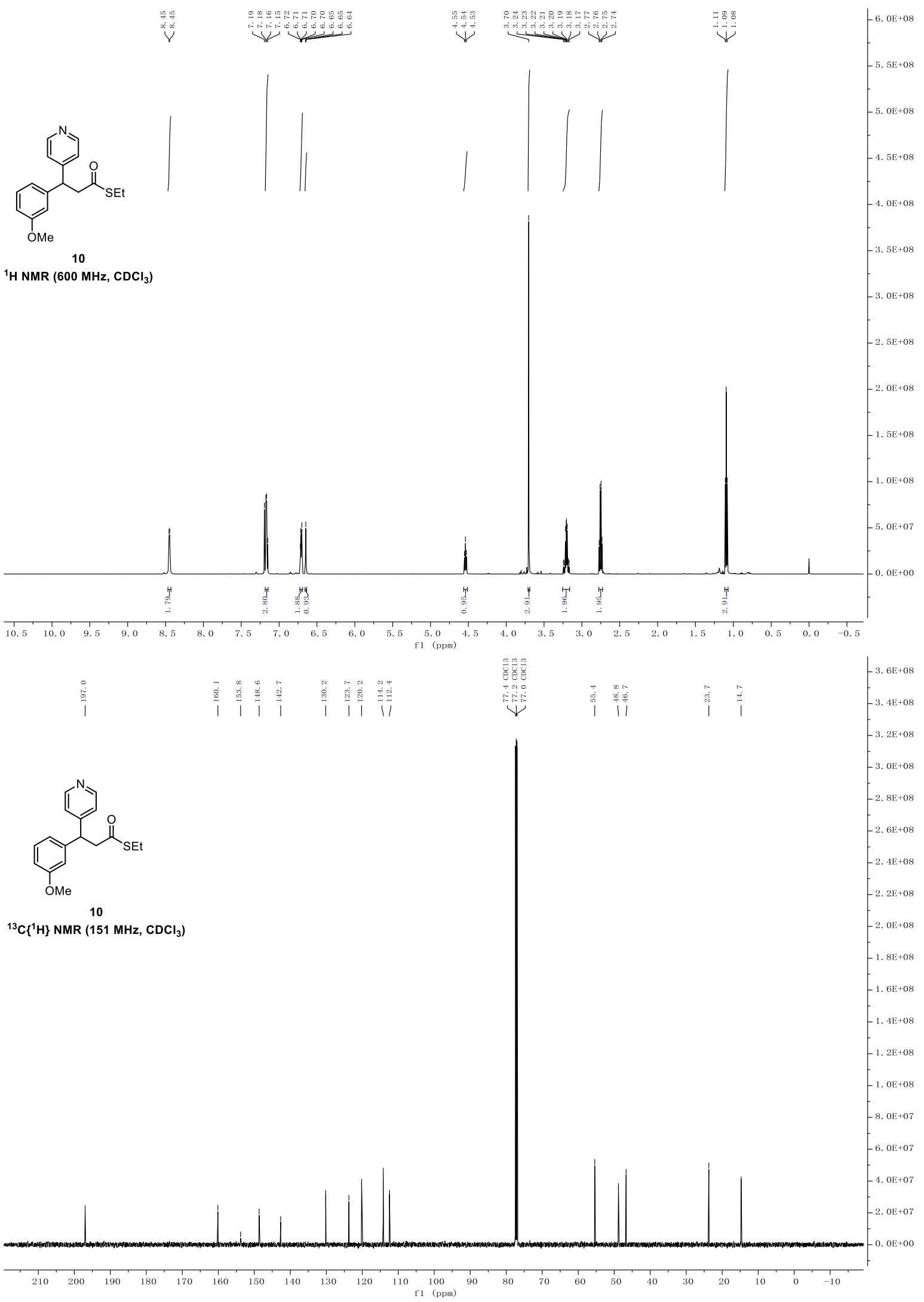




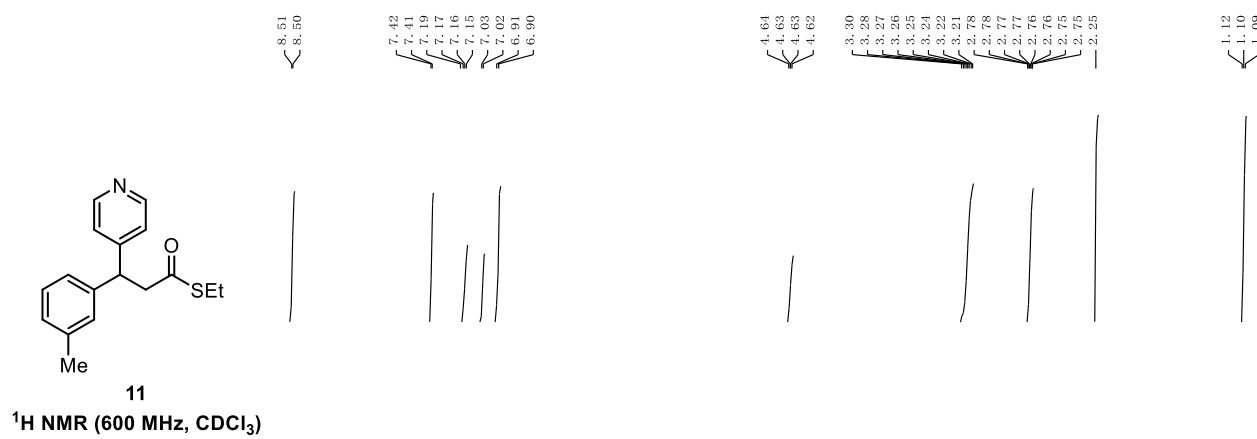

${ }^{1} \mathrm{H}$ NMR $\left(600 \mathrm{MHz}, \mathrm{CDCl}_{3}\right)$
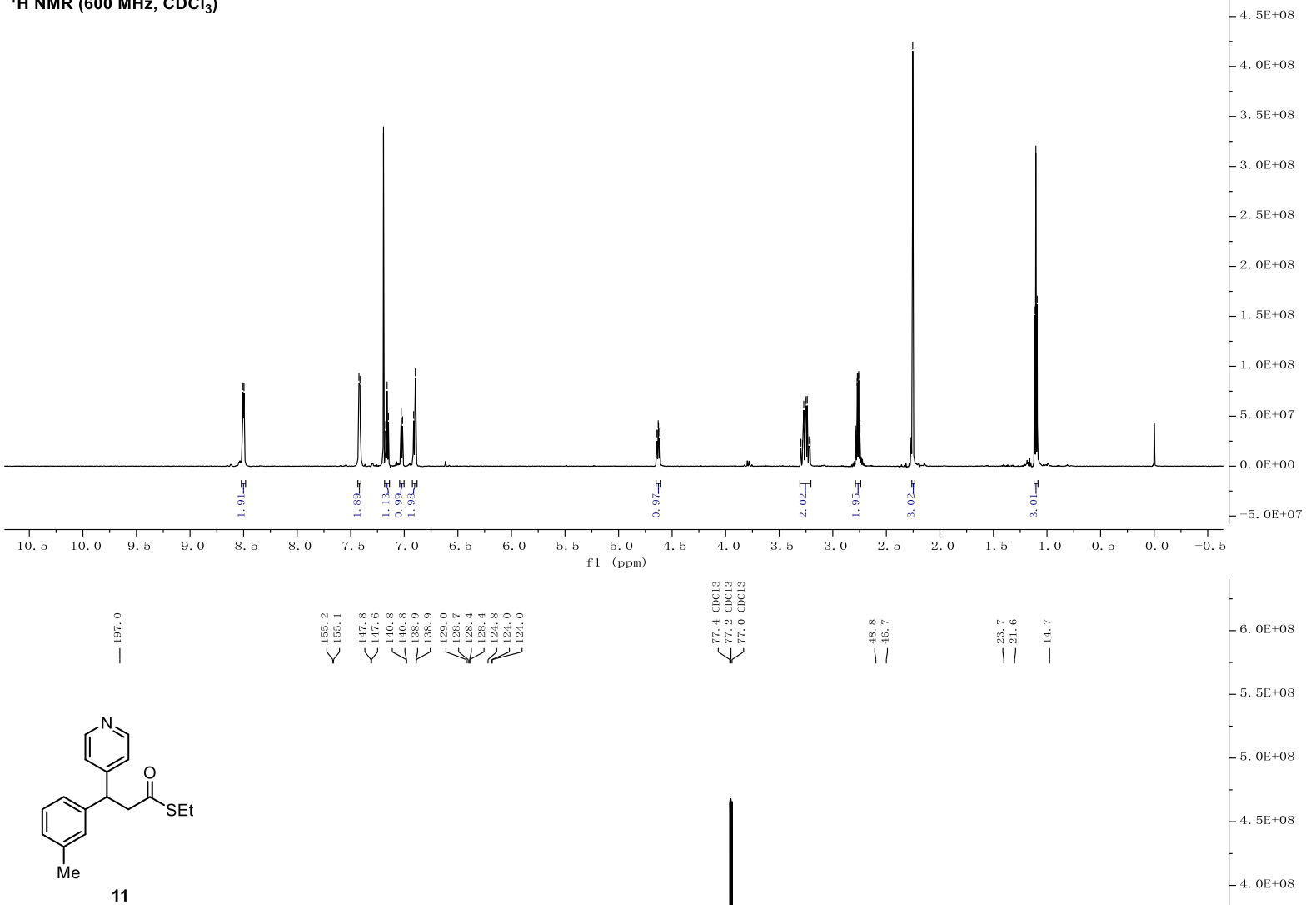

${ }^{13} \mathrm{C}\left\{{ }^{1} \mathrm{H}\right\}$ NMR (151 MHz, $\left.\mathrm{CDCl}_{3}\right)$
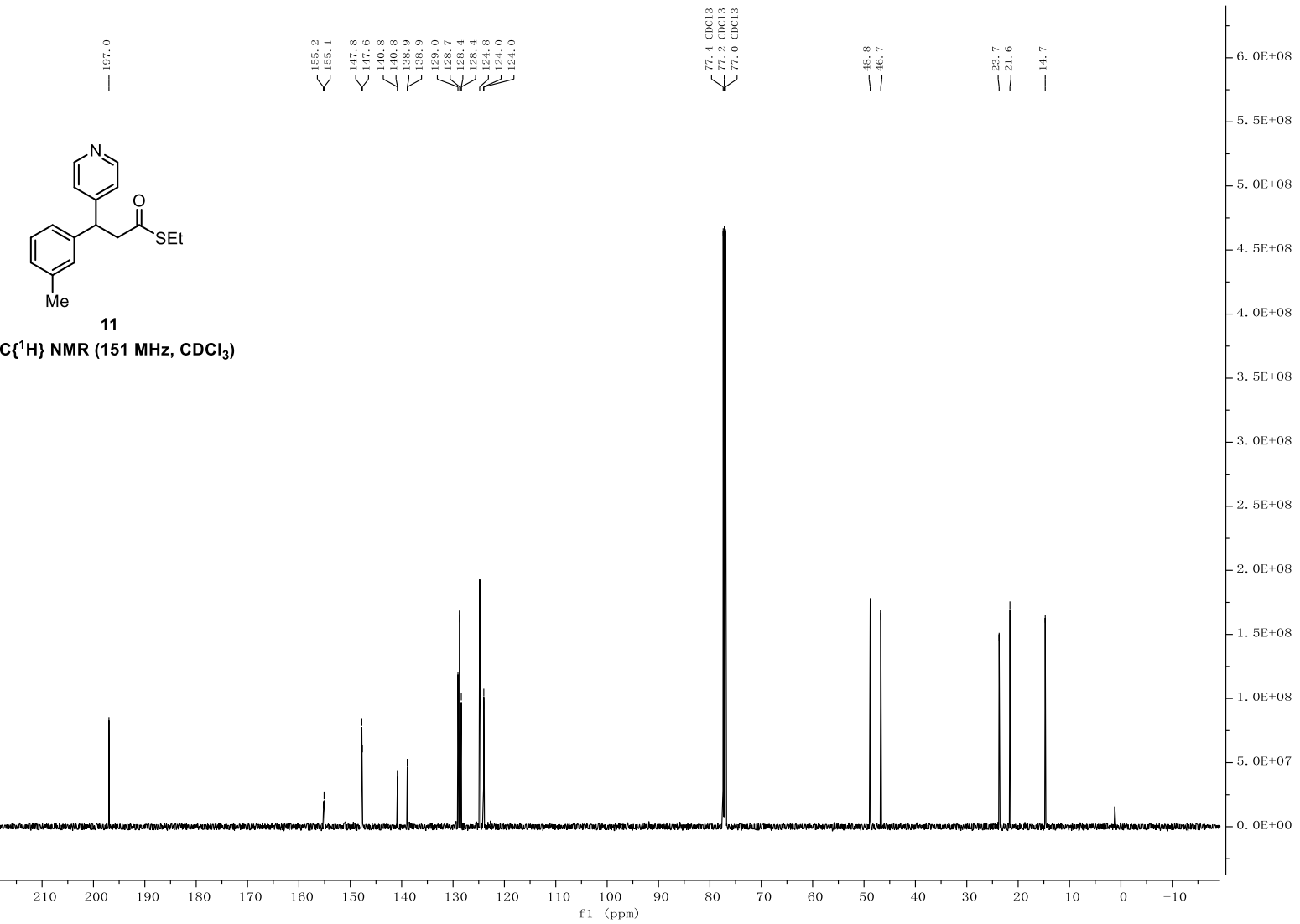

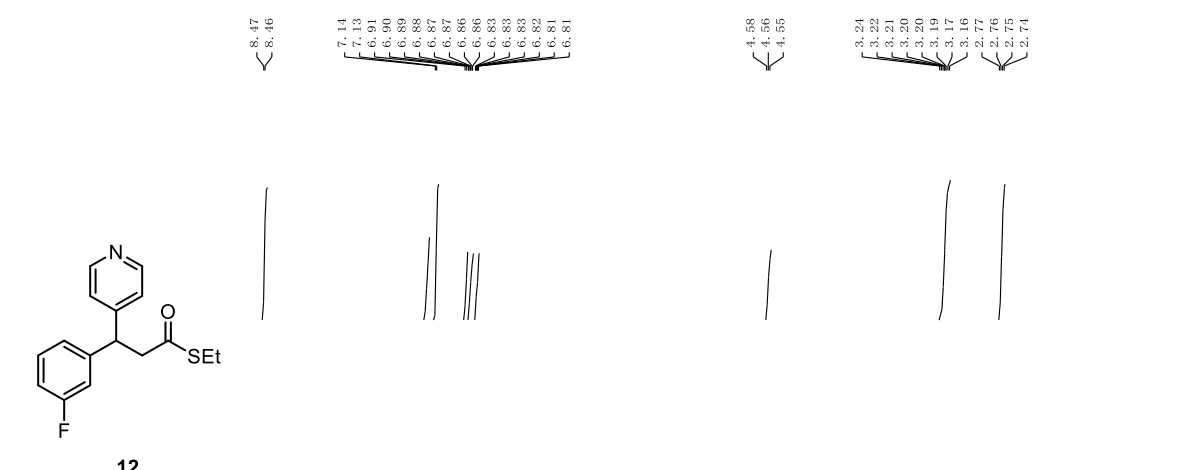

${ }^{1} \mathrm{H}$ NMR $\left(600 \mathrm{MHz}, \mathrm{CDCl}_{3}\right)$

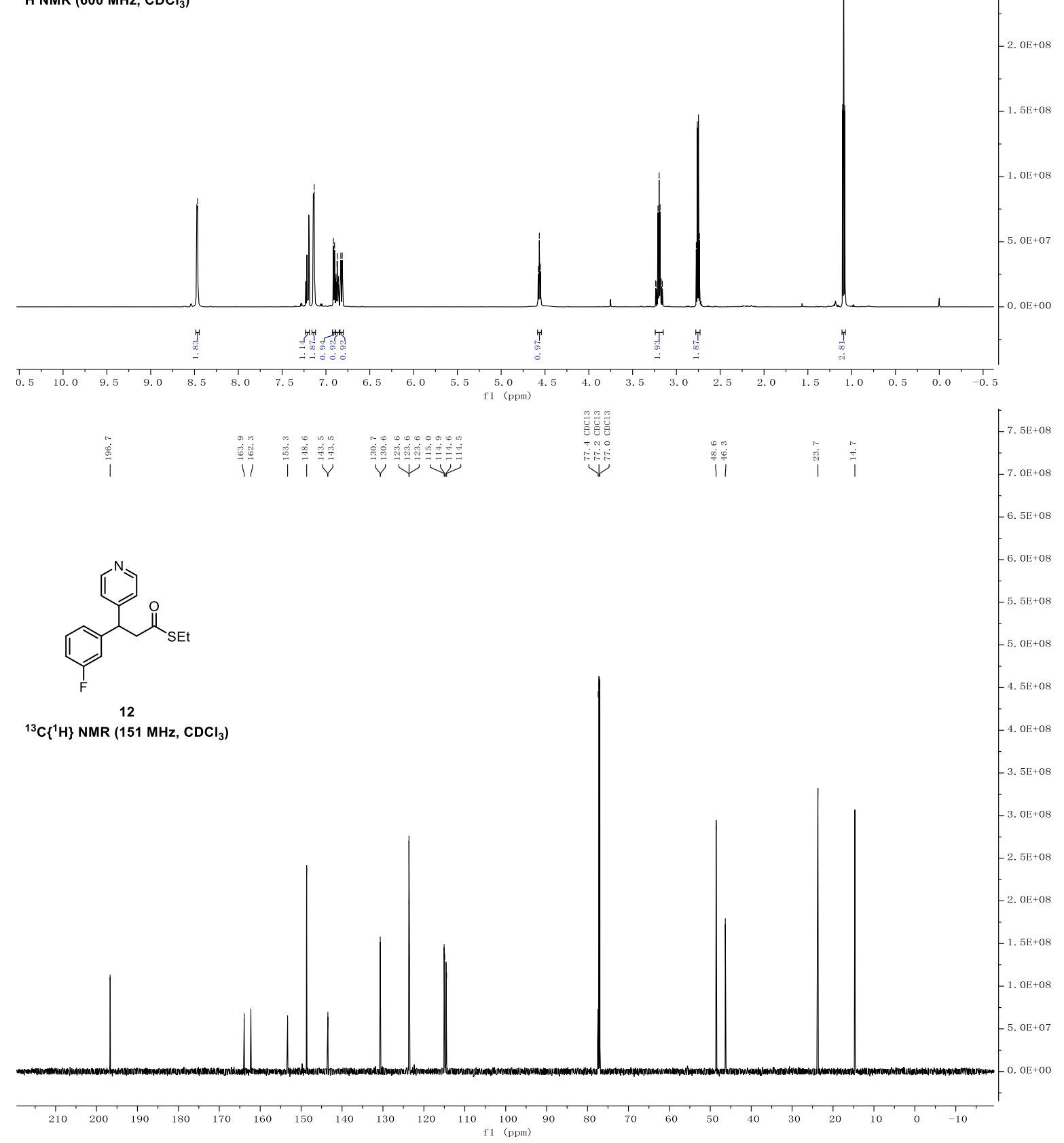




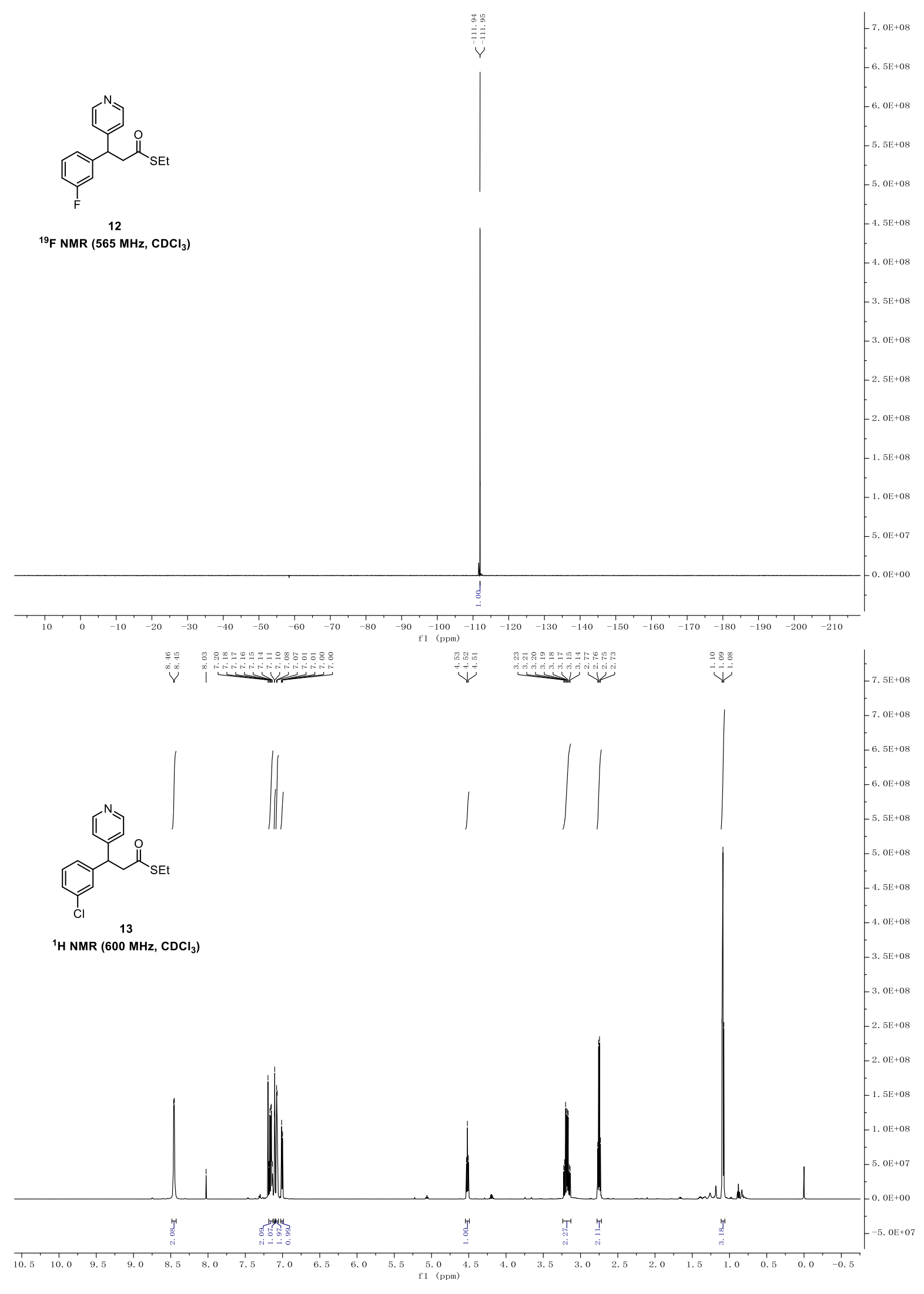




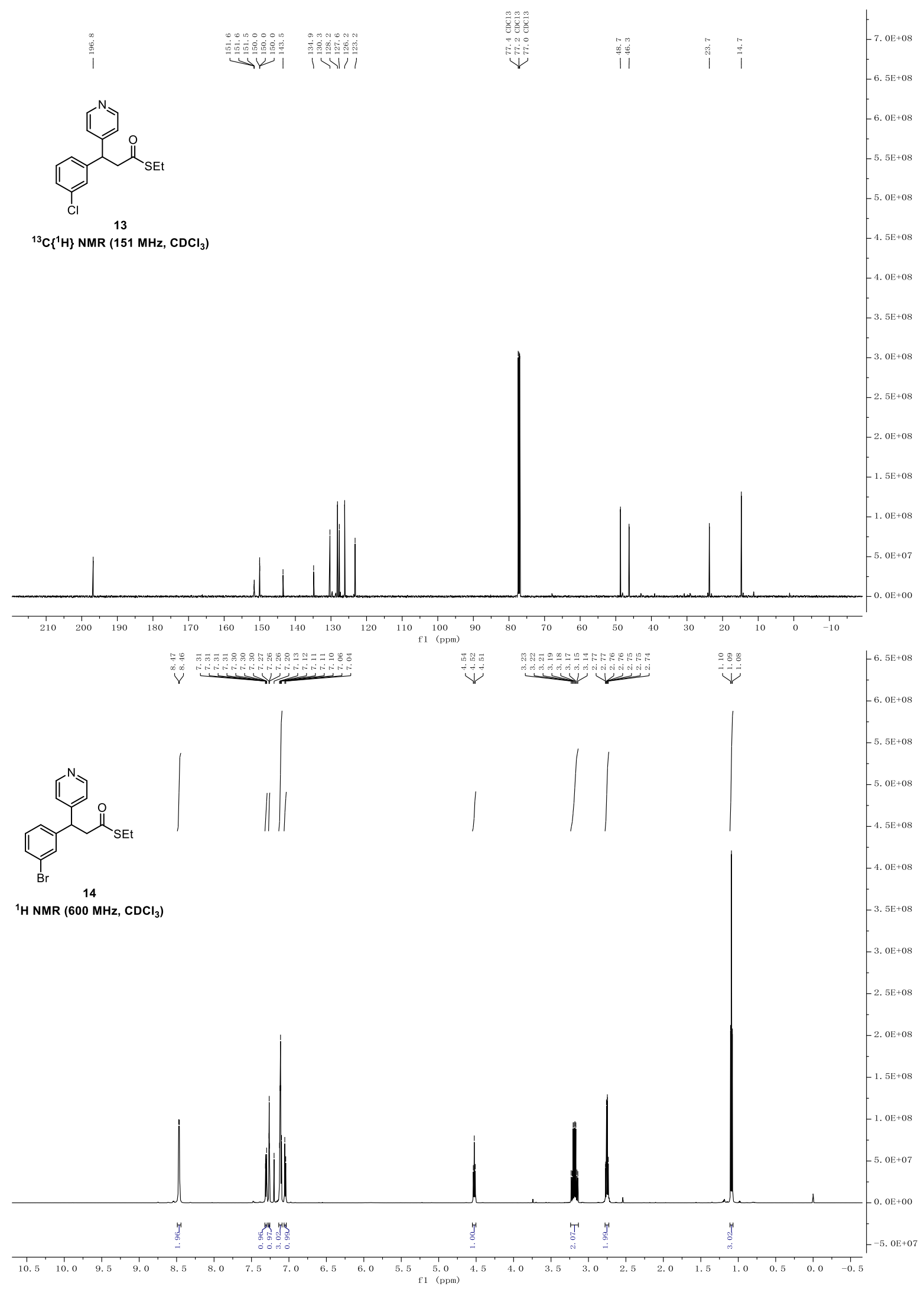




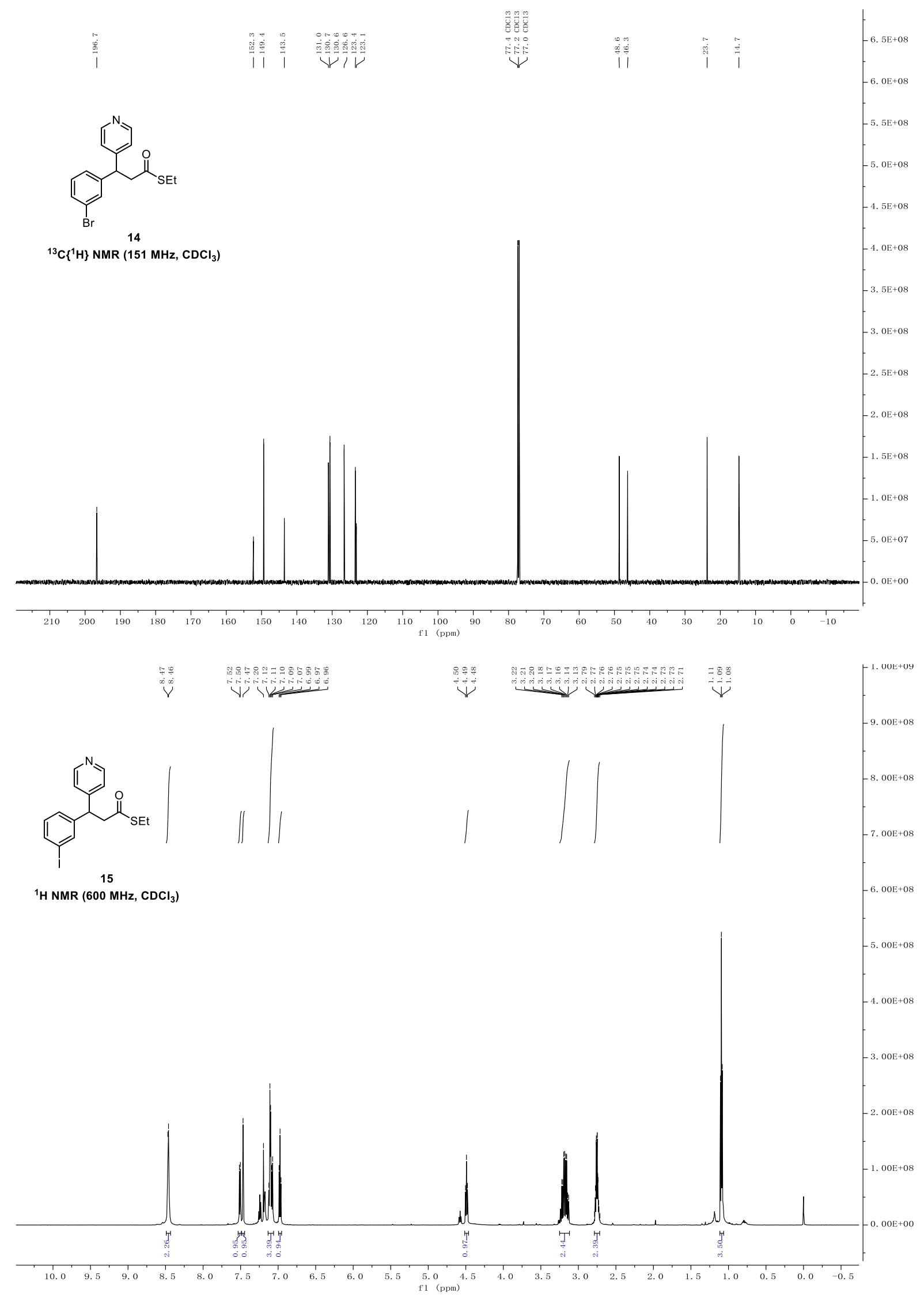




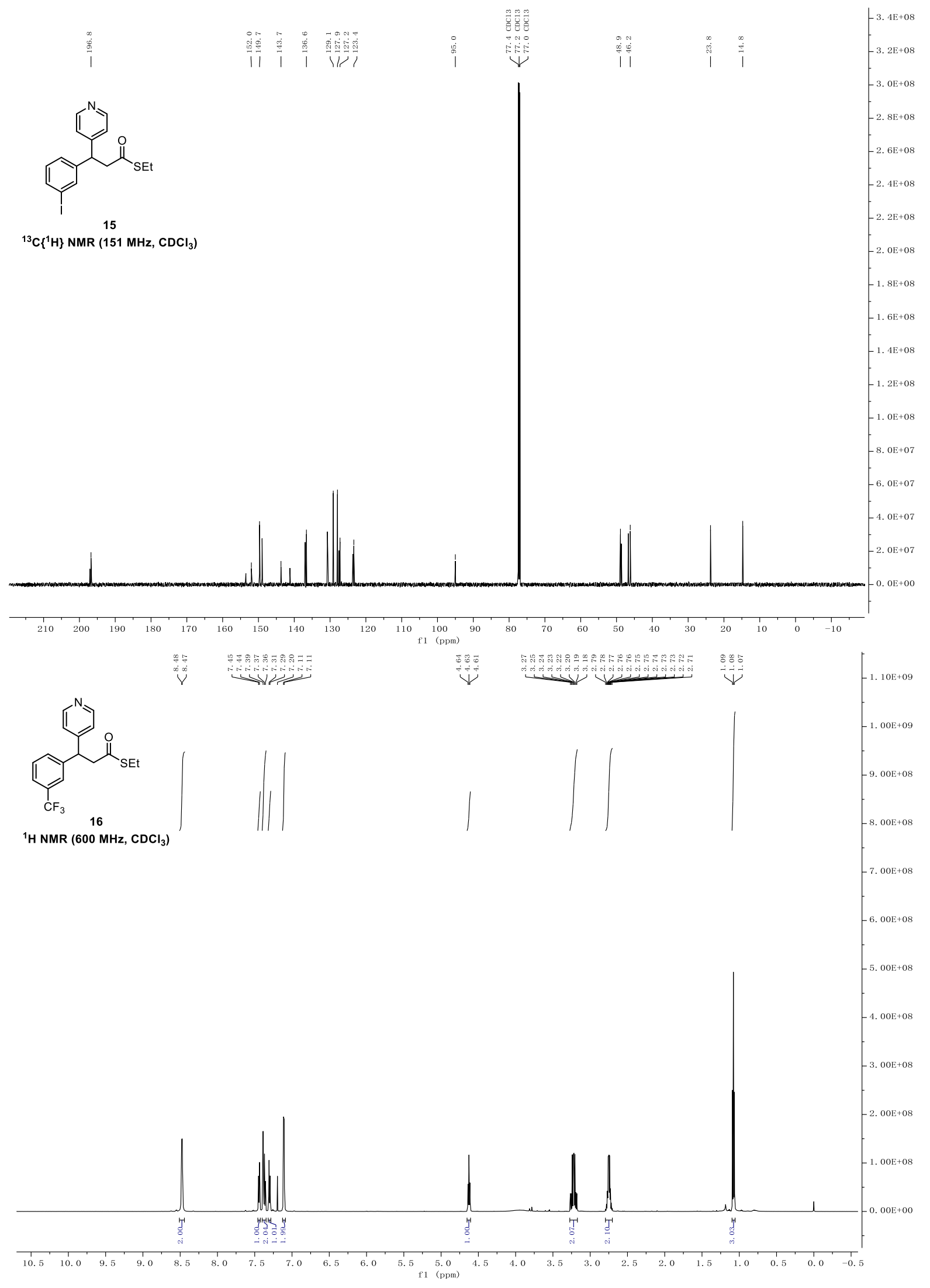




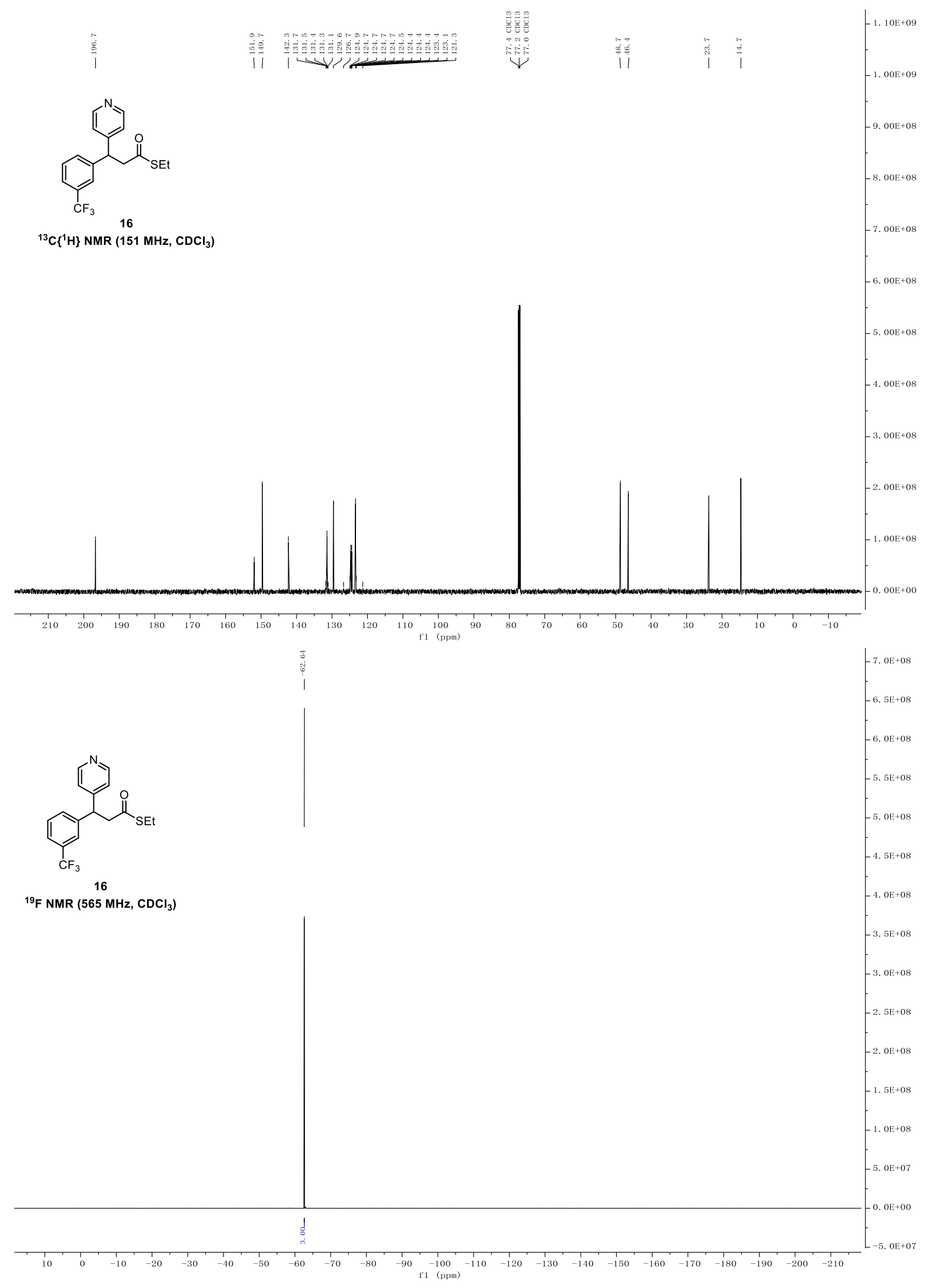




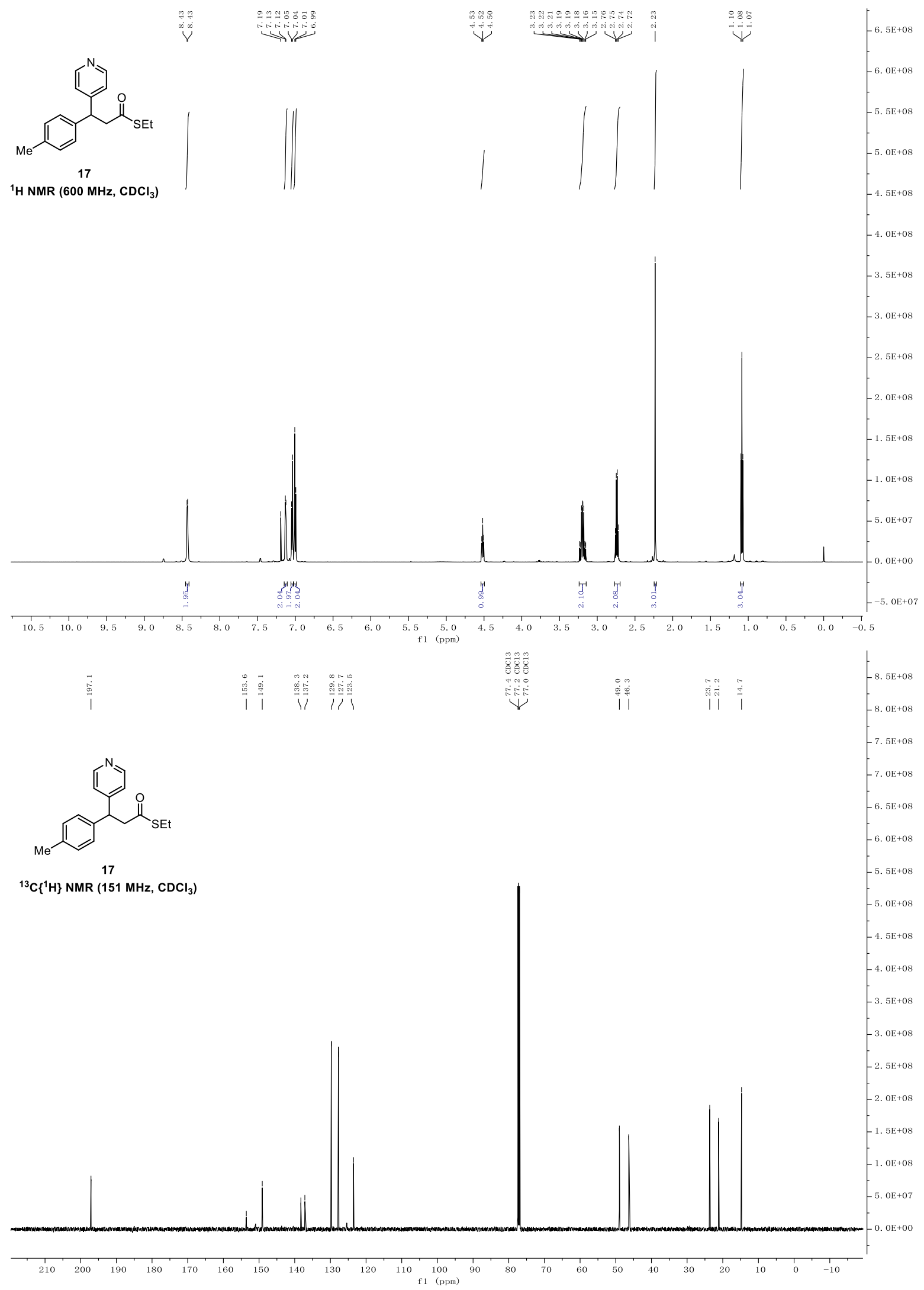




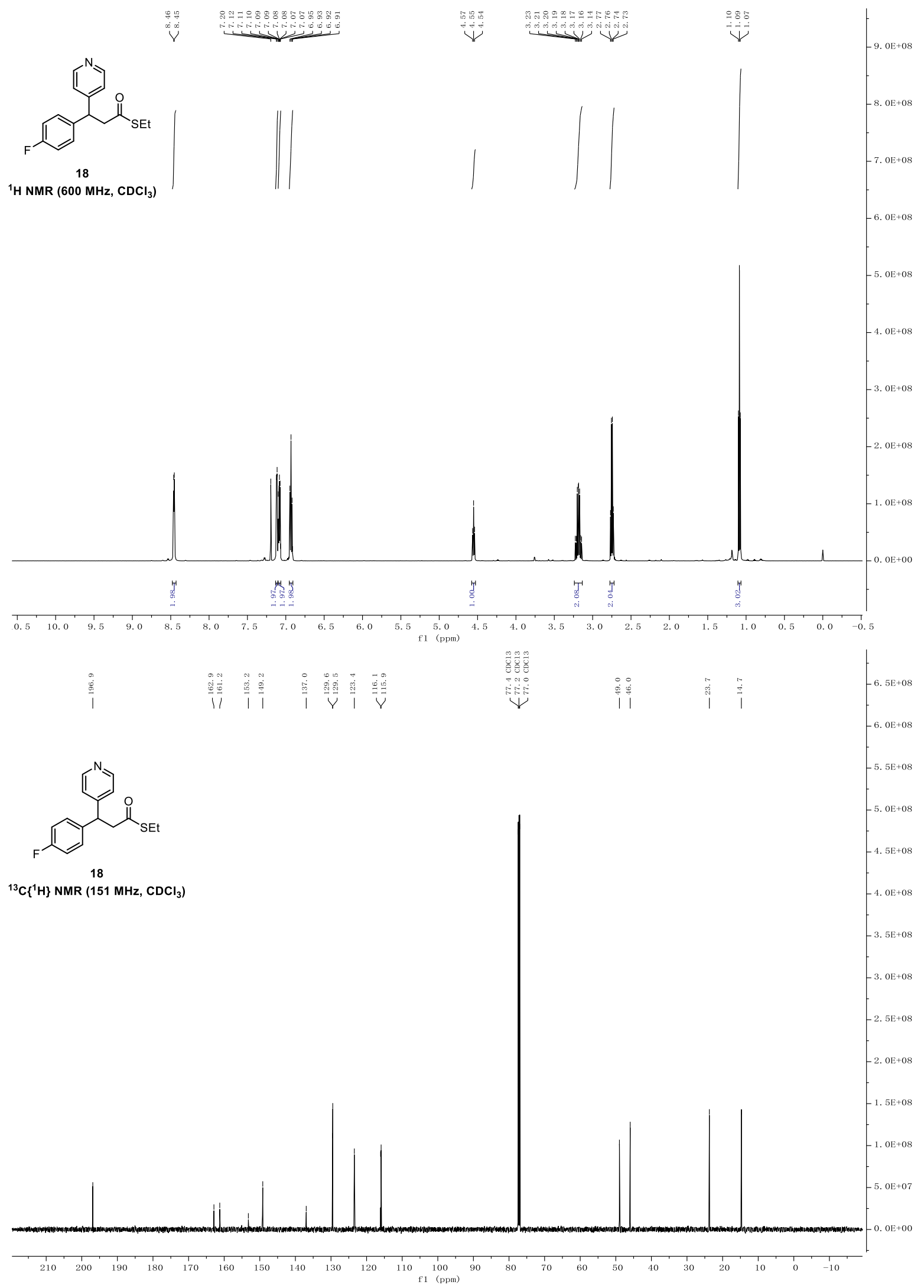



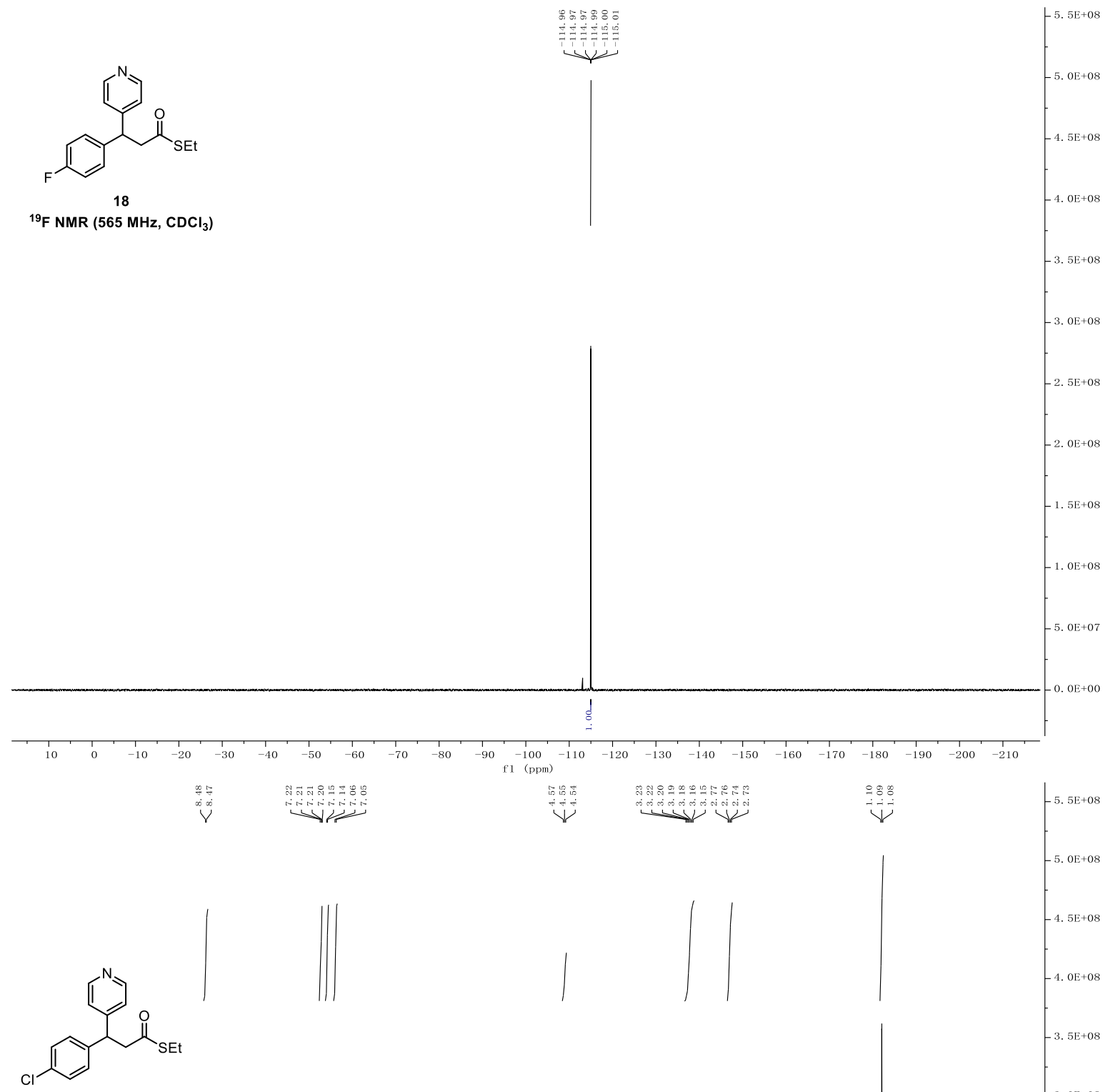

19

${ }^{1} \mathrm{H}$ NMR (600 MHz, $\mathrm{CDCl}_{3}$ )

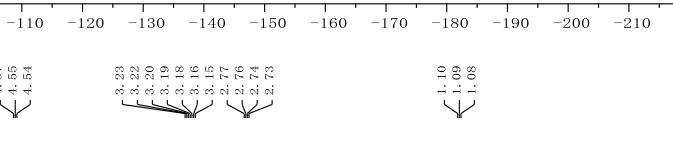

5. $5 \mathrm{E}+08$

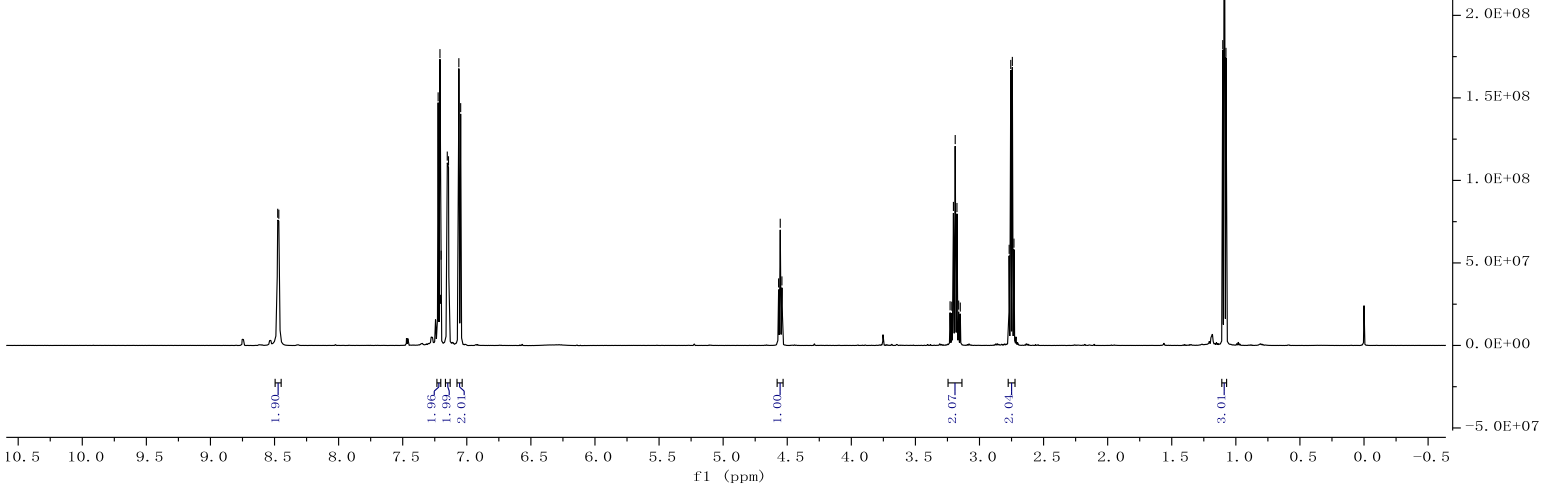




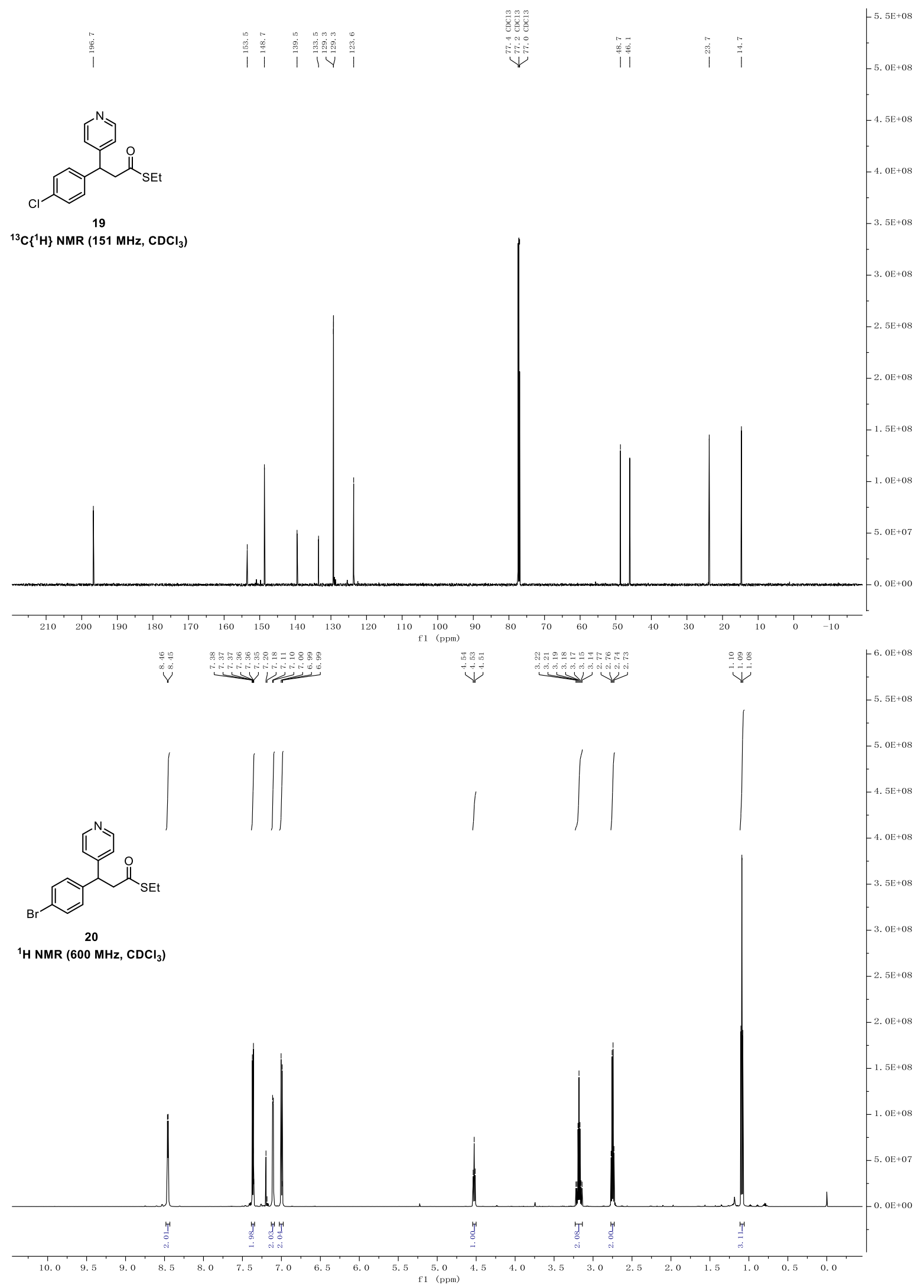




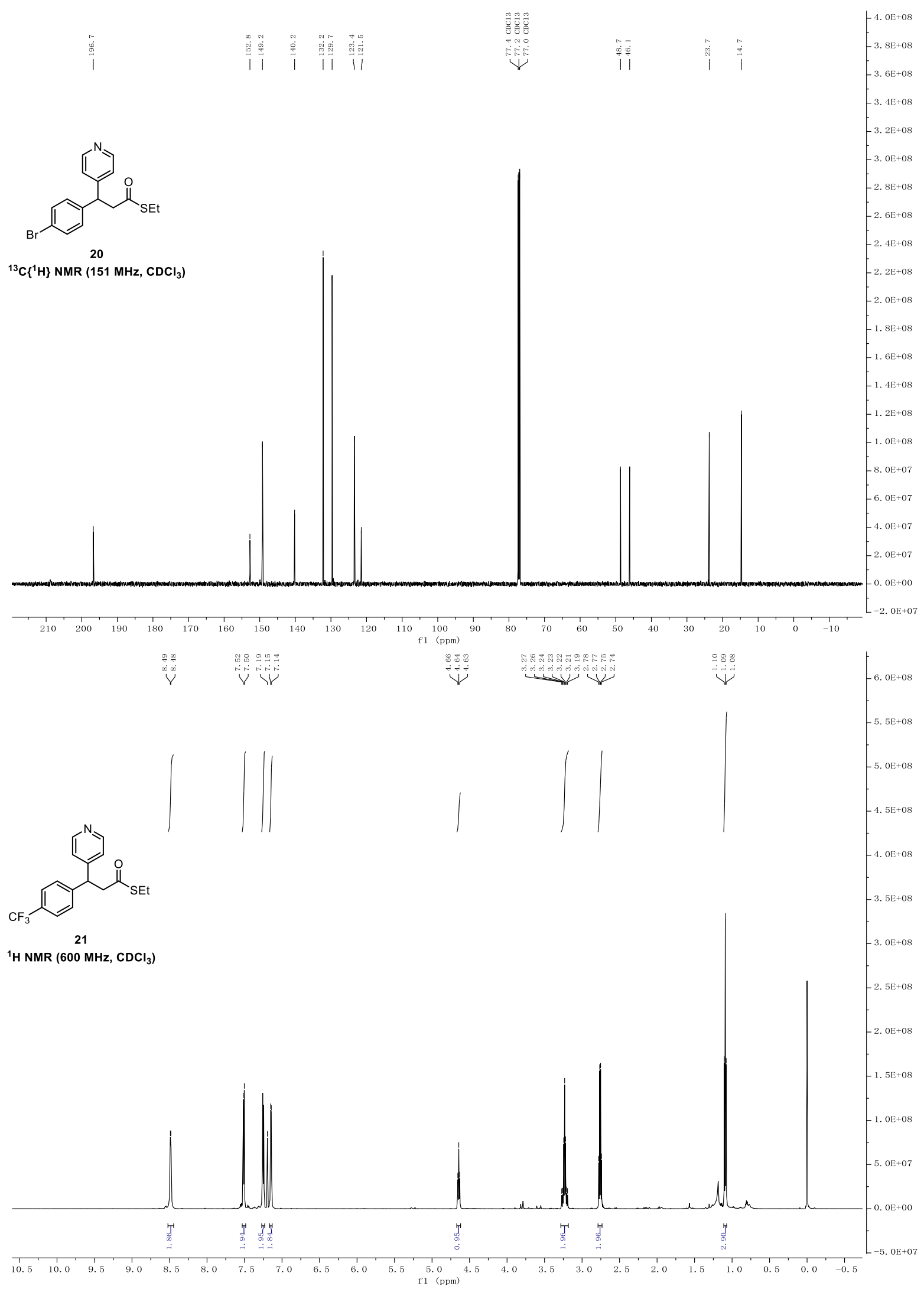




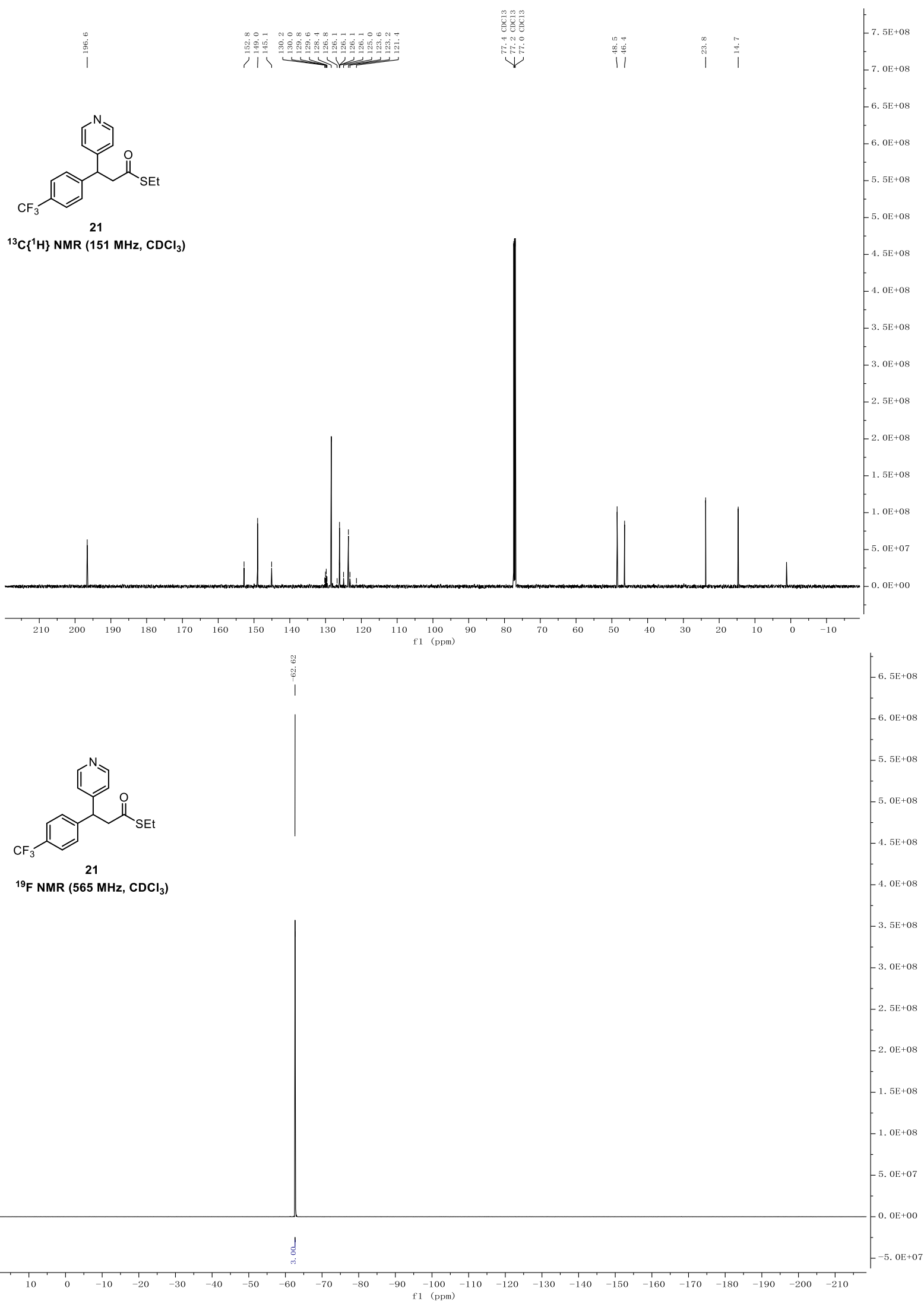




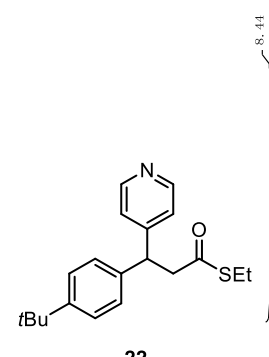

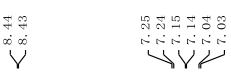

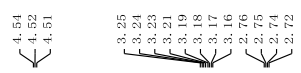

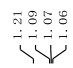

$-7.0 \mathrm{E}+08$

${ }^{1} \mathrm{H}$ NMR $\left(600 \mathrm{MHz} \mathrm{CDCl}_{3}\right)$
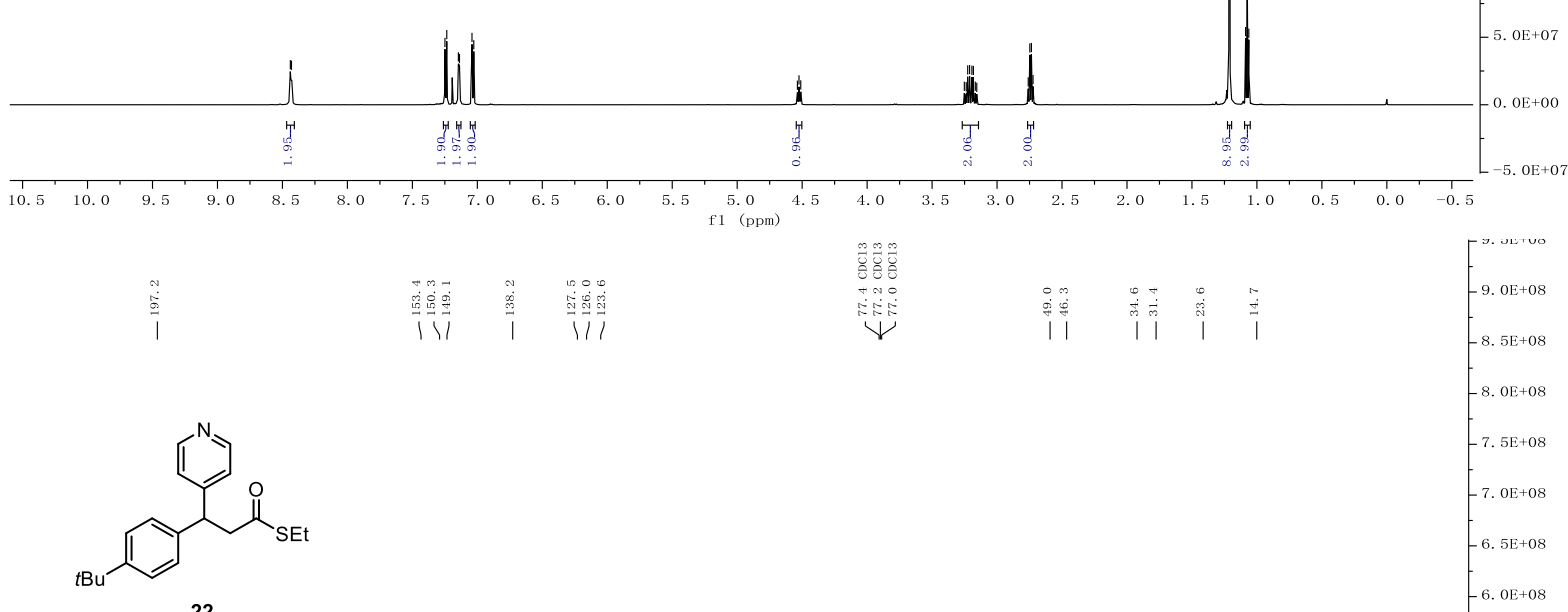

${ }^{13} \mathrm{C}\left\{{ }^{1} \mathrm{H}\right\}$ NMR $\left(151 \mathrm{MHz}, \mathrm{CDCl}_{3}\right)$
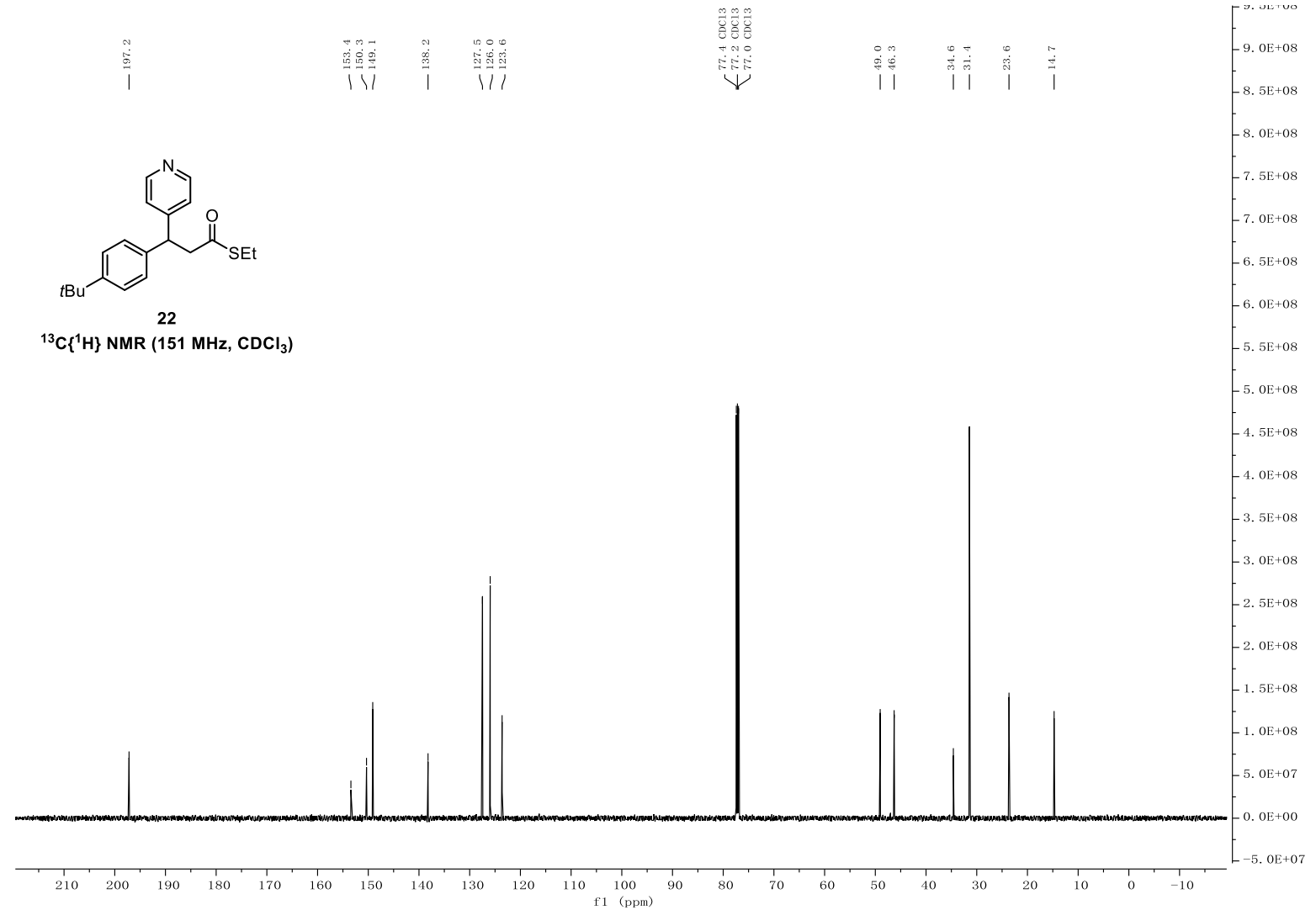


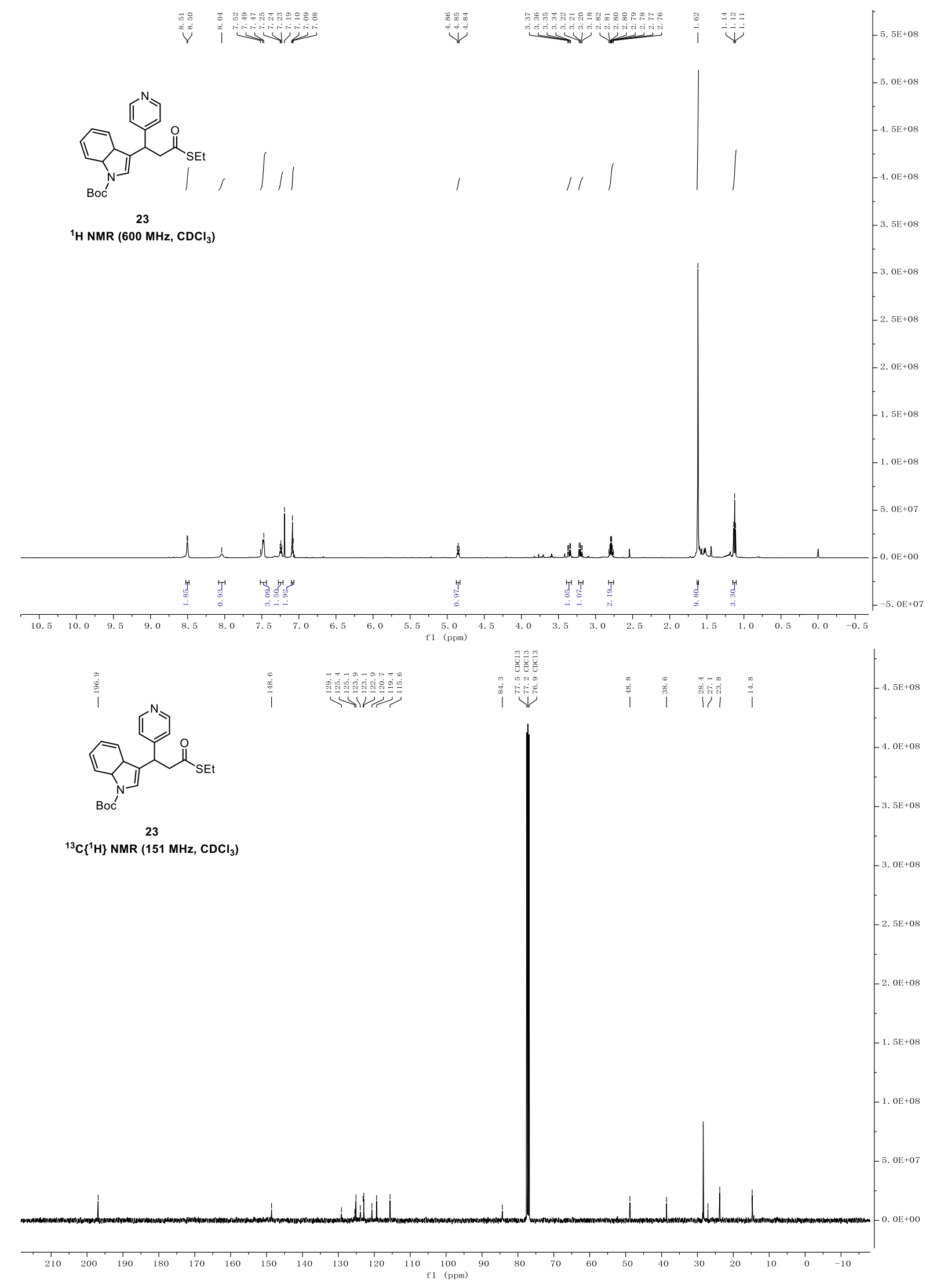




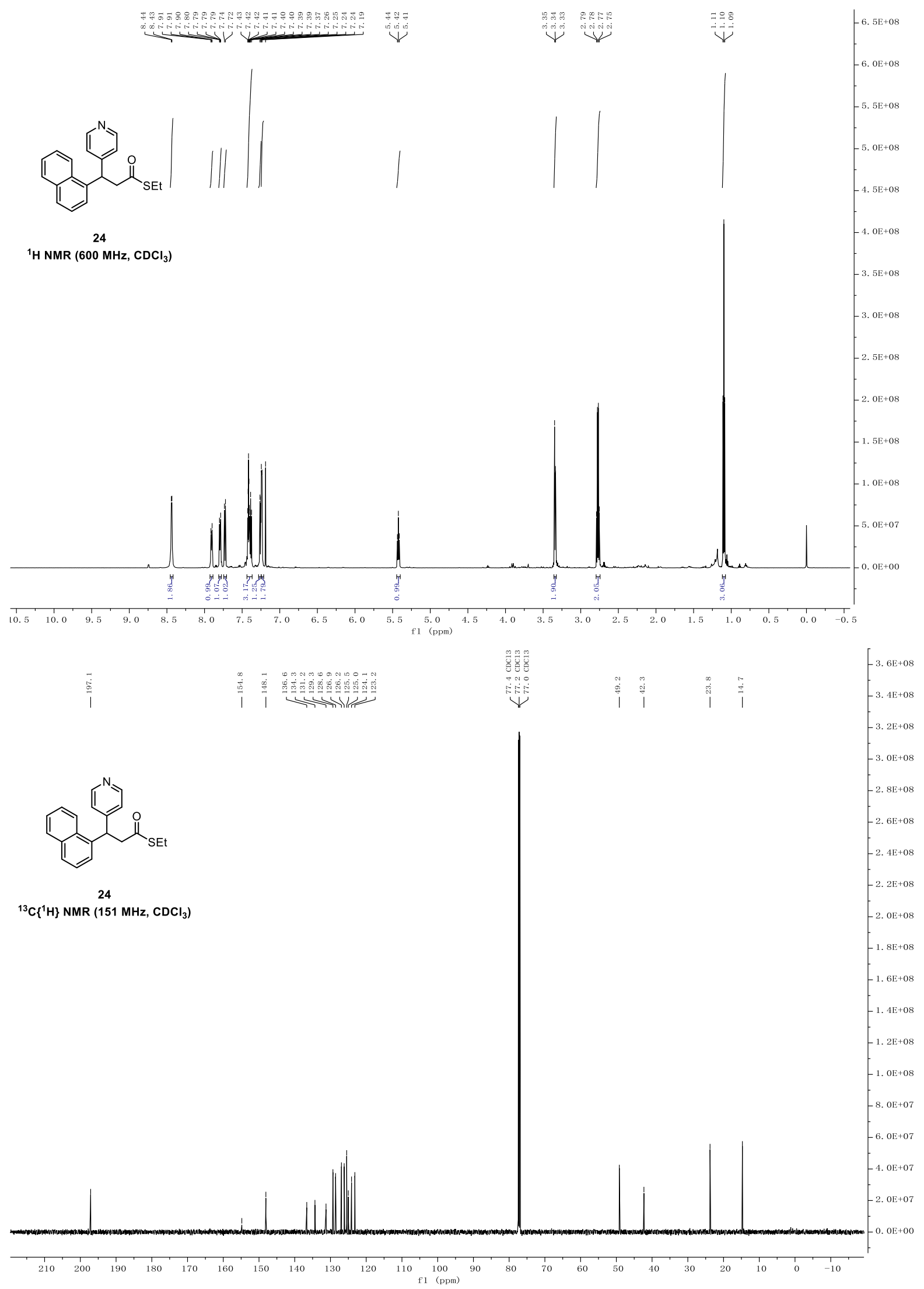

5

S28 


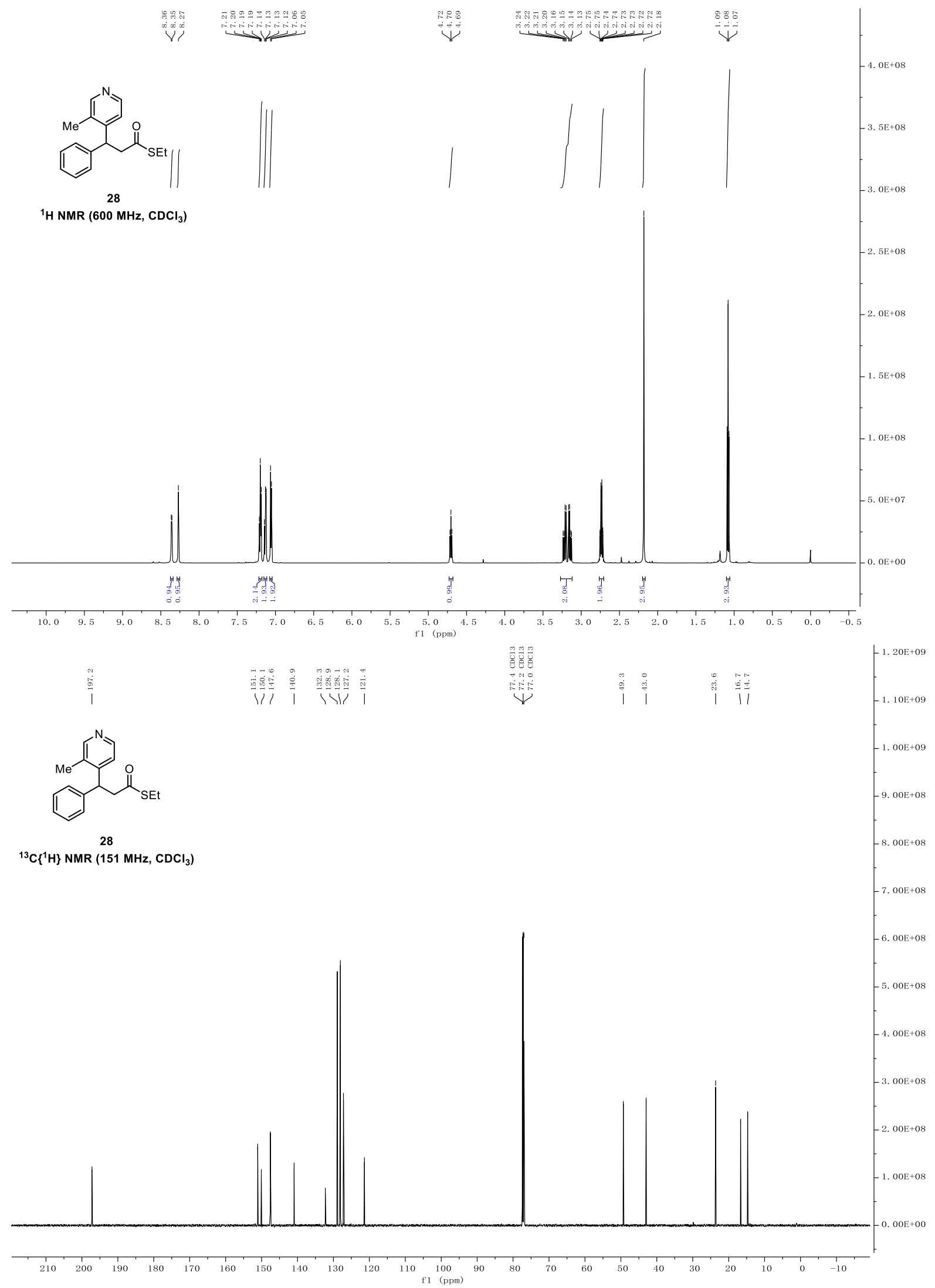



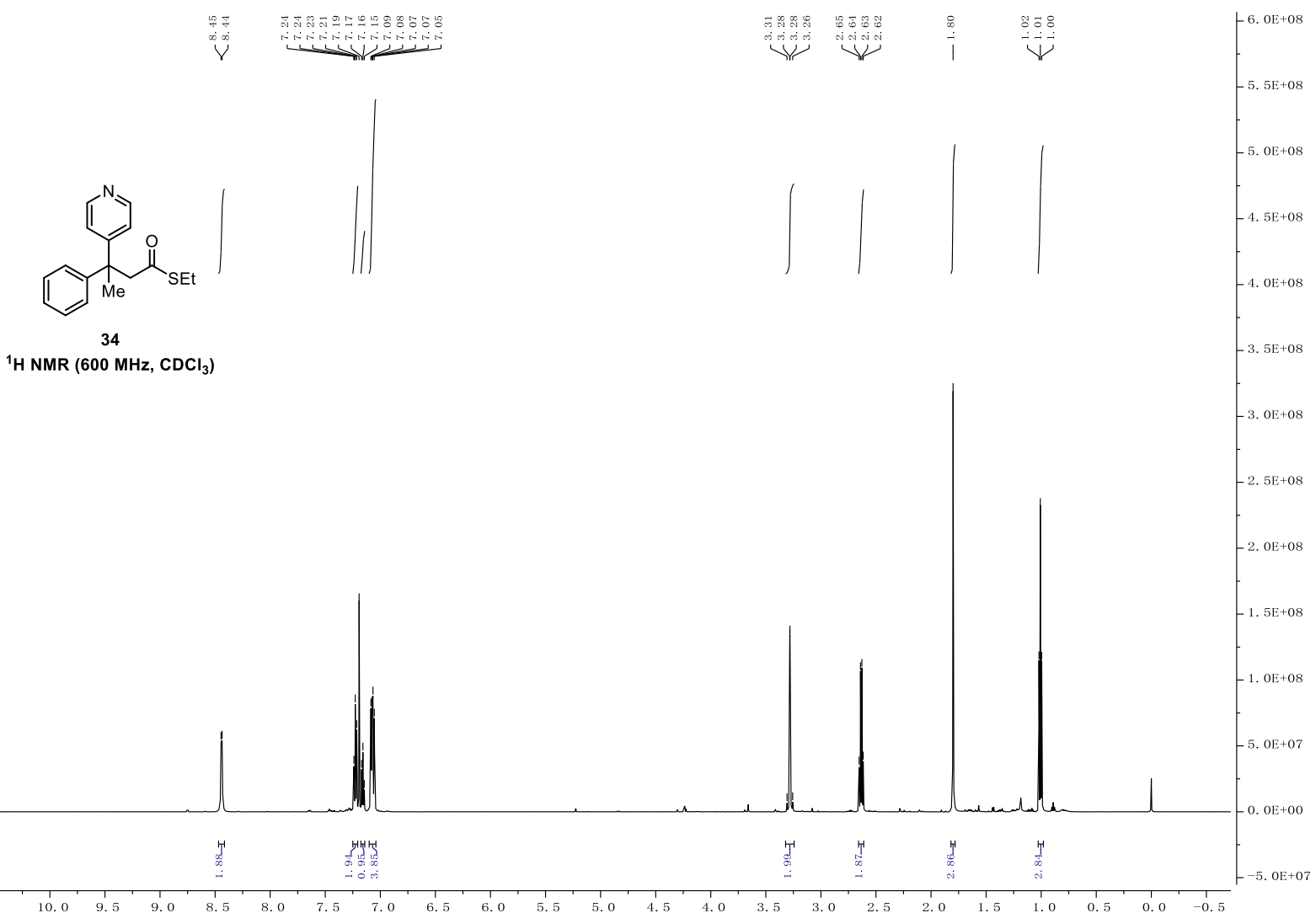

${ }^{1} \mathrm{H}$ NMR $\left(600 \mathrm{MHz}, \mathrm{CDCl}_{3}\right)$

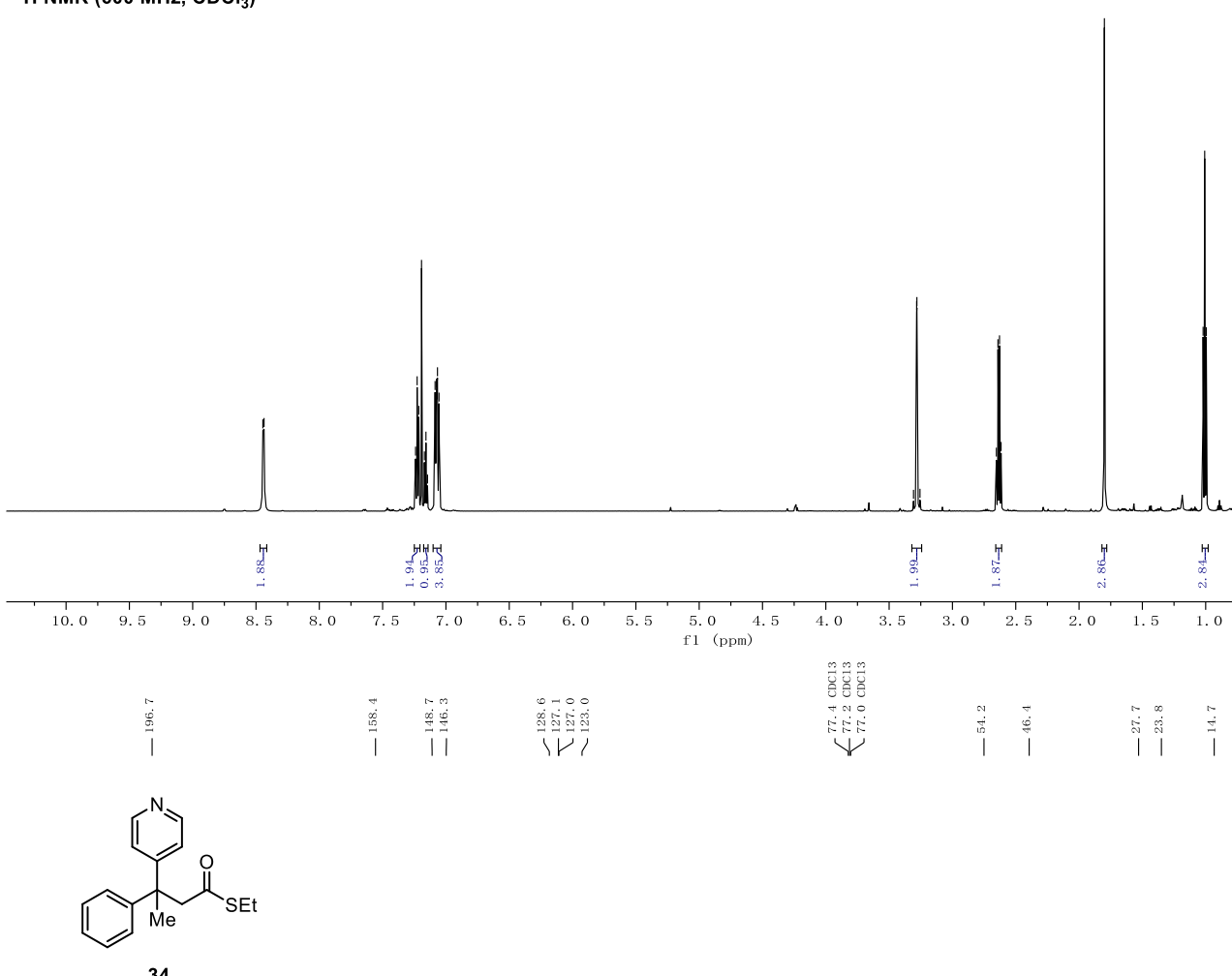

${ }^{13} \mathrm{C}\left\{{ }^{1} \mathrm{H}\right\}$ NMR (151 MHz, $\left.\mathrm{CDCl}_{3}\right)$

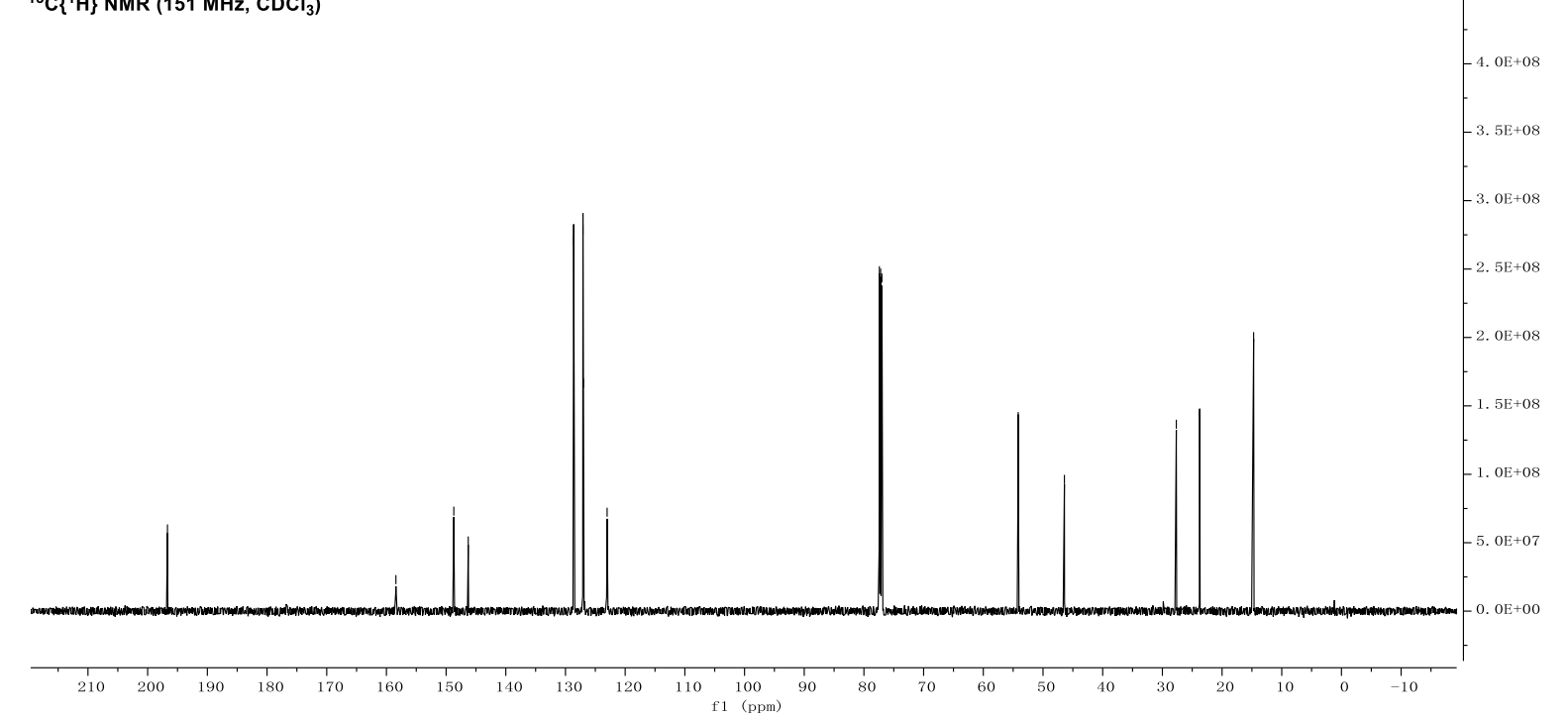




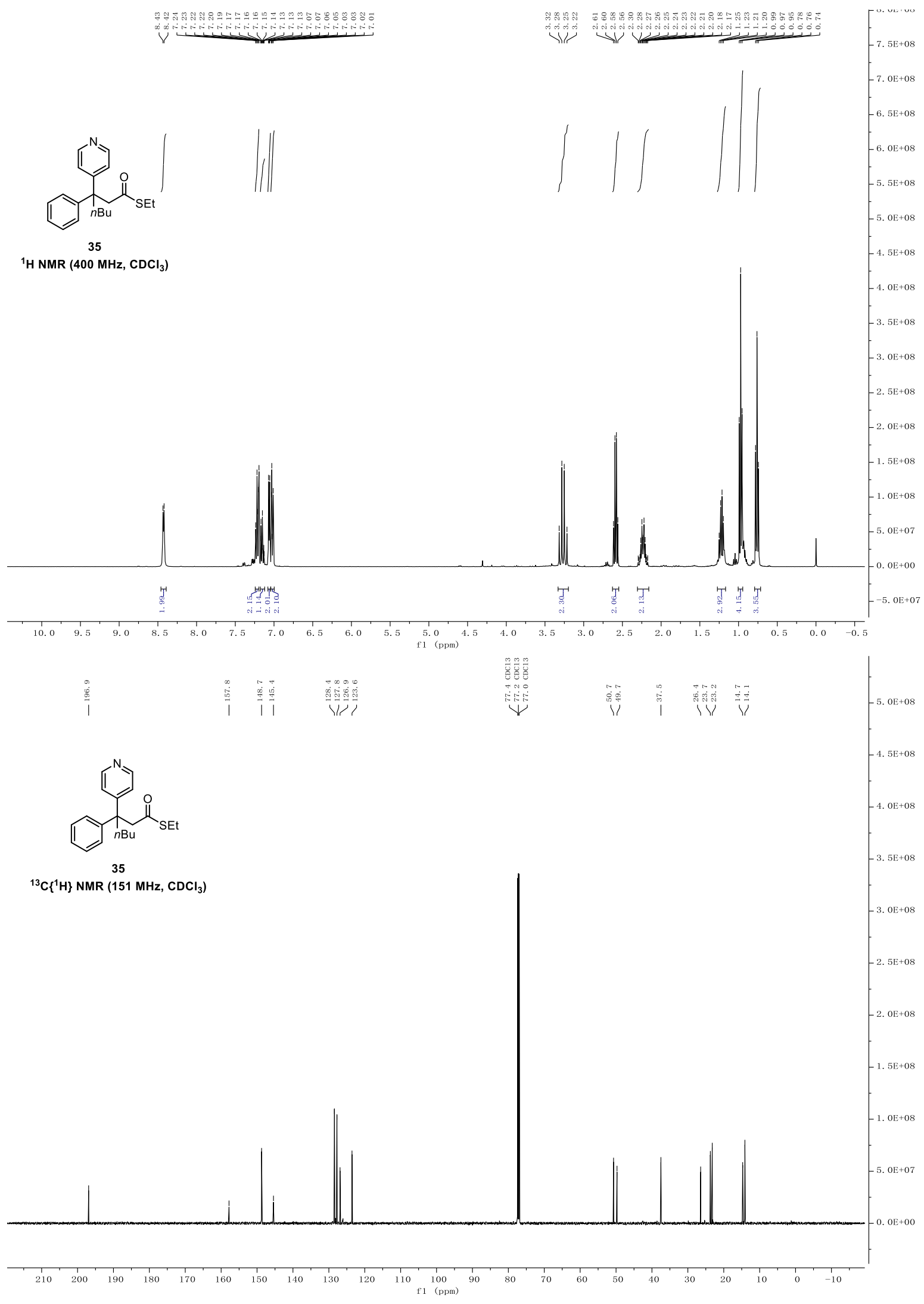



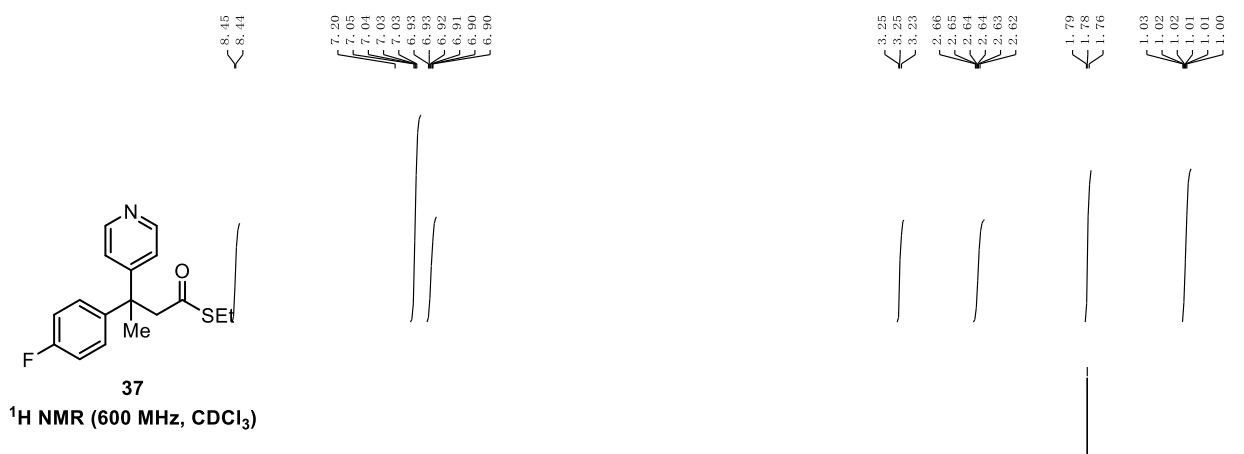

' $\mathrm{H}$ NMR $\left(600 \mathrm{MHz}, \mathrm{CDCl}_{3}\right)$
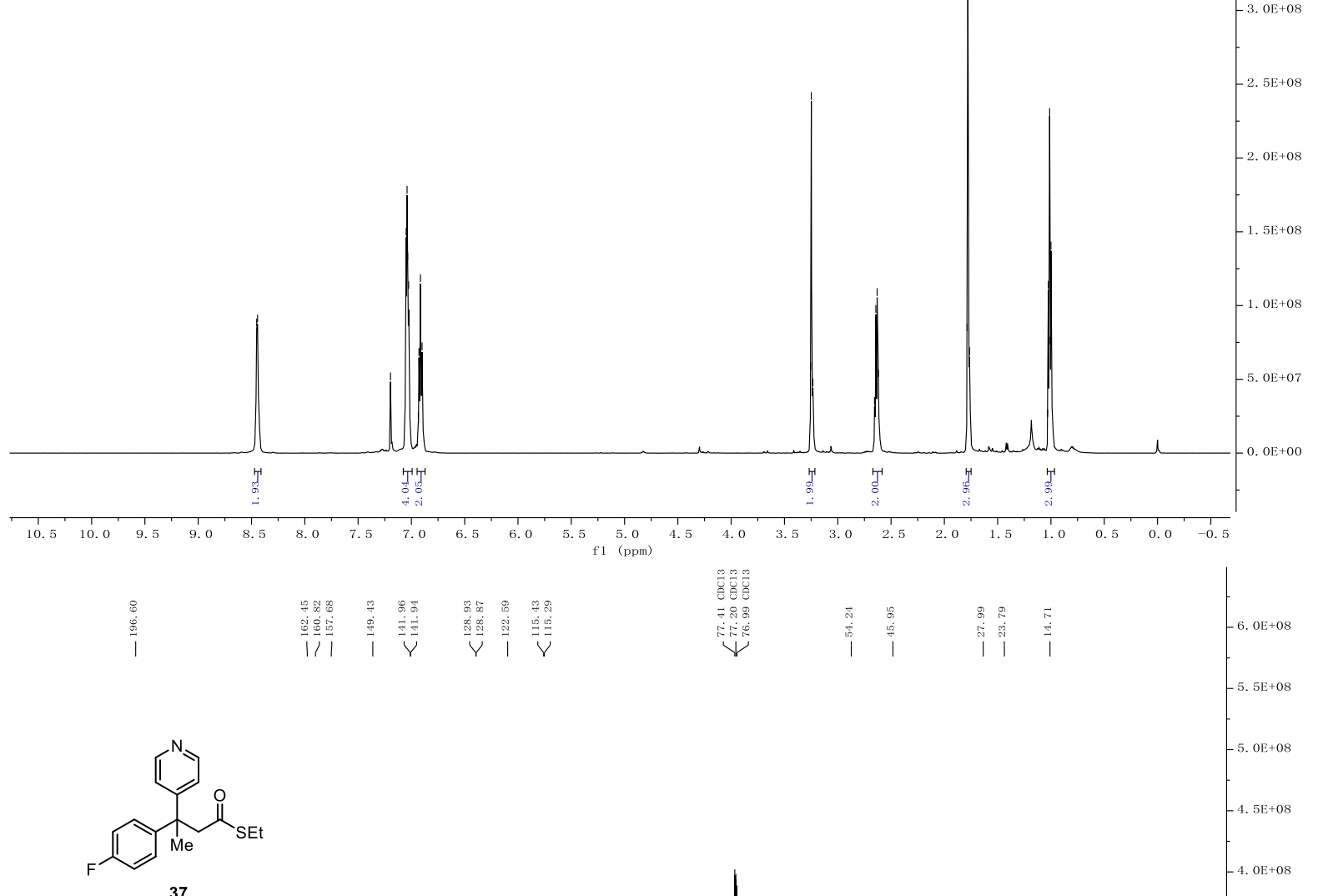

${ }^{13} \mathrm{C}\left\{{ }^{1} \mathrm{H}\right\}$ NMR (151 MHz, $\left.\mathrm{CDCl}_{3}\right)$
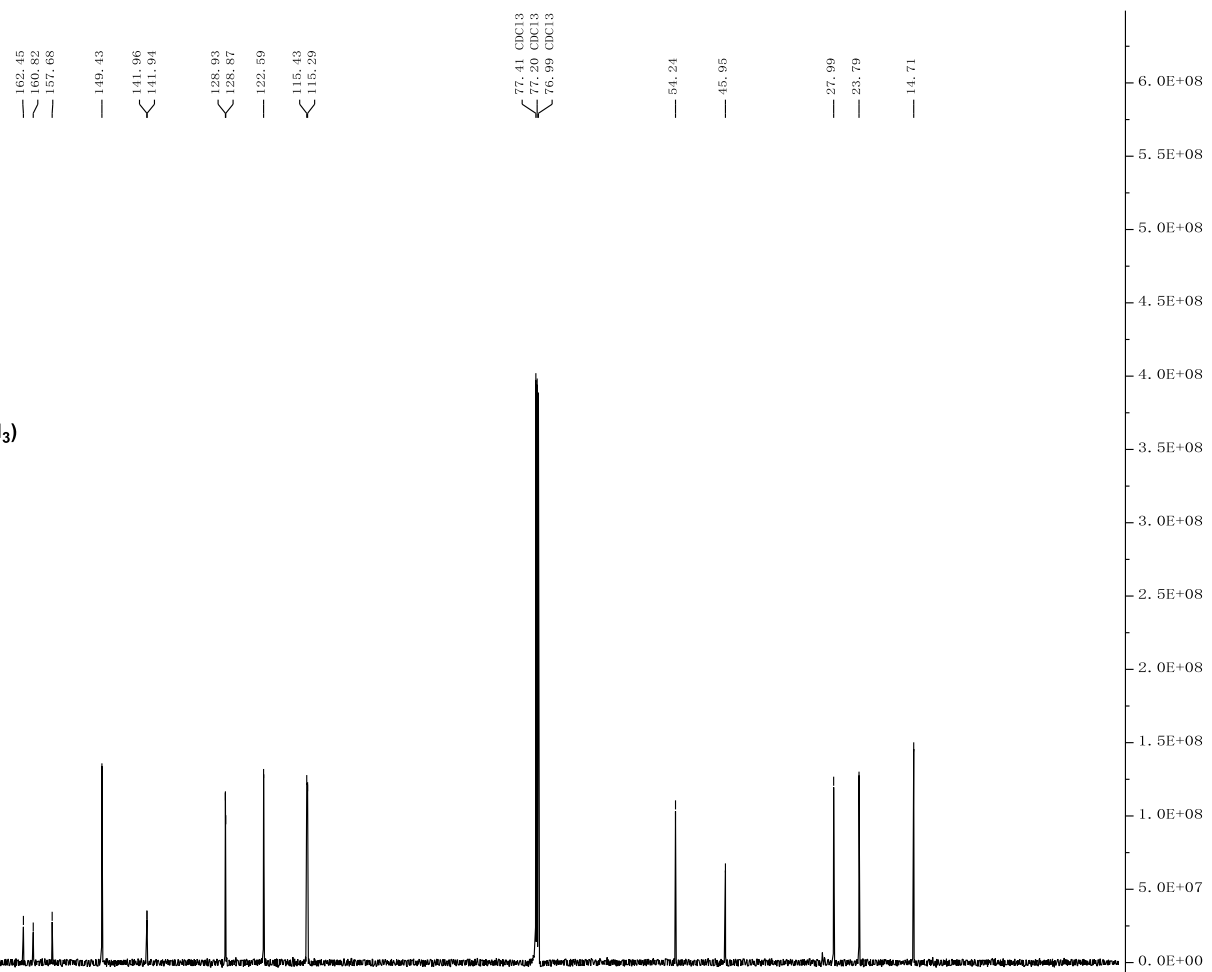


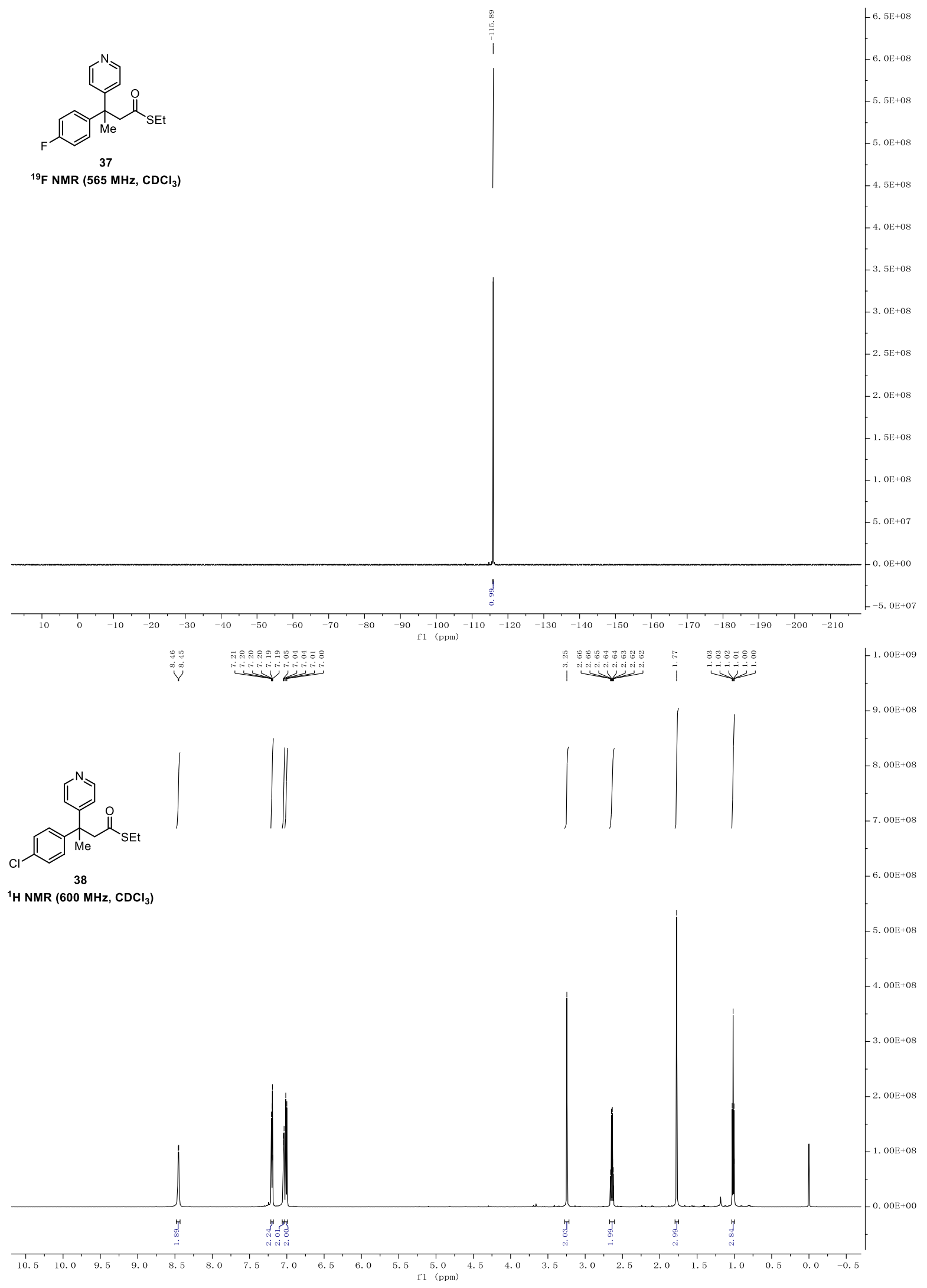




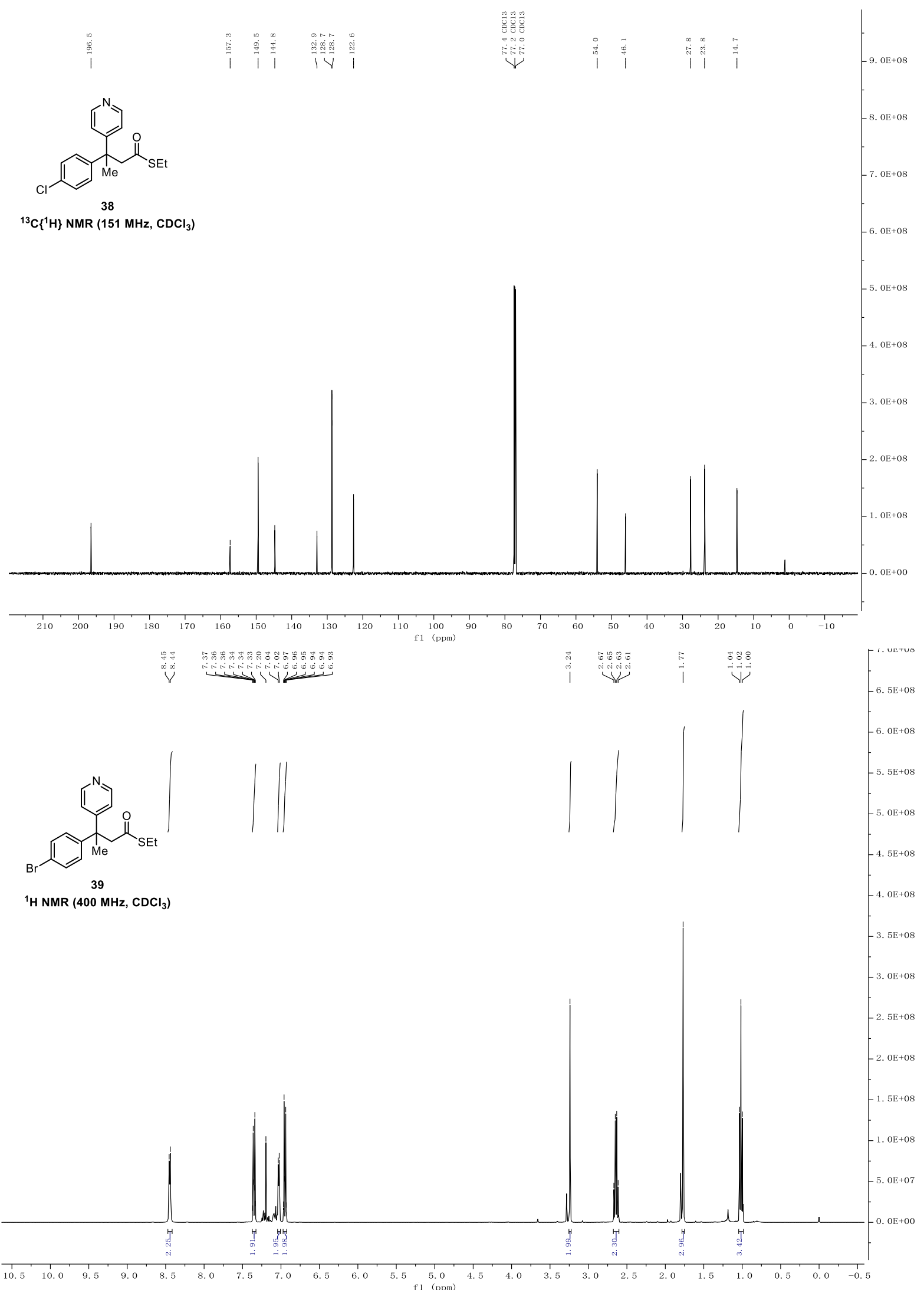




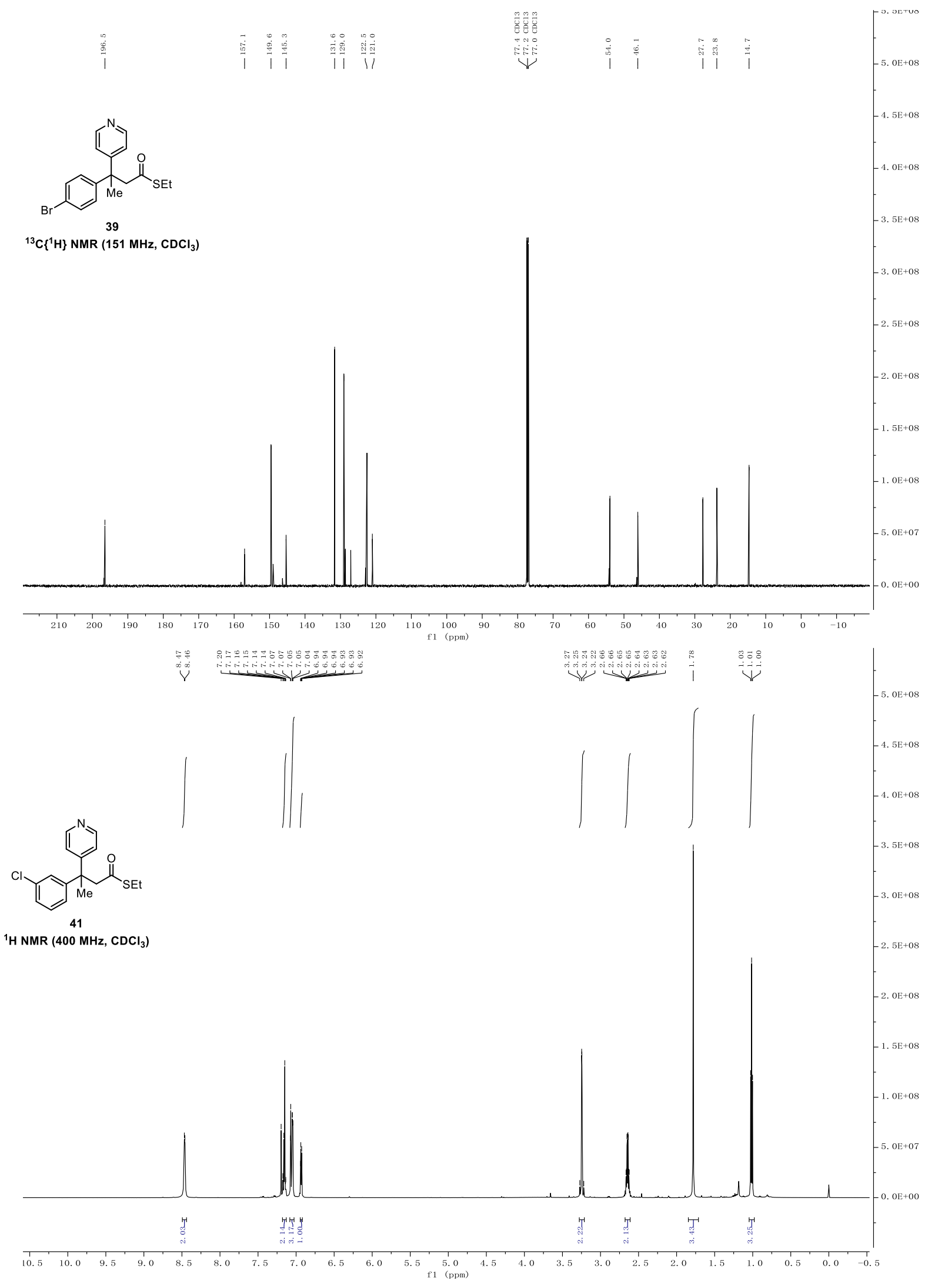




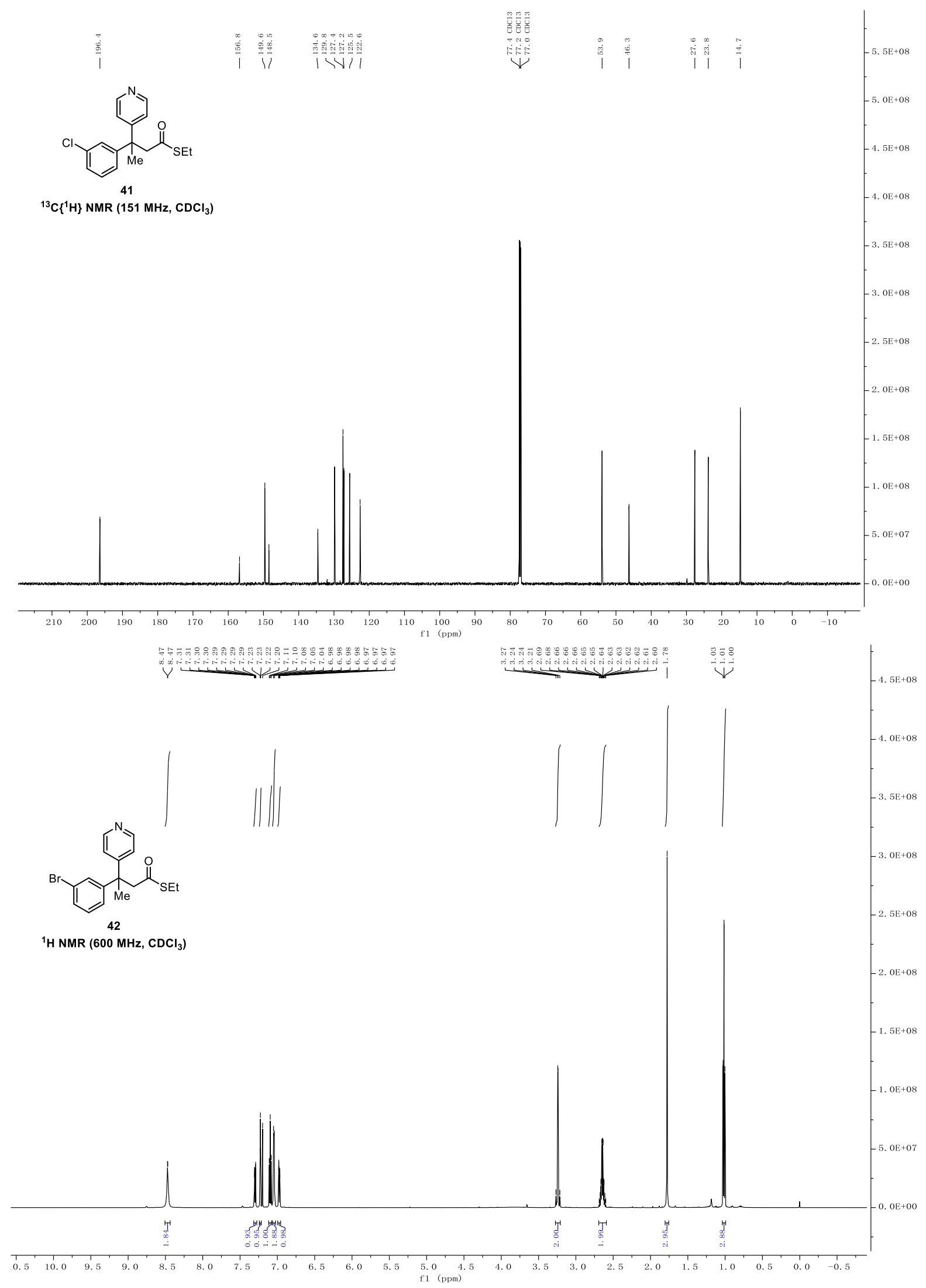




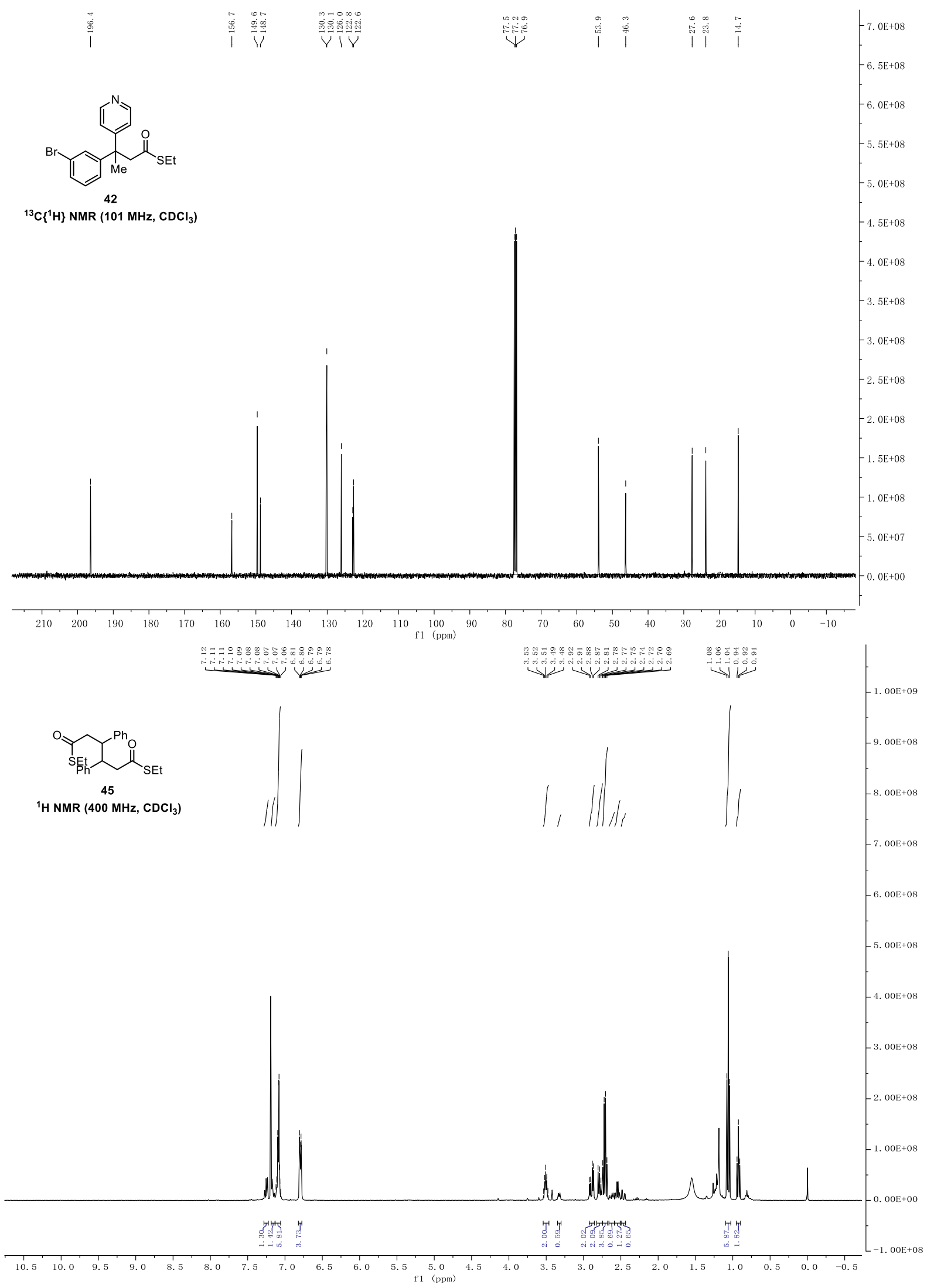




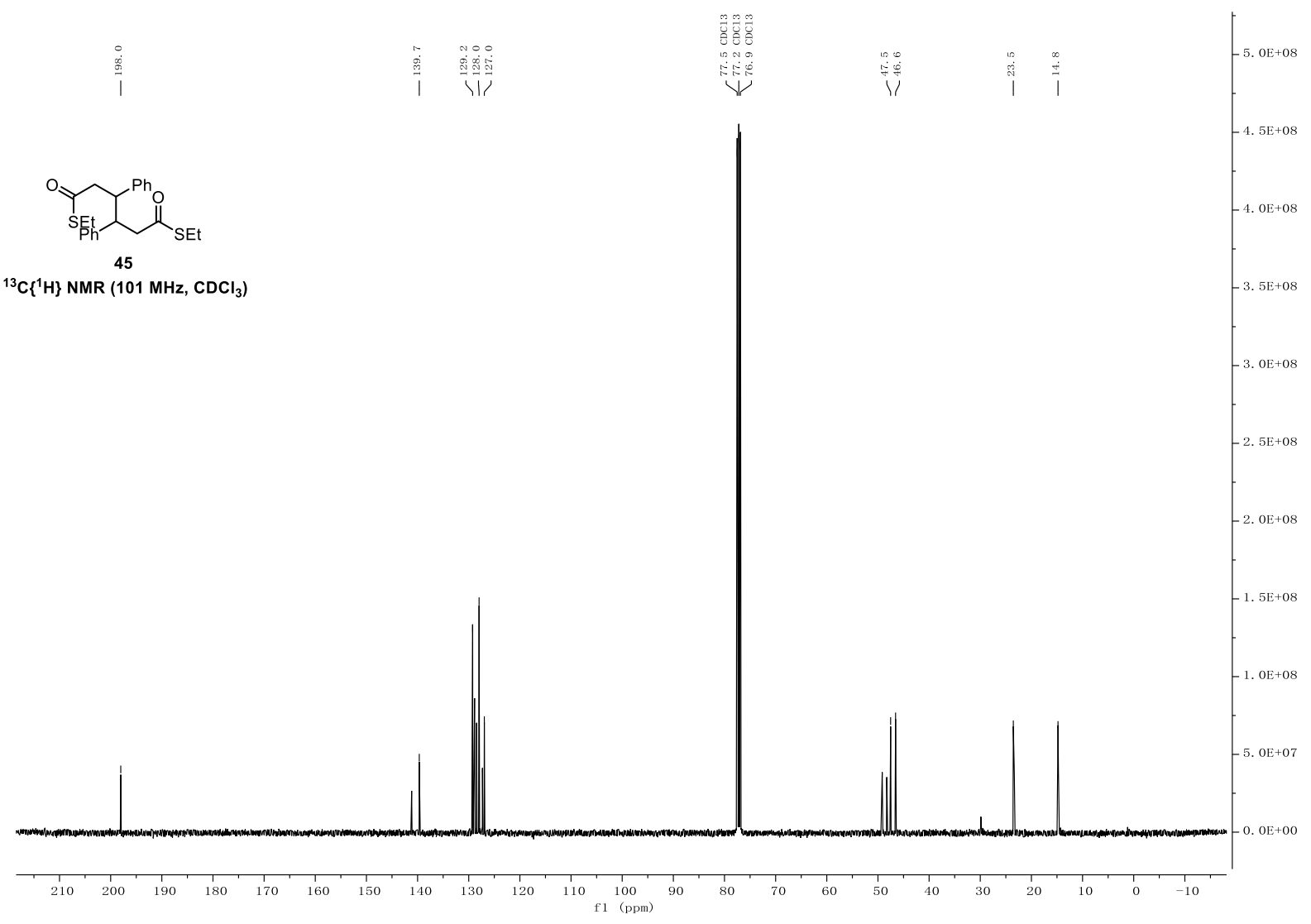




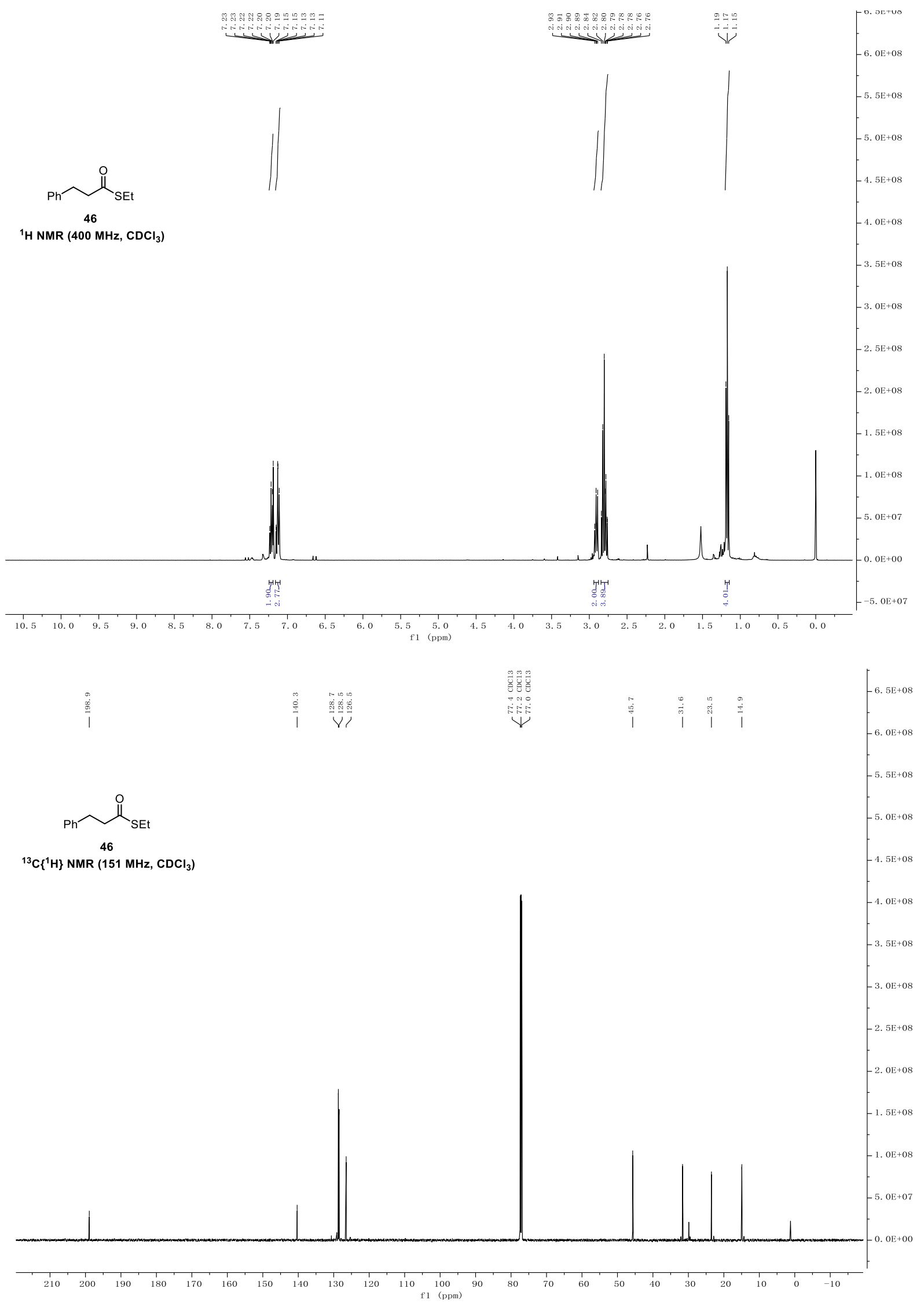




\section{NMR Spectra of New Olefin Substrates}

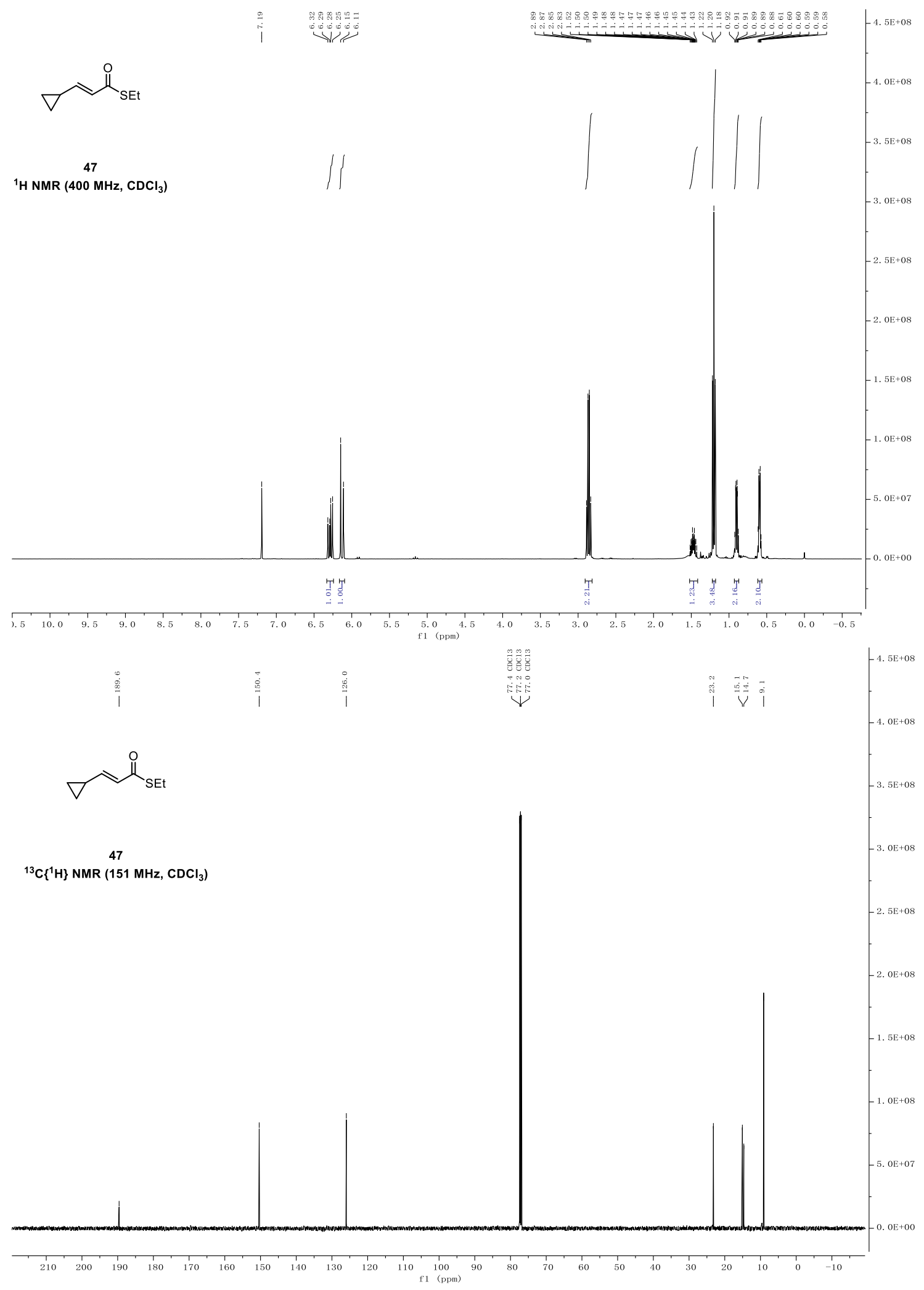




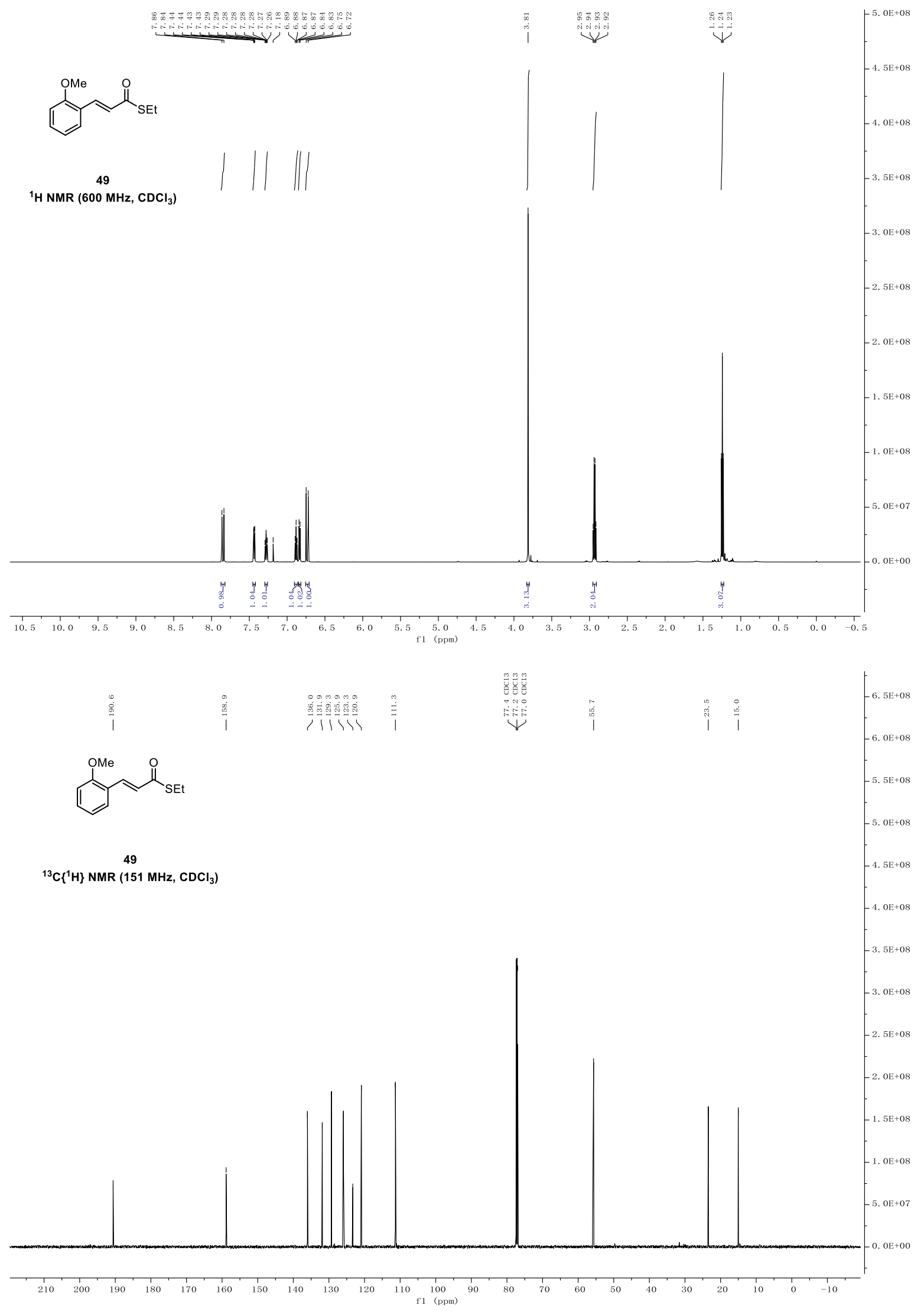




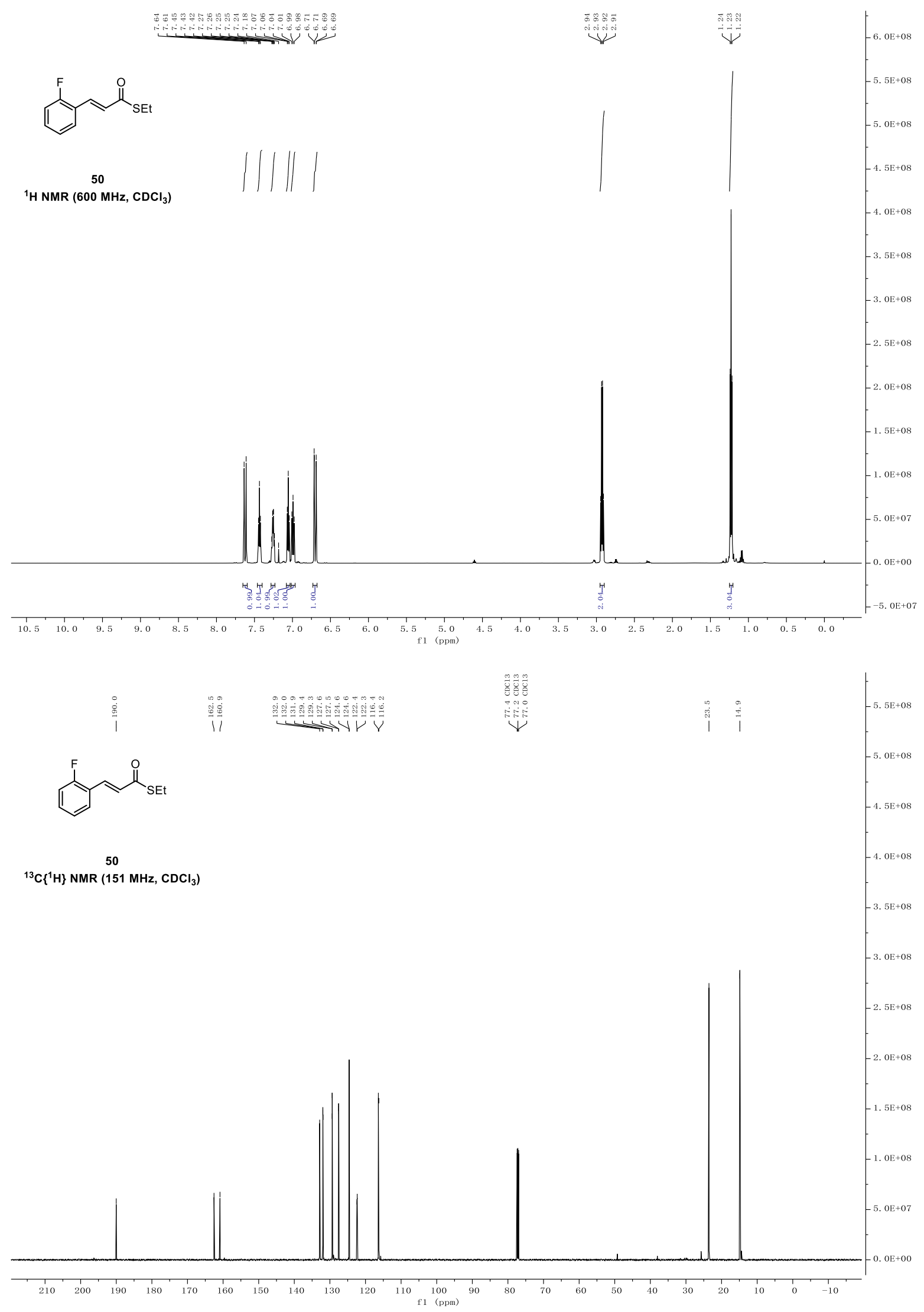




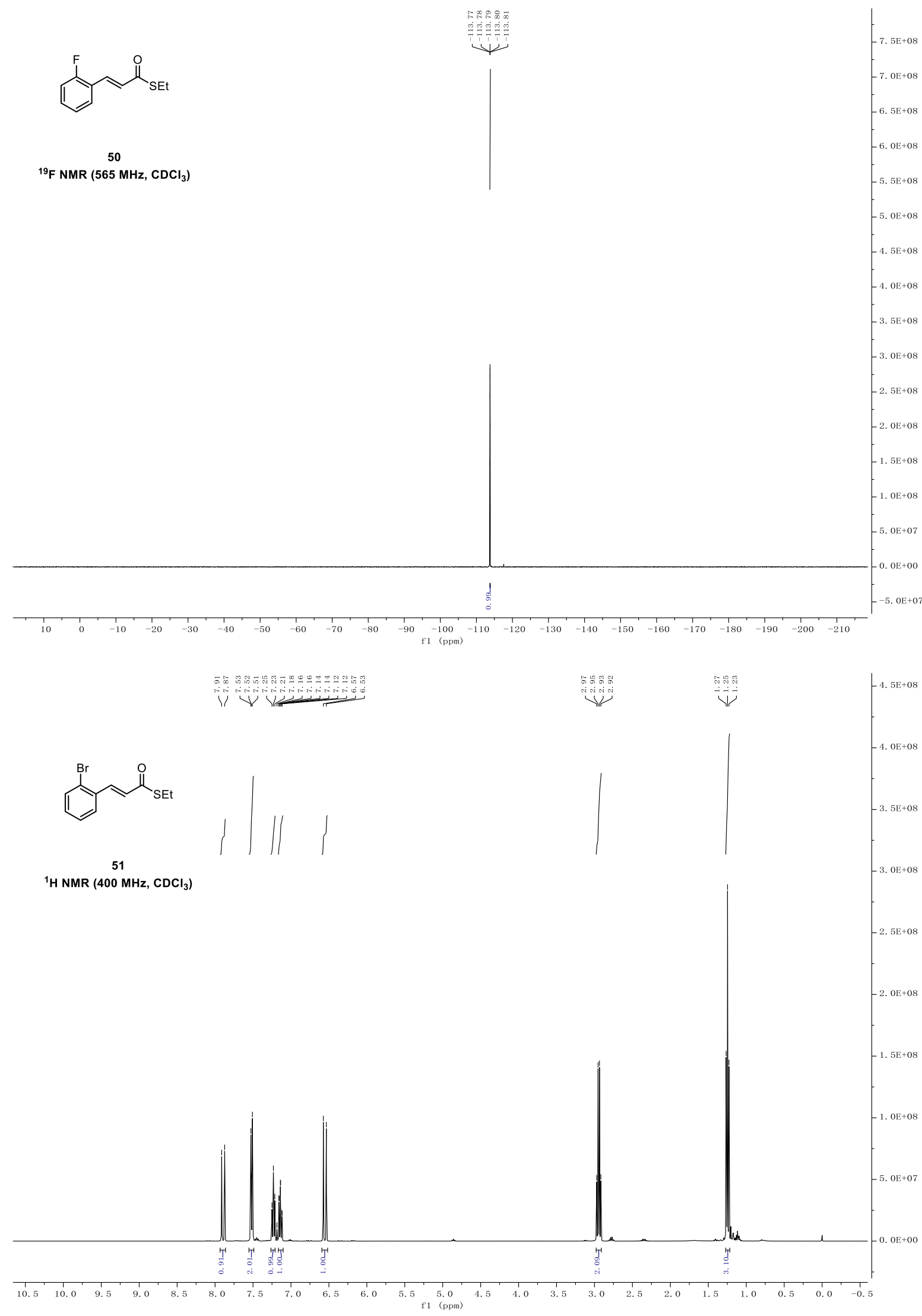




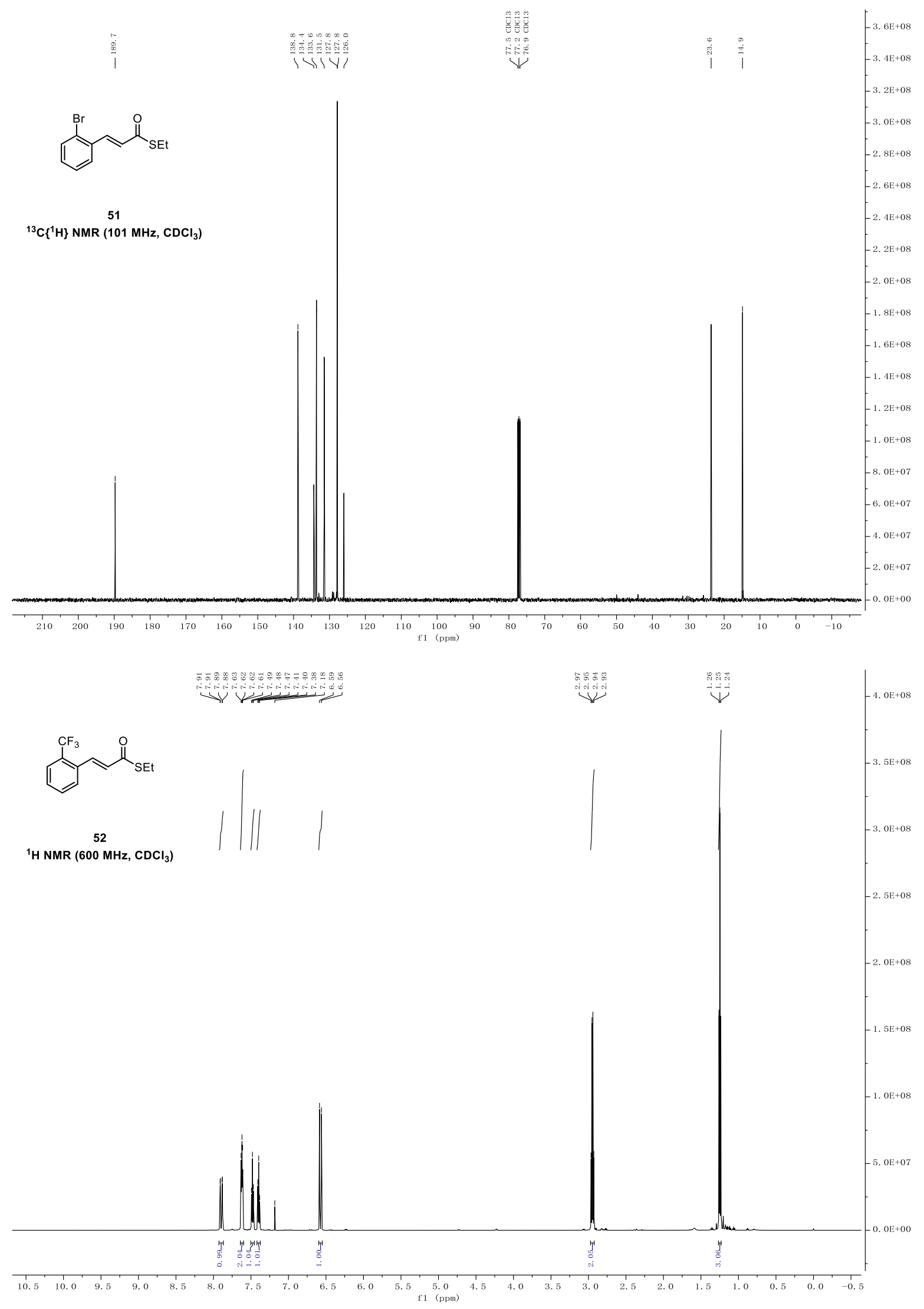




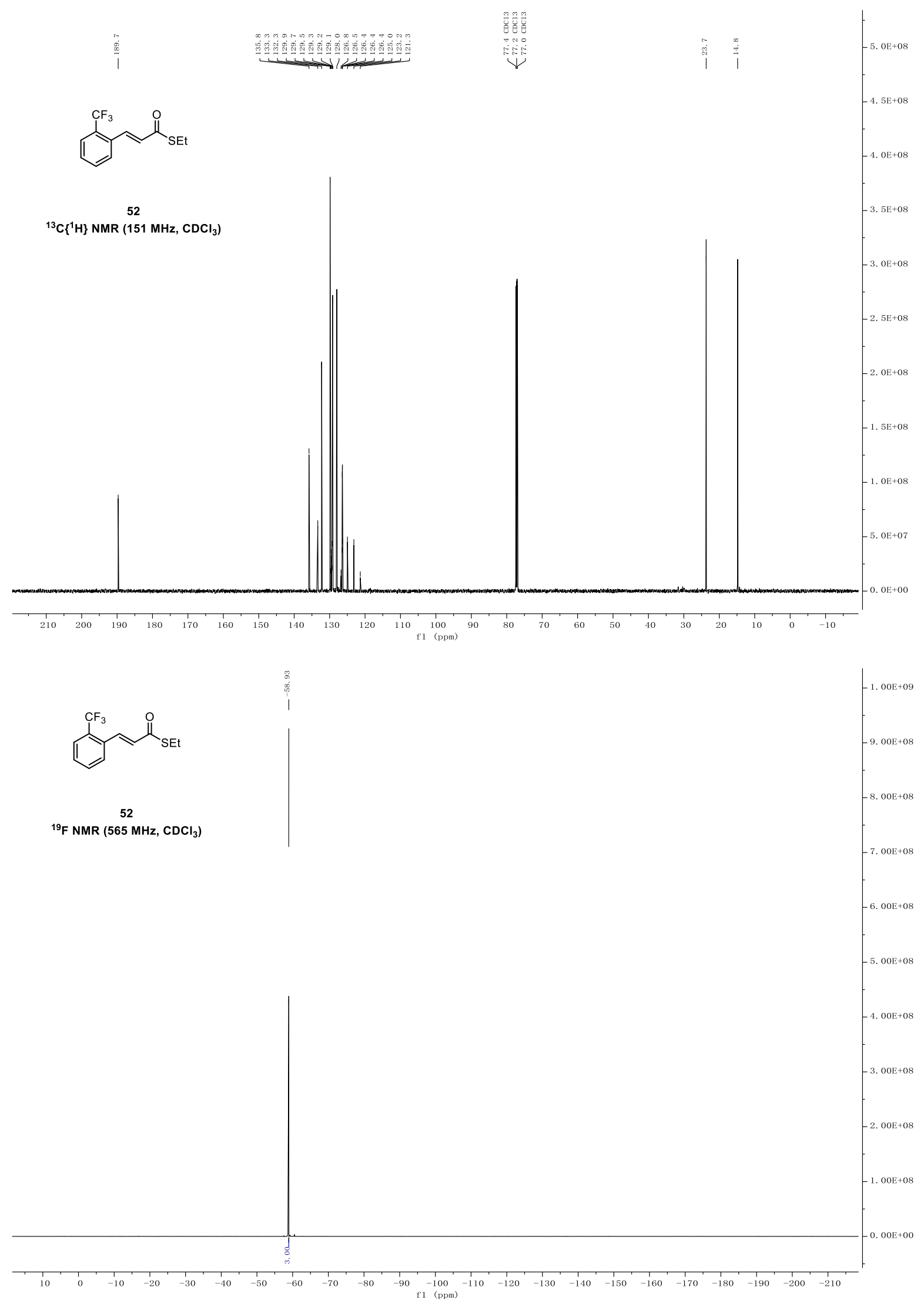




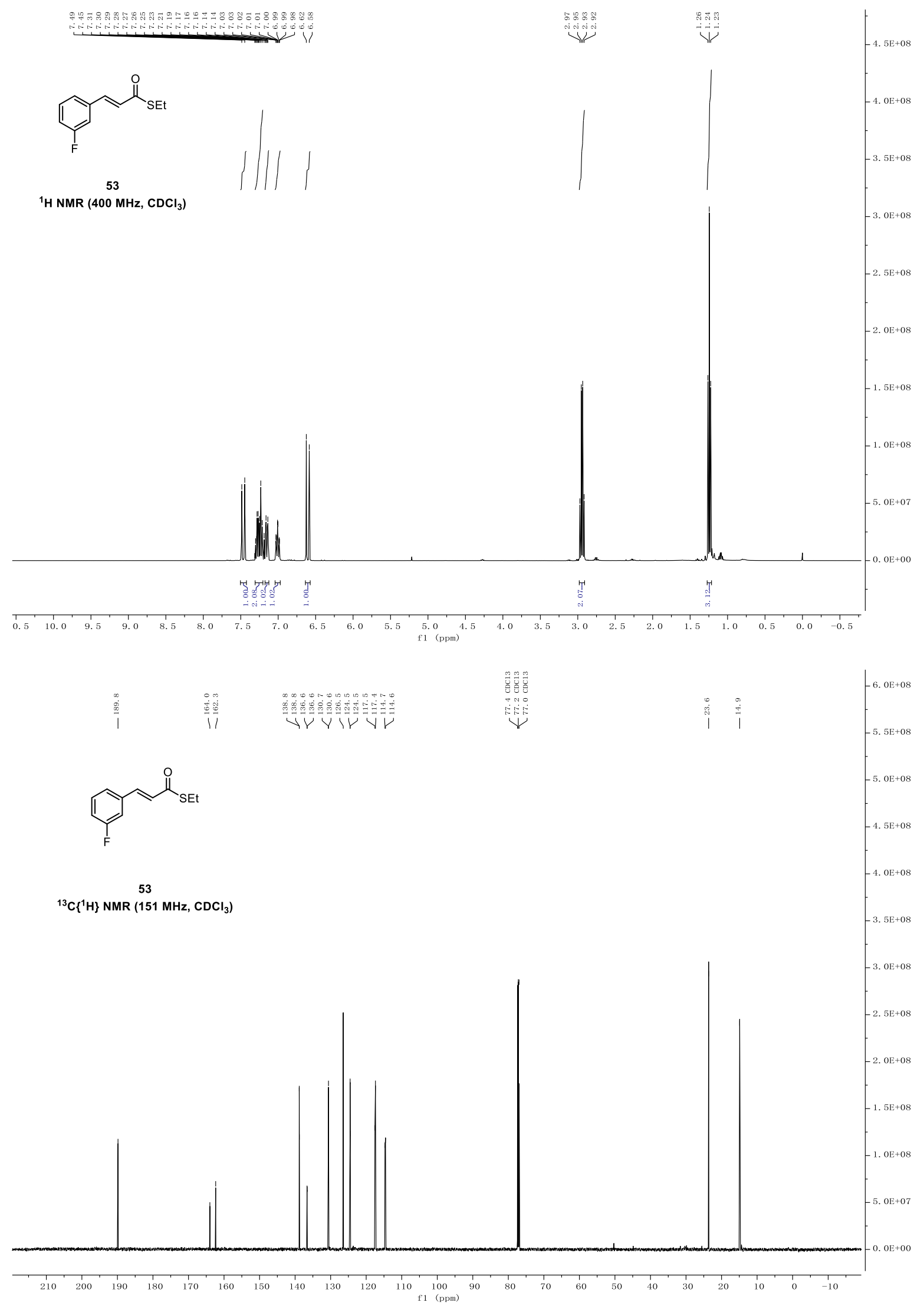




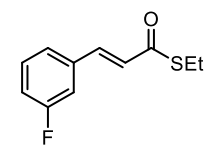

53

${ }^{19} \mathrm{~F} \mathrm{NMR}\left(565 \mathrm{MHz}, \mathrm{CDCl}_{3}\right.$ )

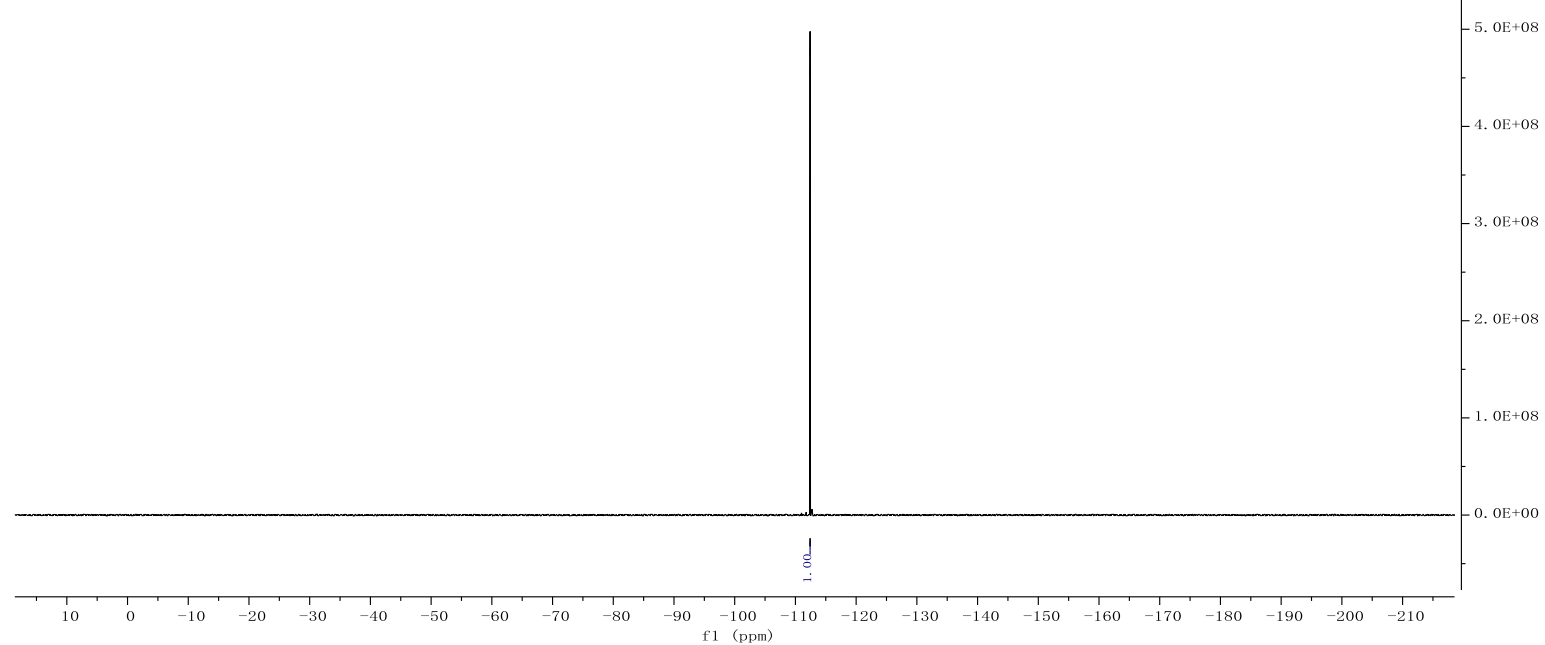

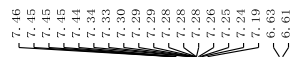
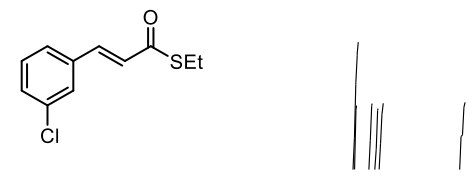

54

${ }^{1} \mathrm{H}$ NMR $\left(600 \mathrm{MHz}, \mathrm{CDCl}_{3}\right)$

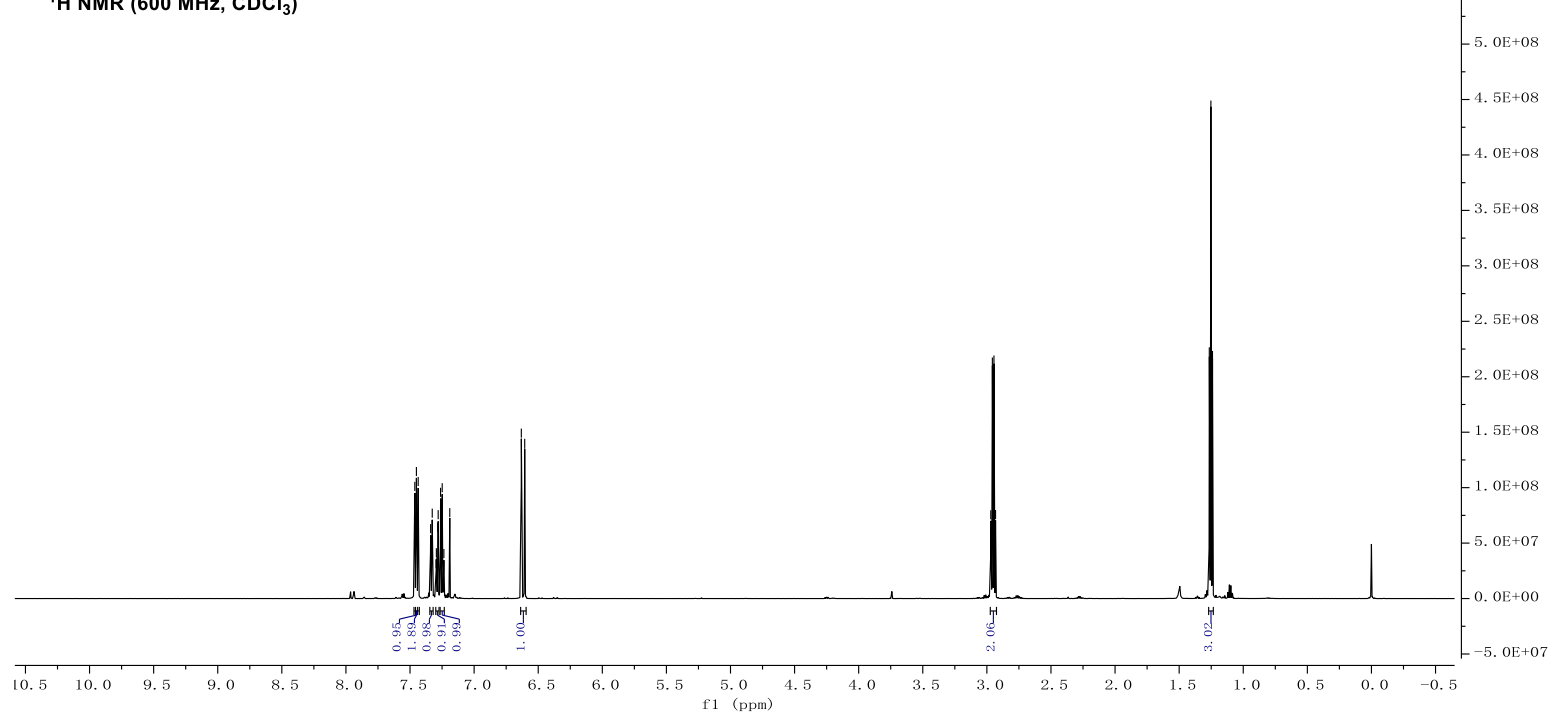




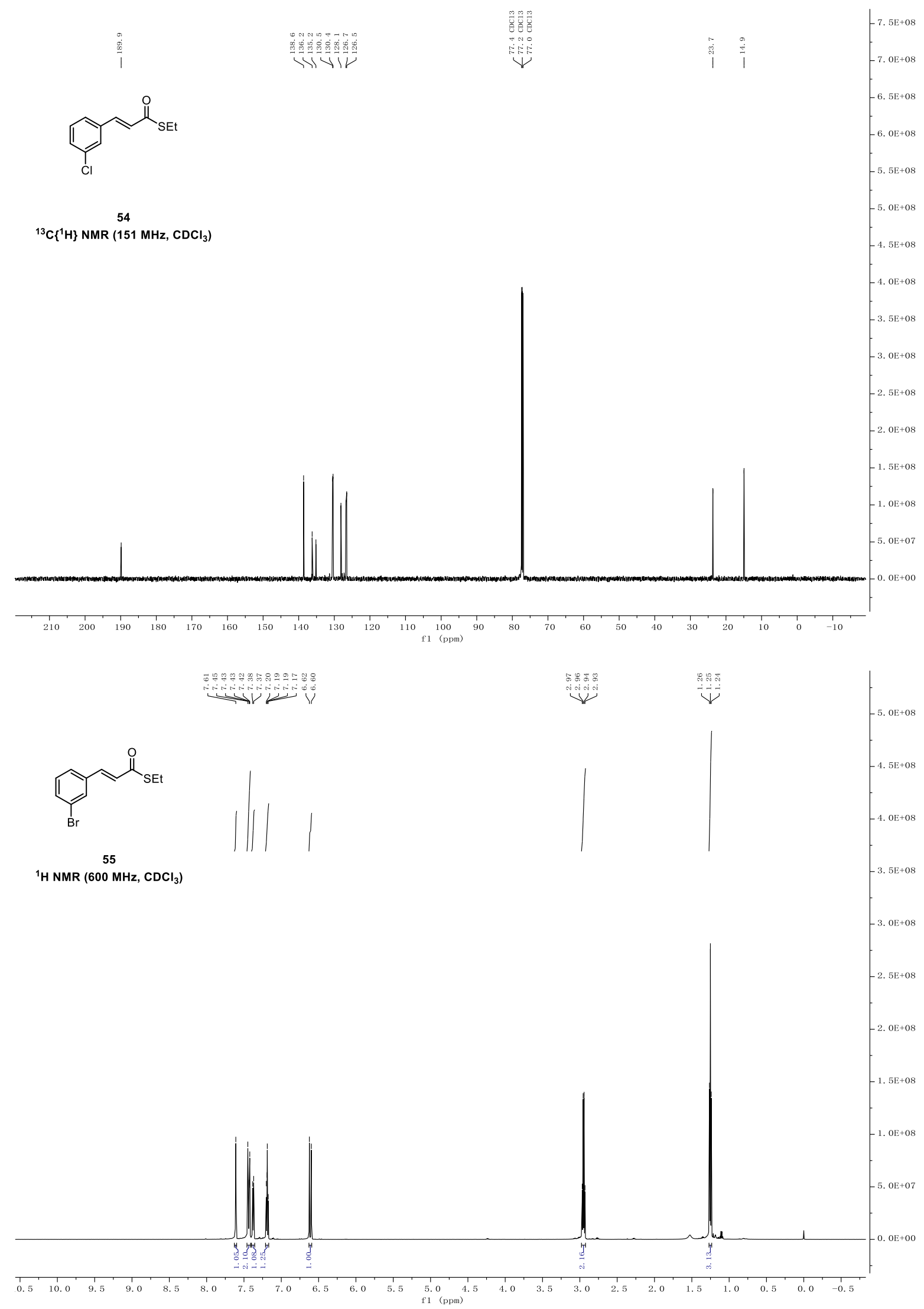

S48 

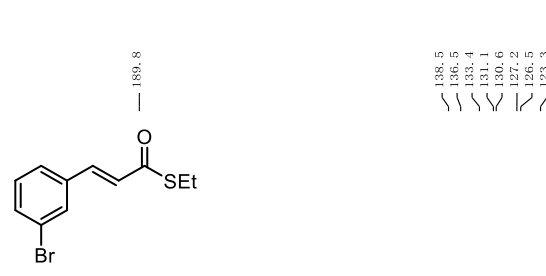

1

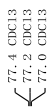

55

${ }^{3} \mathrm{C}\left\{{ }^{1} \mathrm{H}\right\}$ NMR (151 MHz, $\left.\mathrm{CDCl}_{3}\right)$

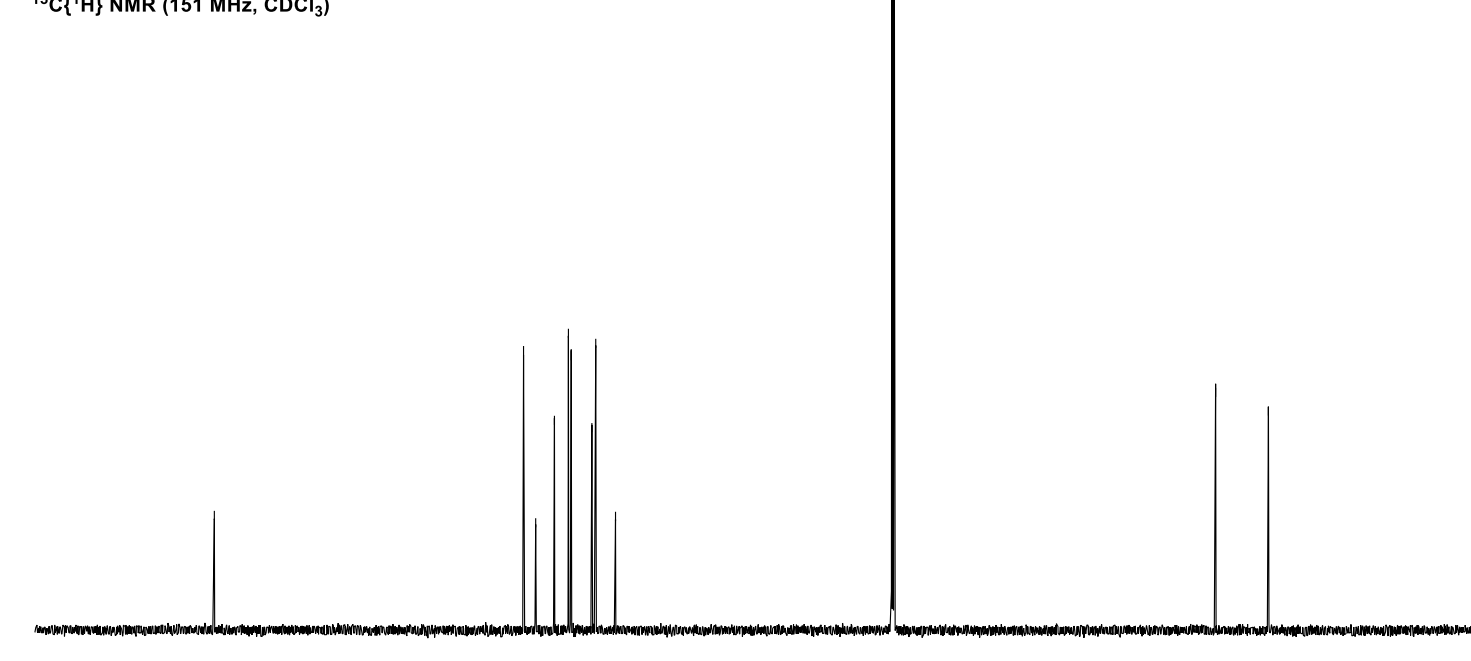

3. $5 \mathrm{E}+08$

3. $0 \mathrm{E}+08$

2. $5 \mathrm{E}+08$

2. $0 \mathrm{E}+08$

1. $5 \mathrm{E}+08$

$-0.0 \mathrm{E}+00$

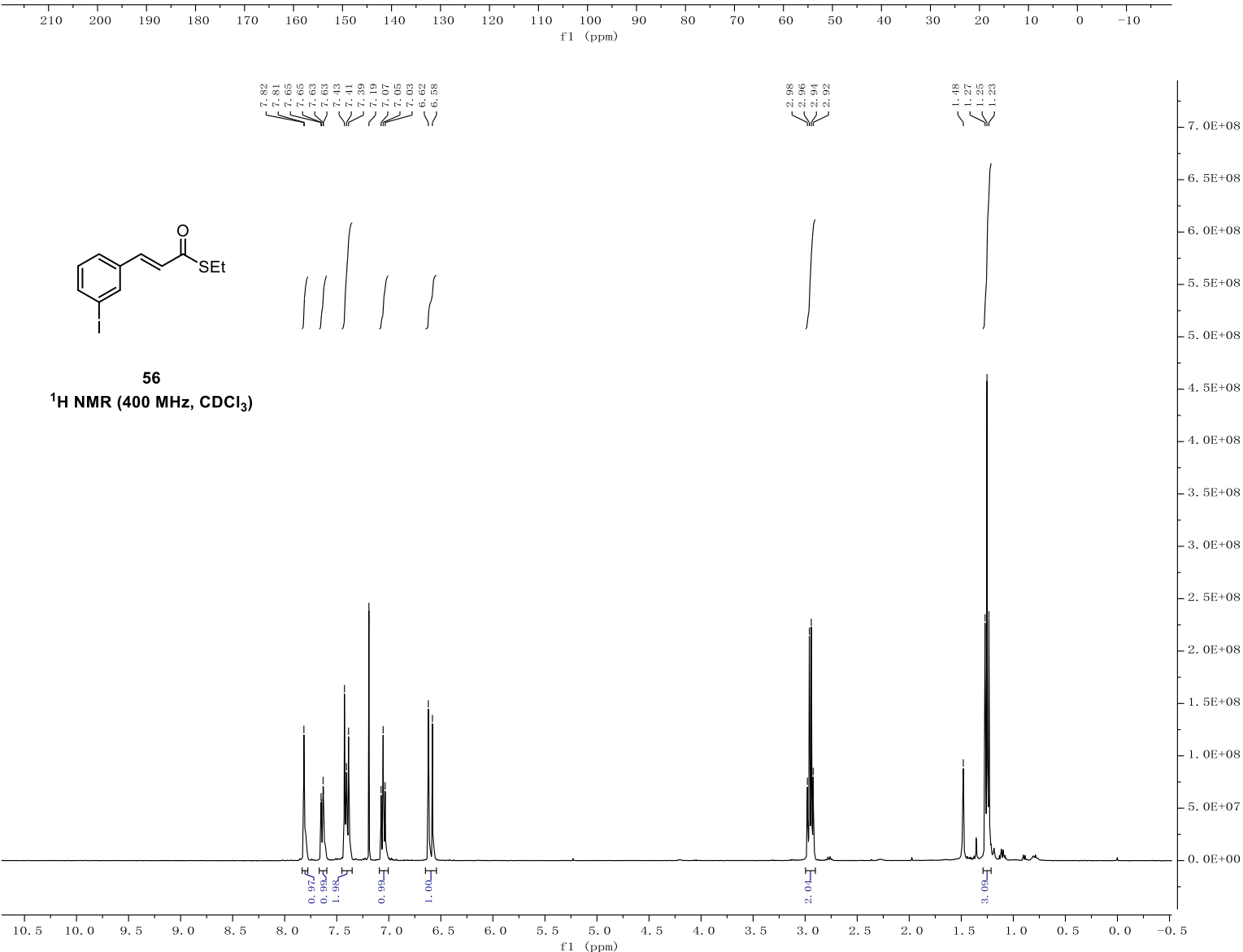




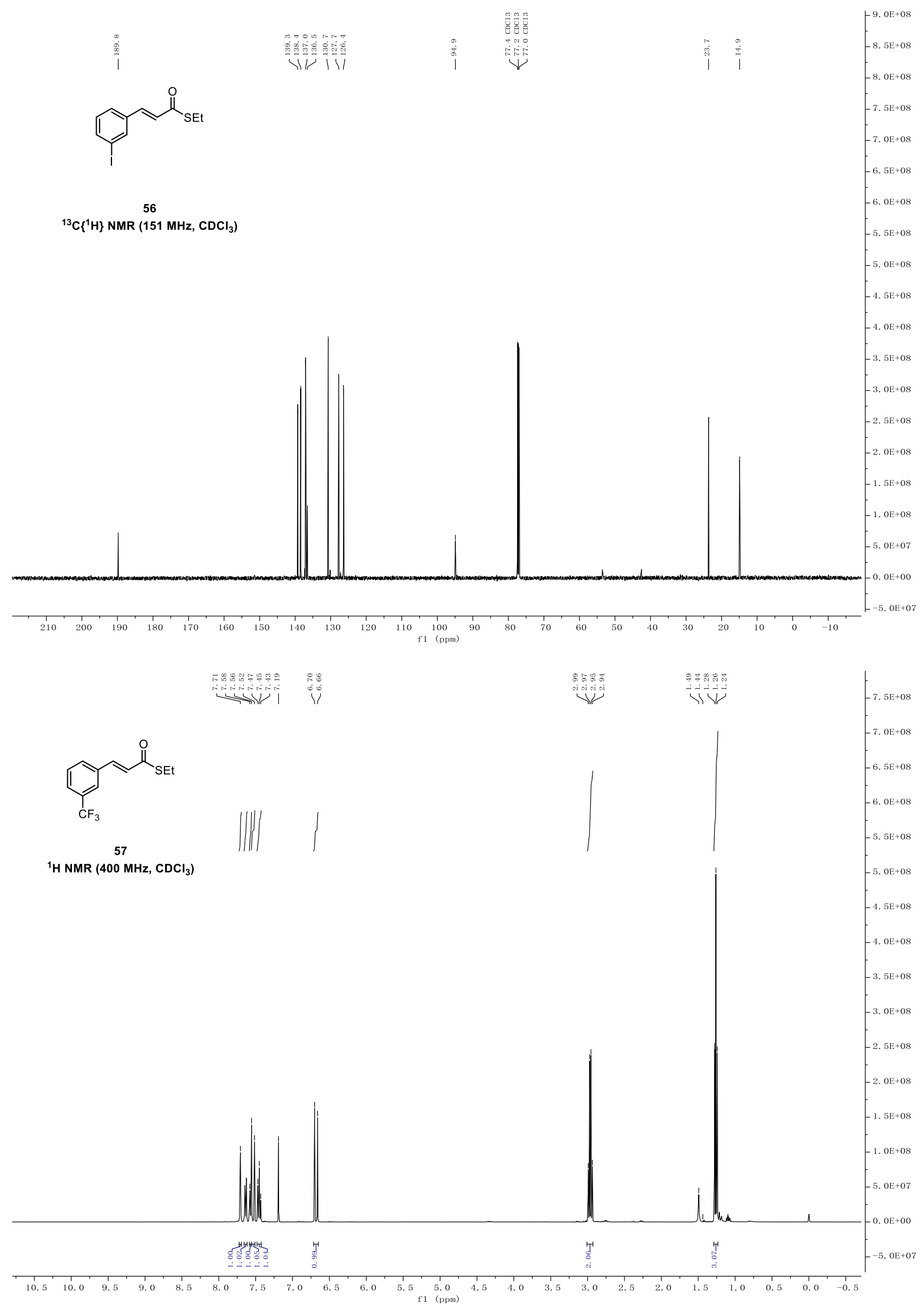



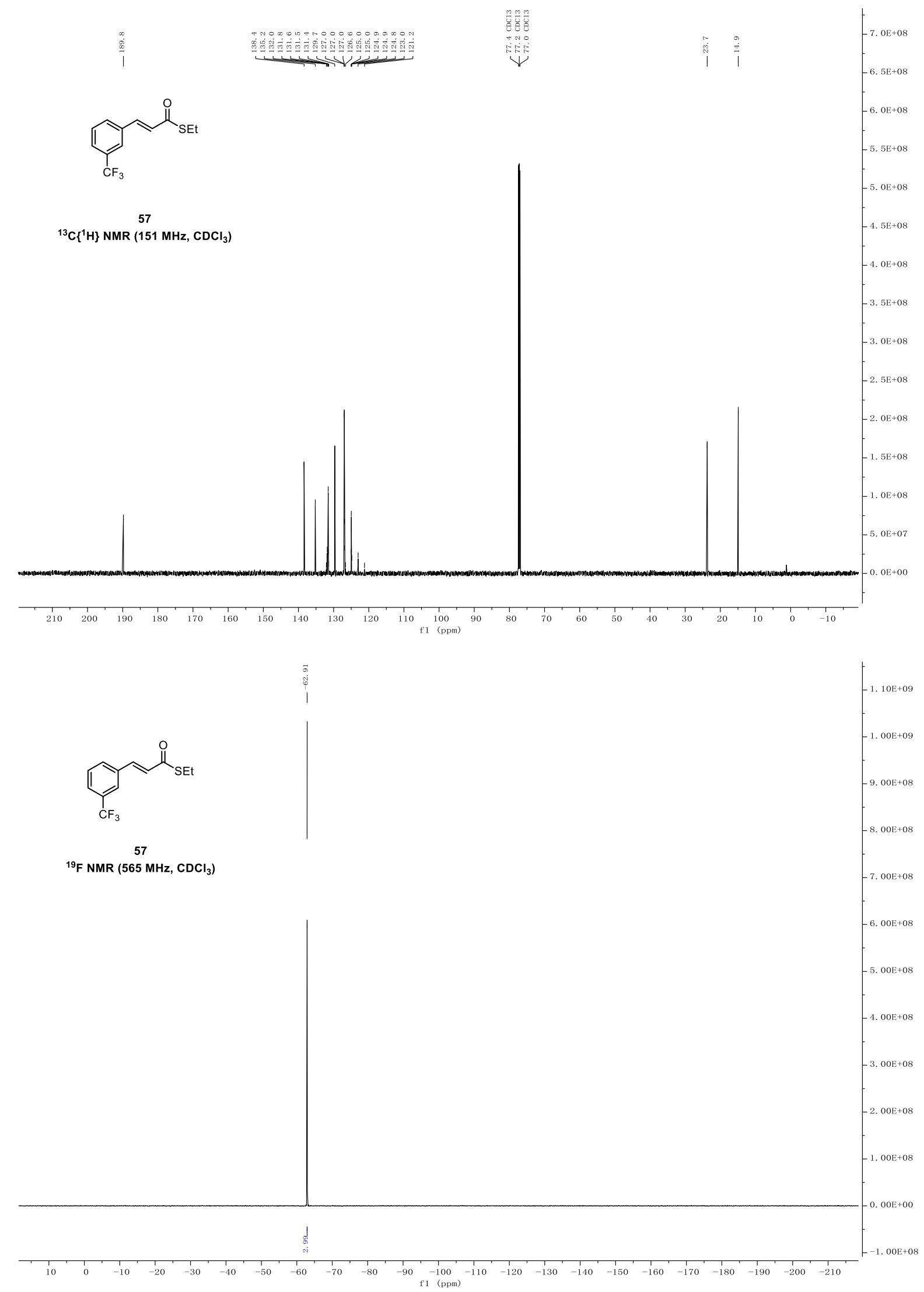

S51 


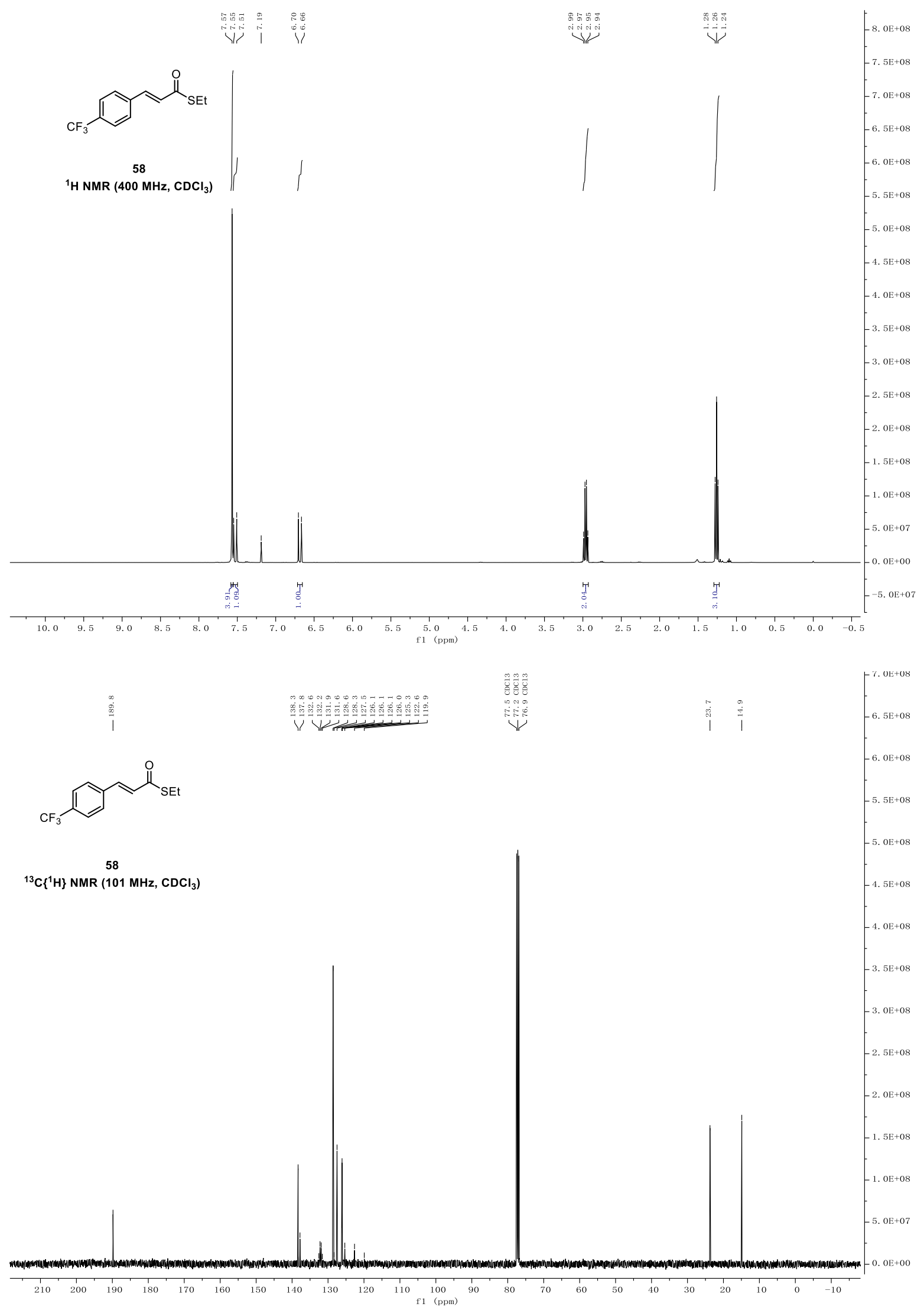




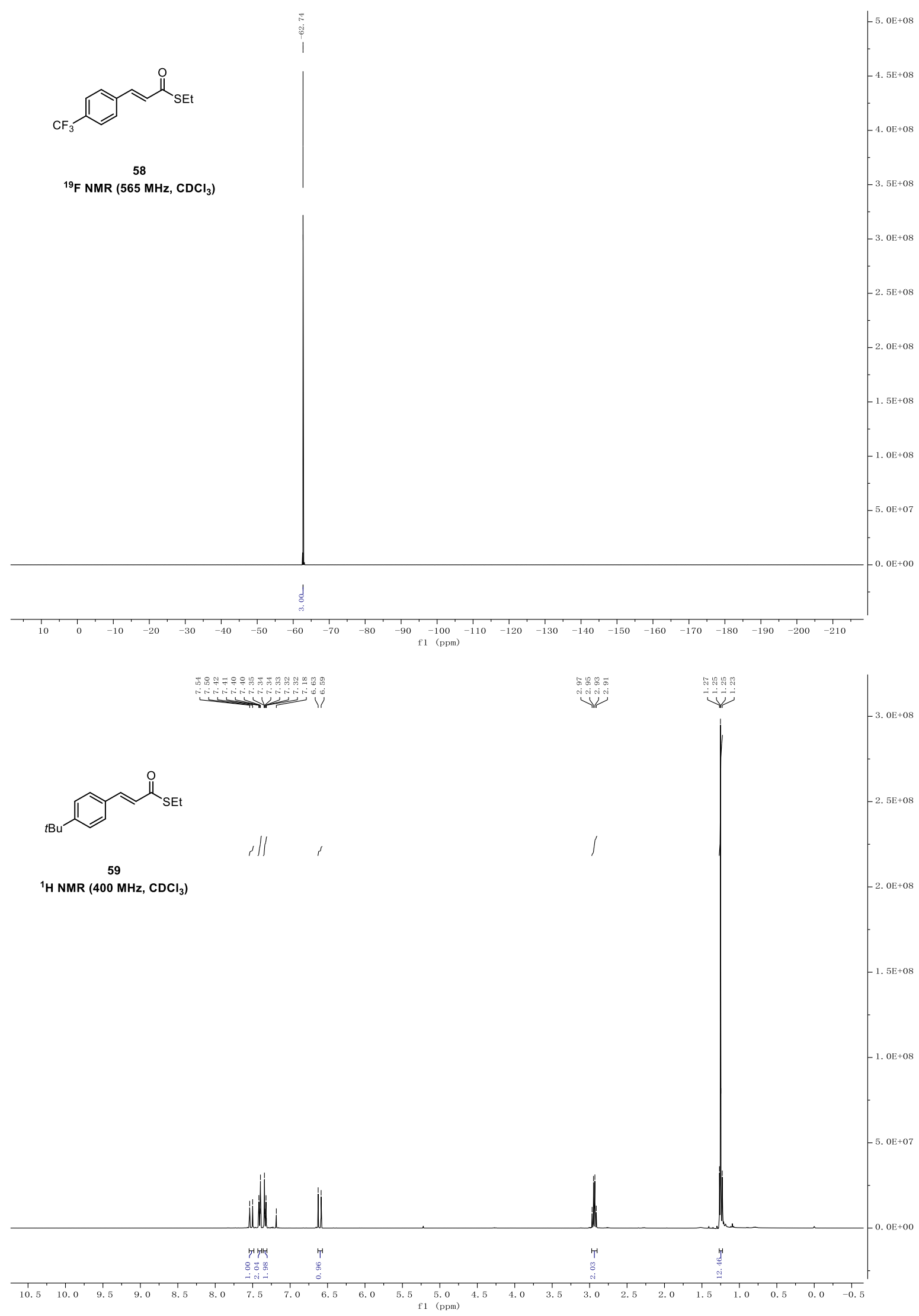




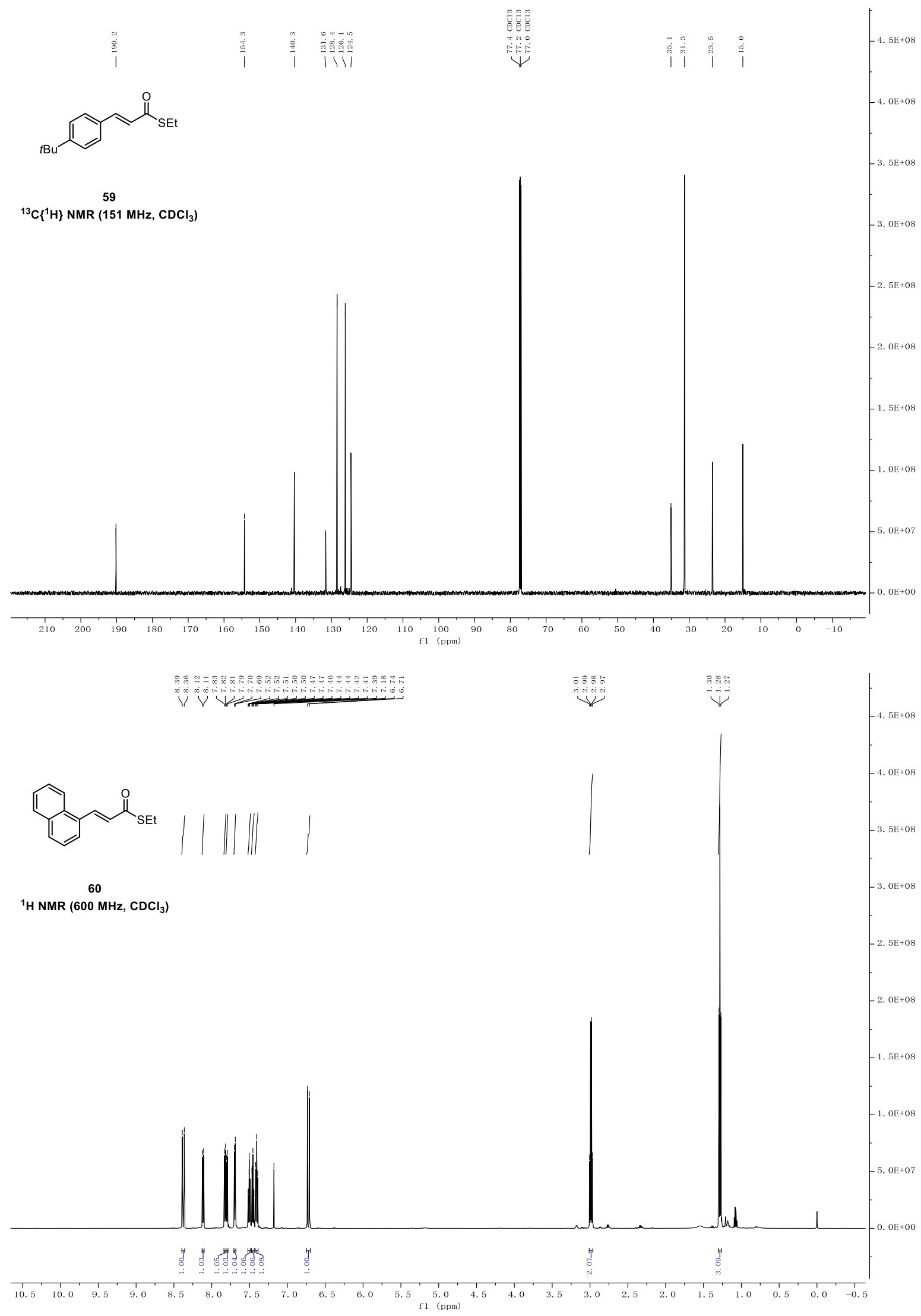




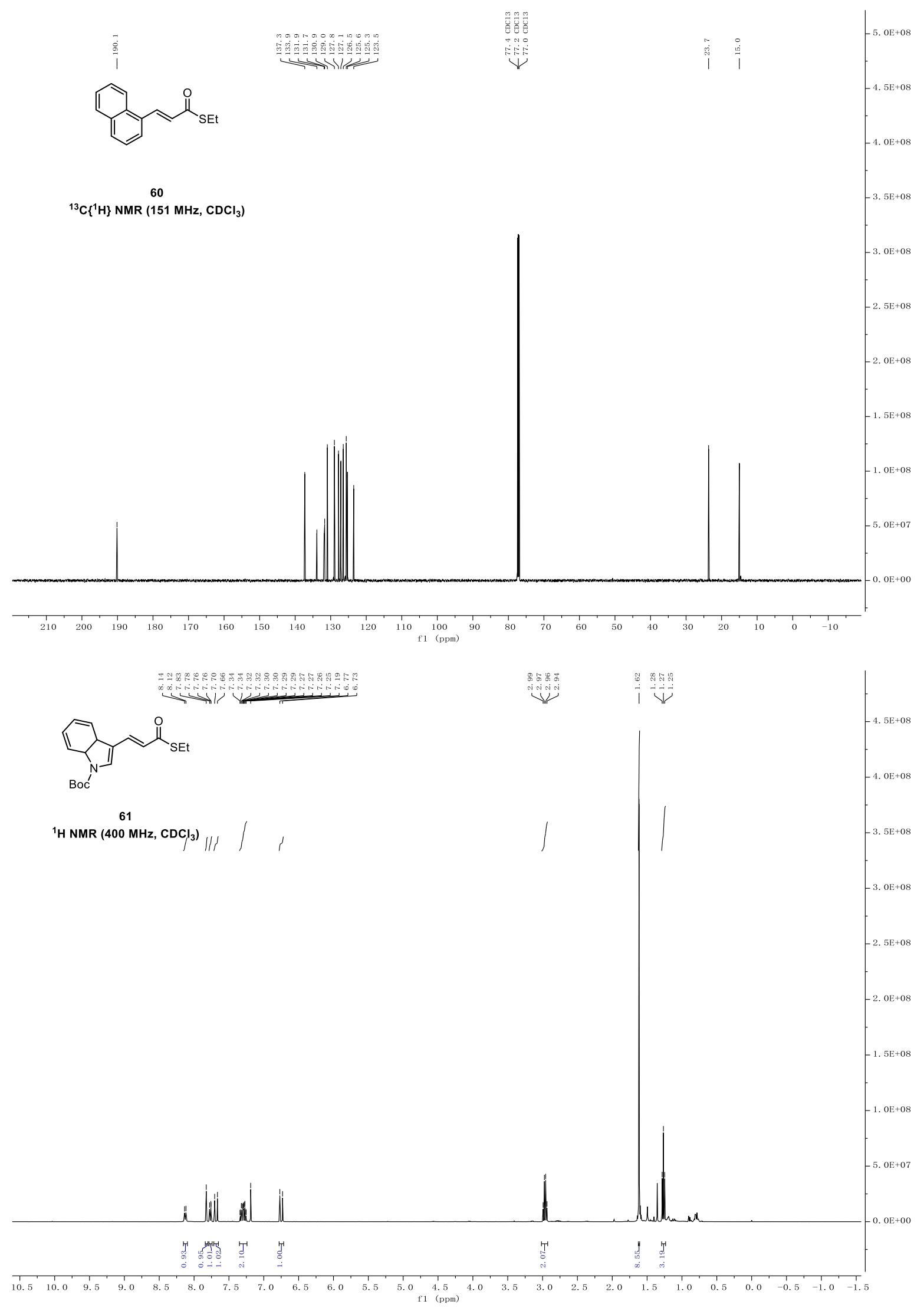



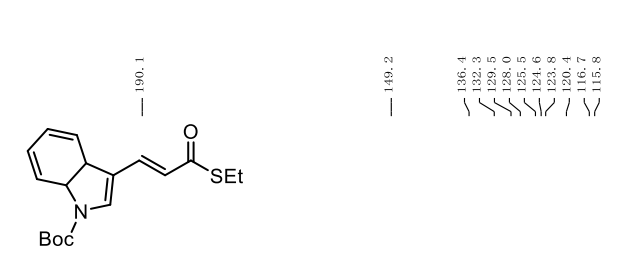

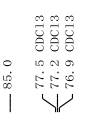

|

$\left.{ }^{13} \mathrm{C}^{1} \mathrm{H}\right\} \mathrm{NMR}\left(101 \mathrm{MHz}, \mathrm{CDCl}_{3}\right)$

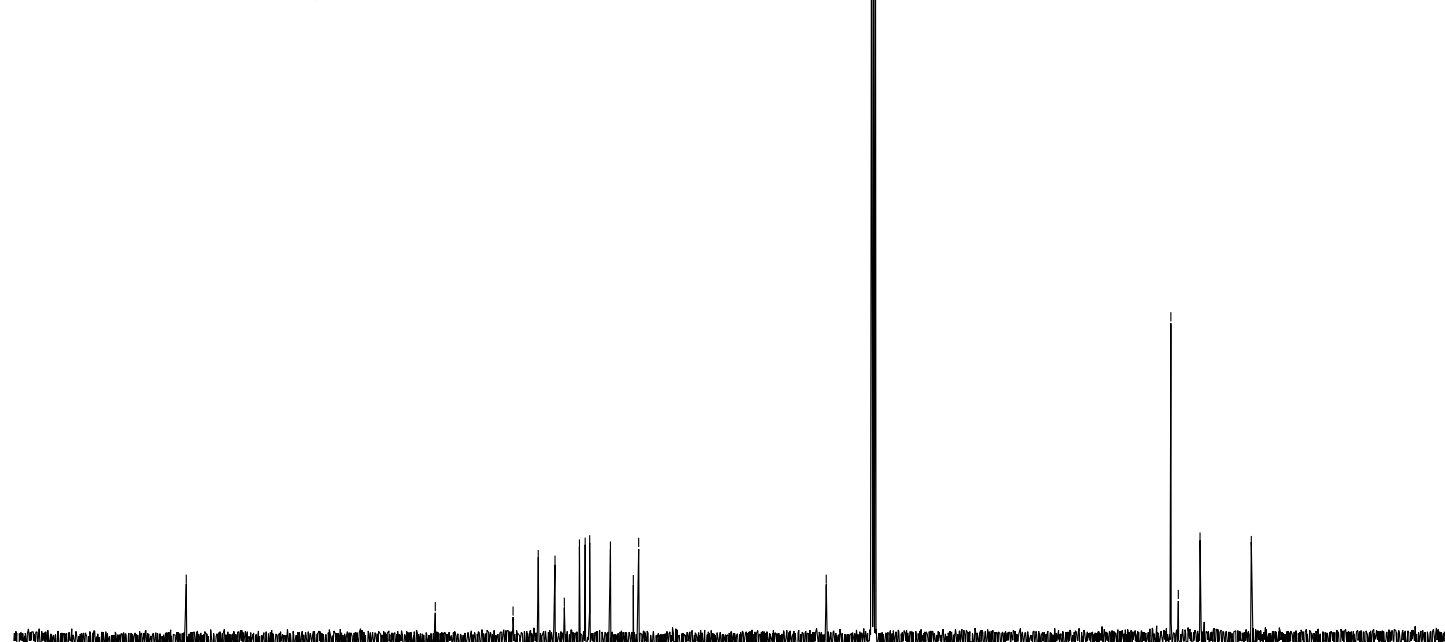

$-0.0 \mathrm{E}+00$

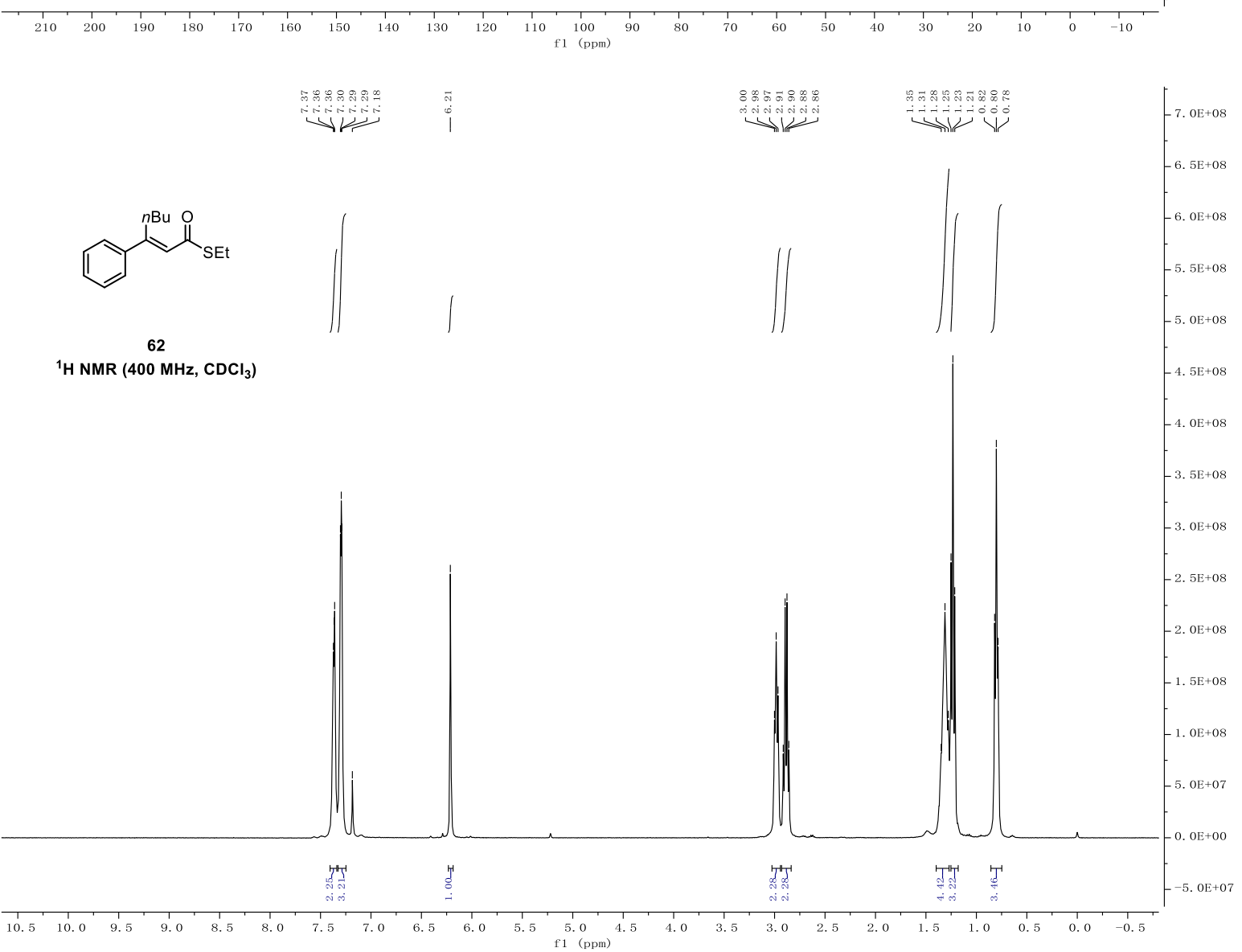




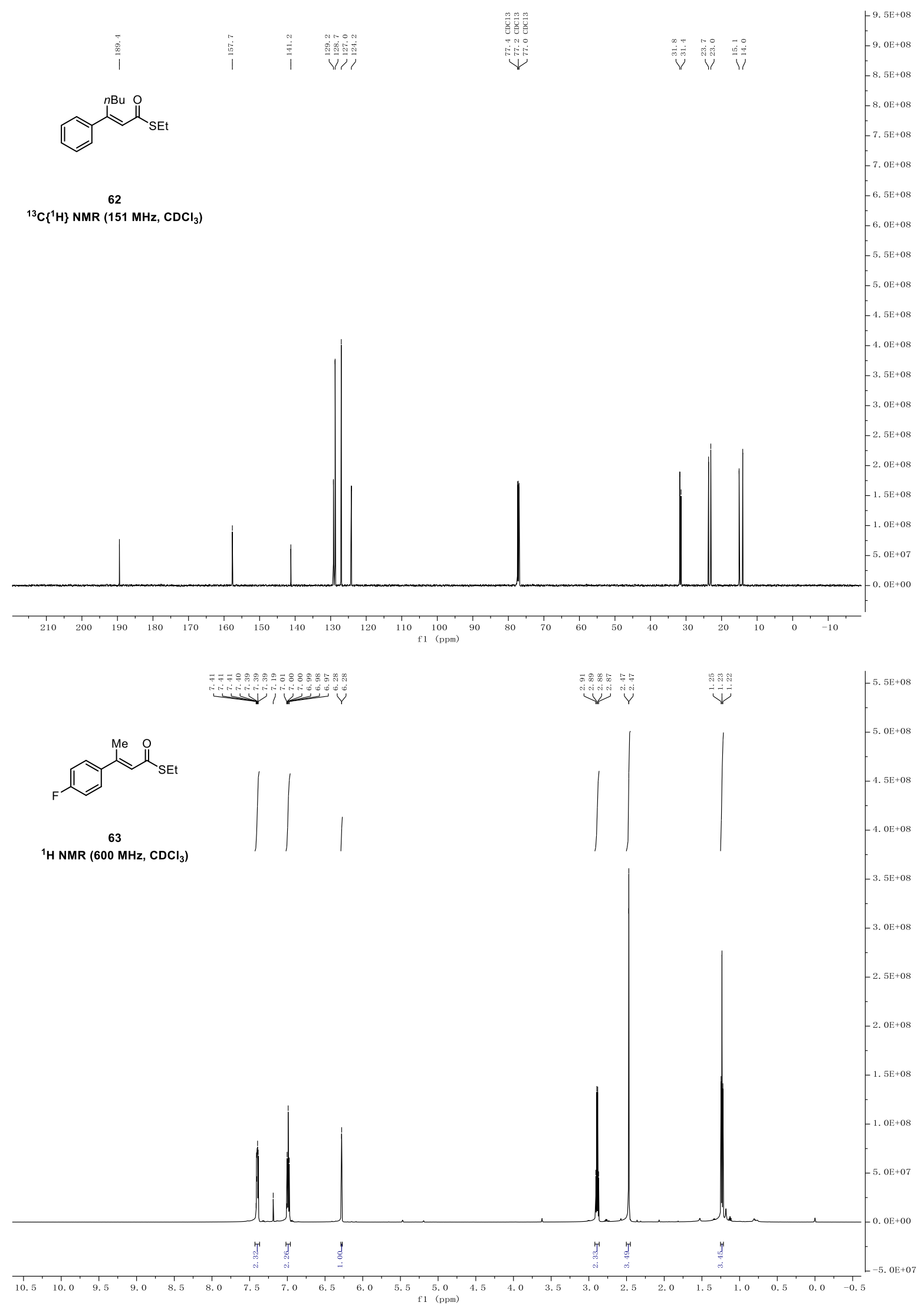




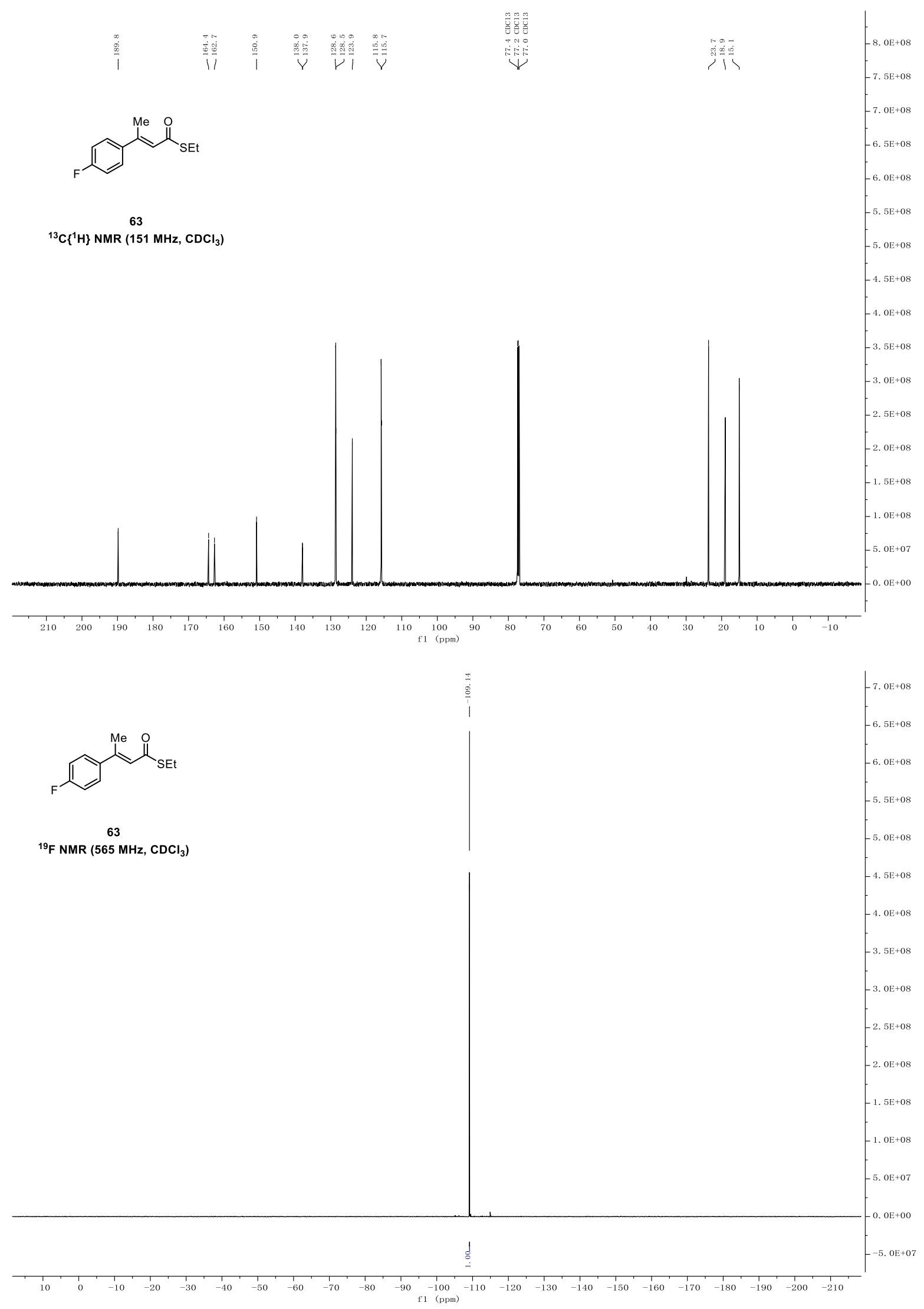




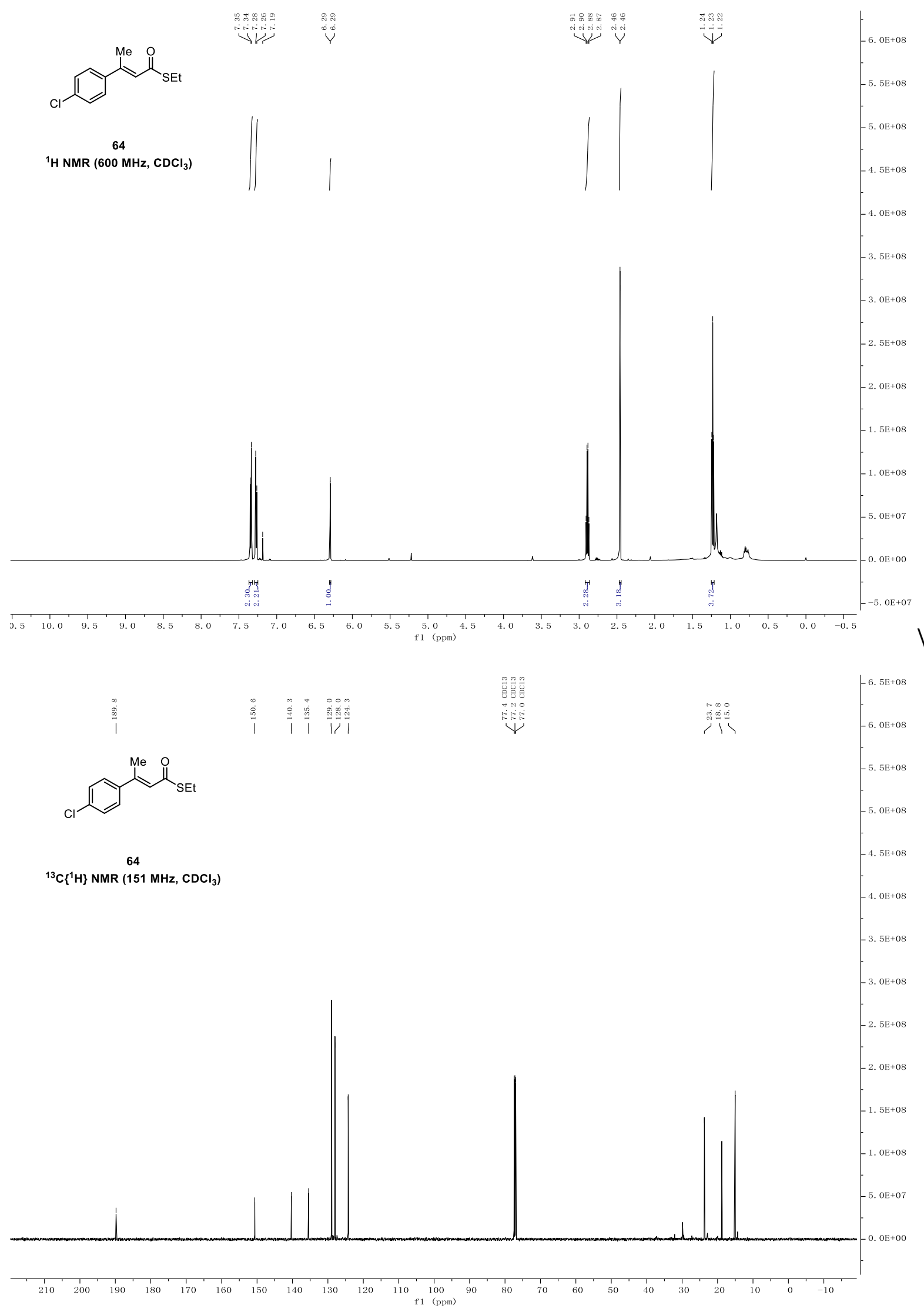




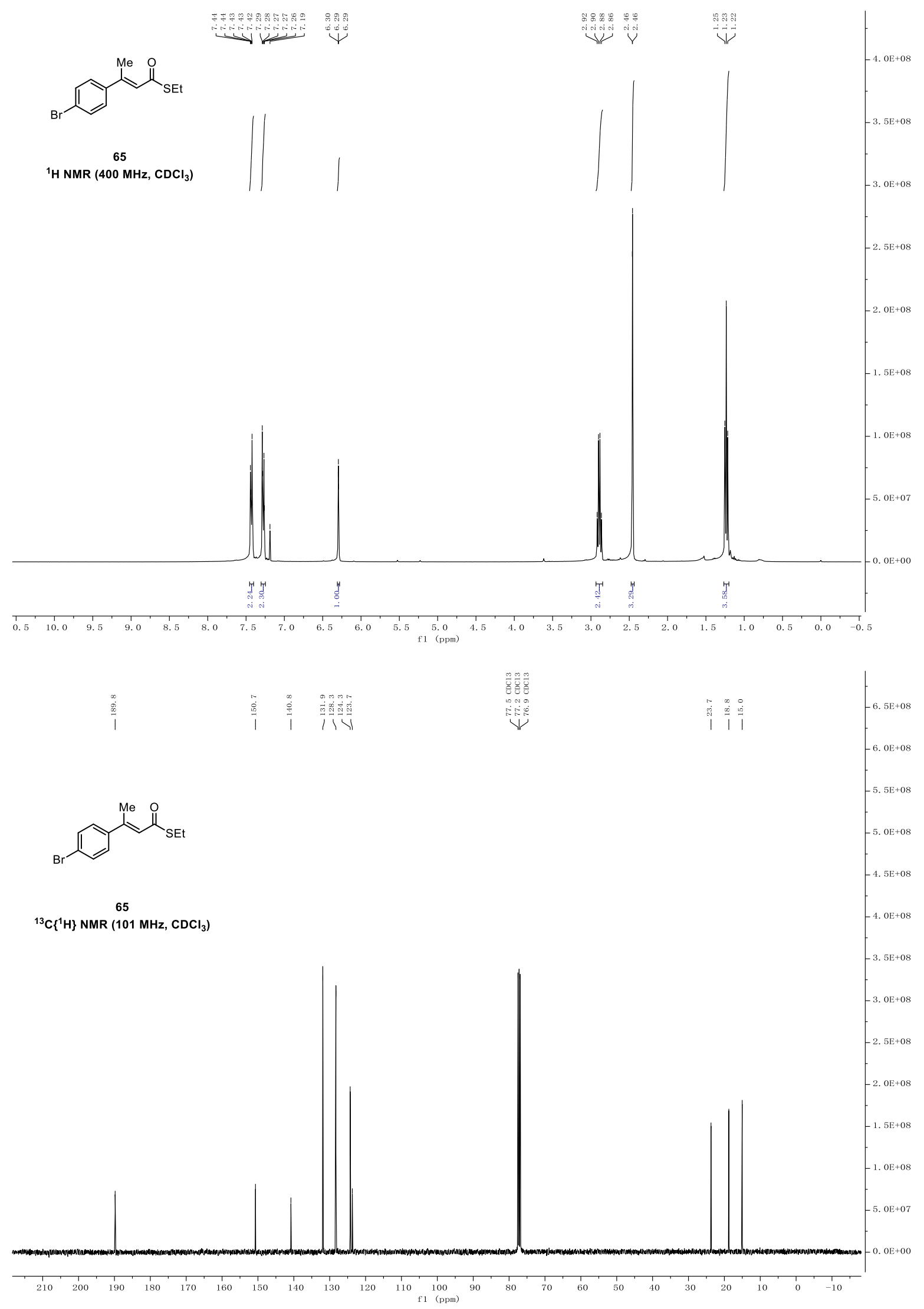




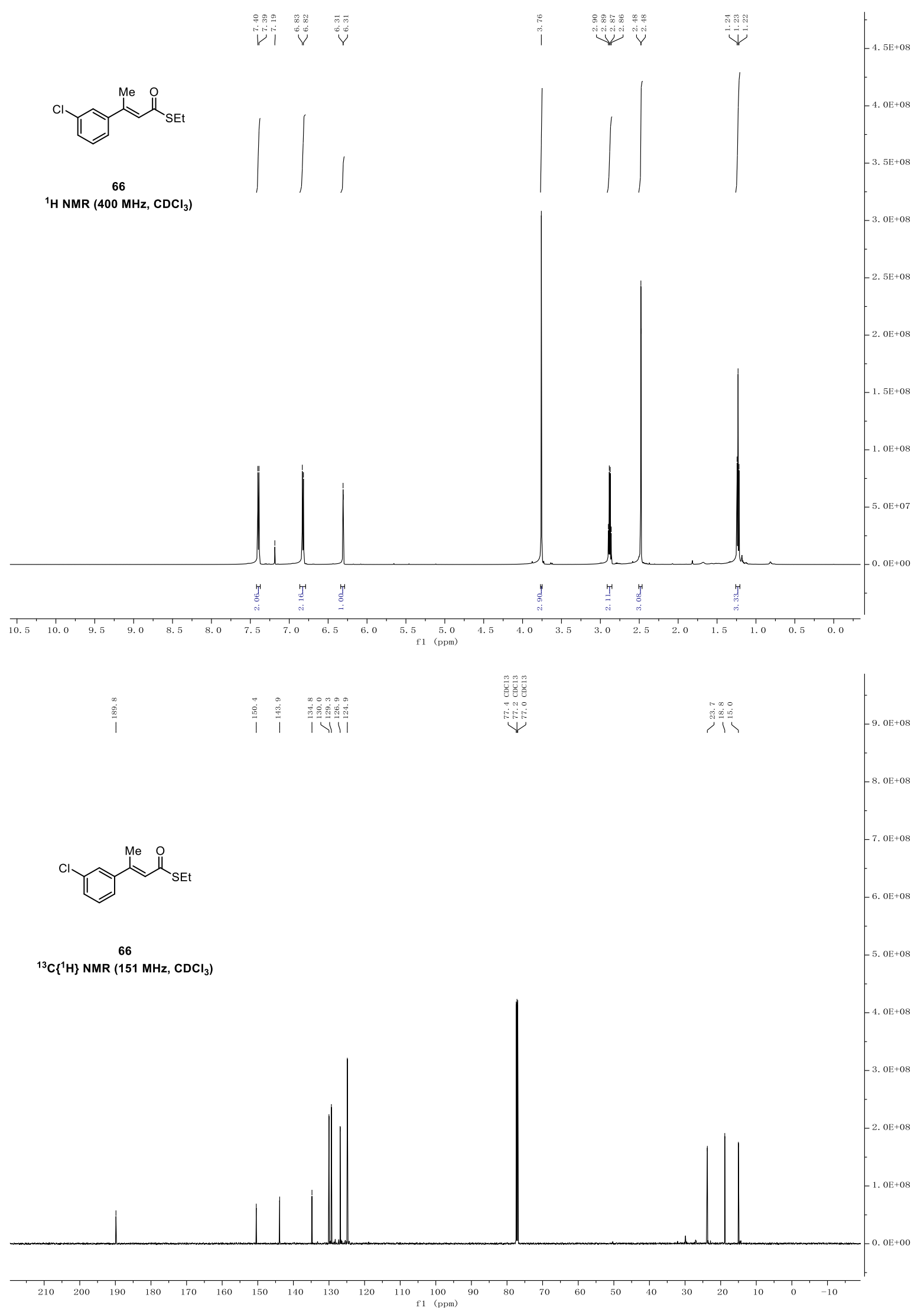




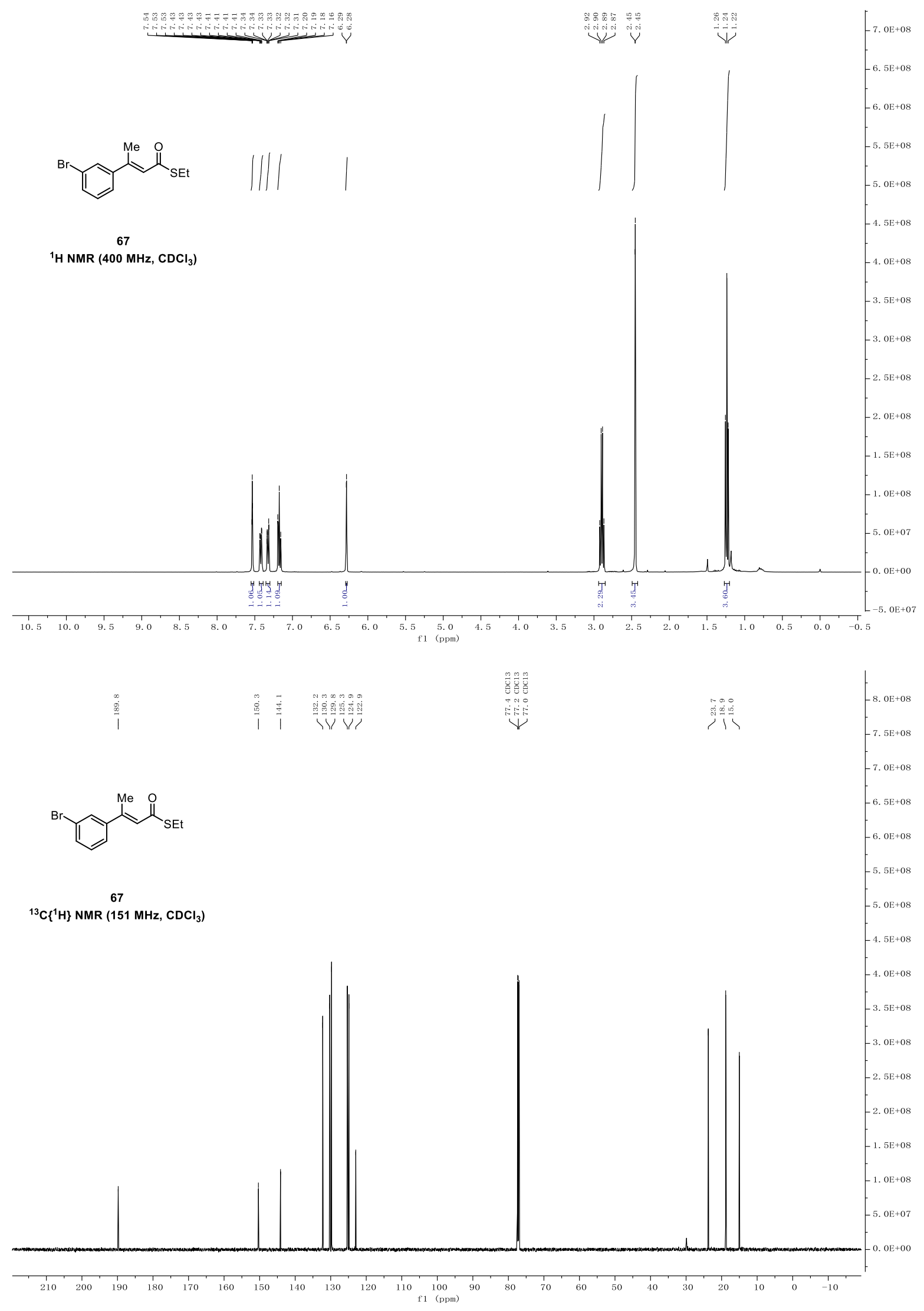



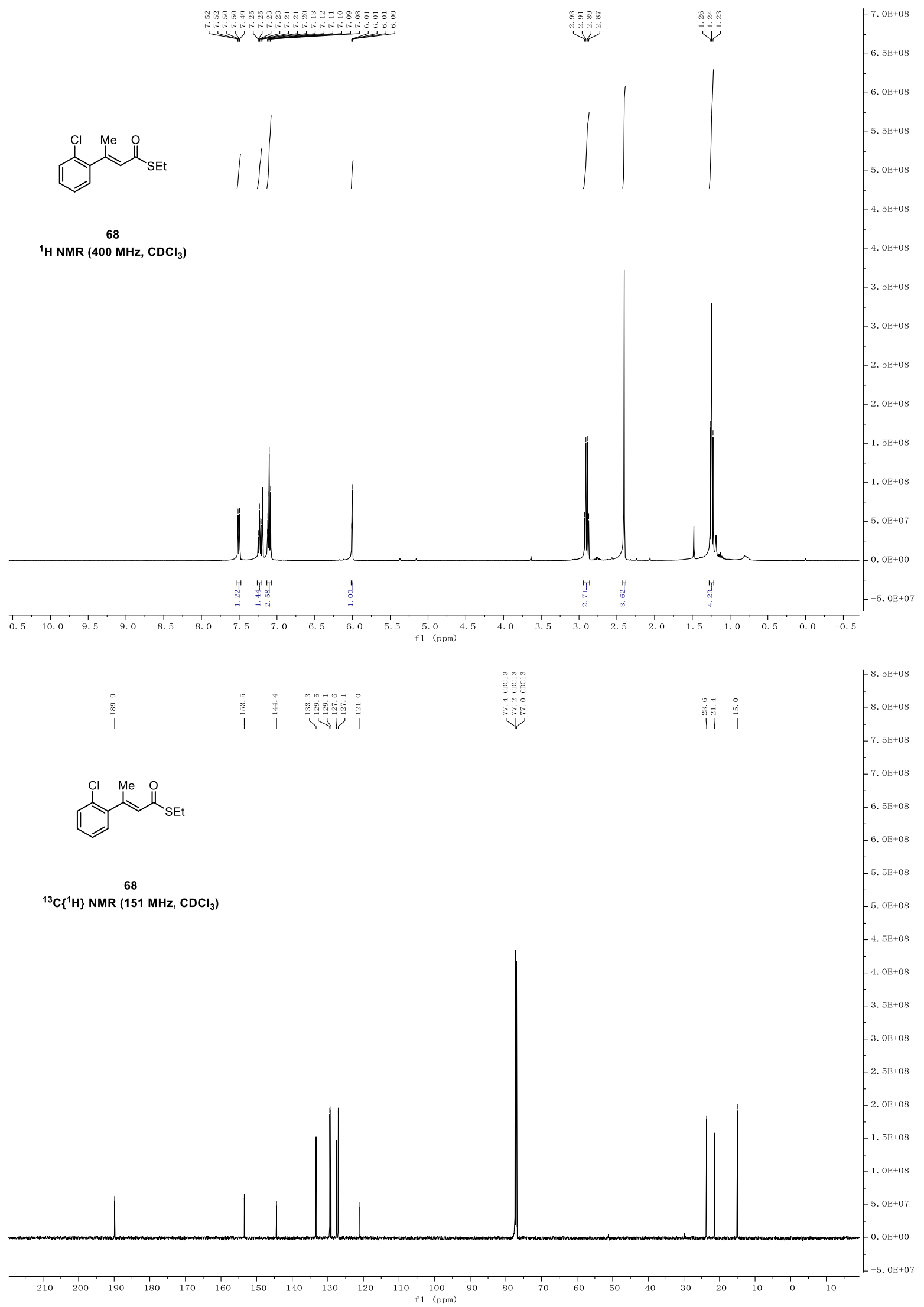


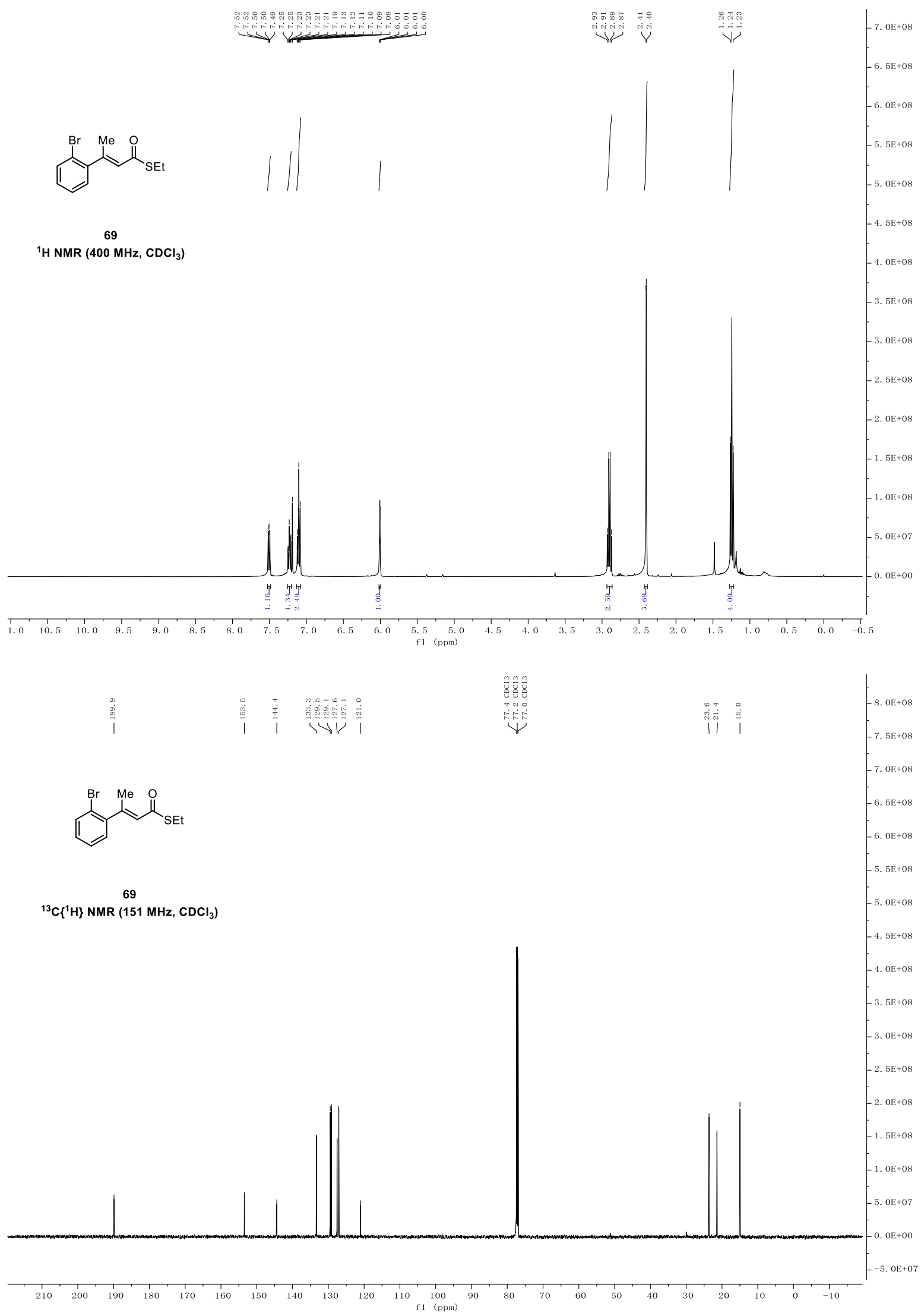

S64 


\section{High-Resolution Mass Spectrum of Product 48}<smiles>CCOC(=O)CC(/C=C(\CC)c1ccccc1)c1ccccc1</smiles>

S-Ethyl (Z)-3,5-diphenyloct-5-enethioate (48). HRMS (ESI-TOF) m/z: $[\mathrm{M}+\mathrm{Na}]^{+}$calcd for $\mathrm{C}_{22} \mathrm{H}_{26} \mathrm{OSNa} 361.1597$, Found 361.1592.

\section{Mass Spectrum SmartFormula Report}
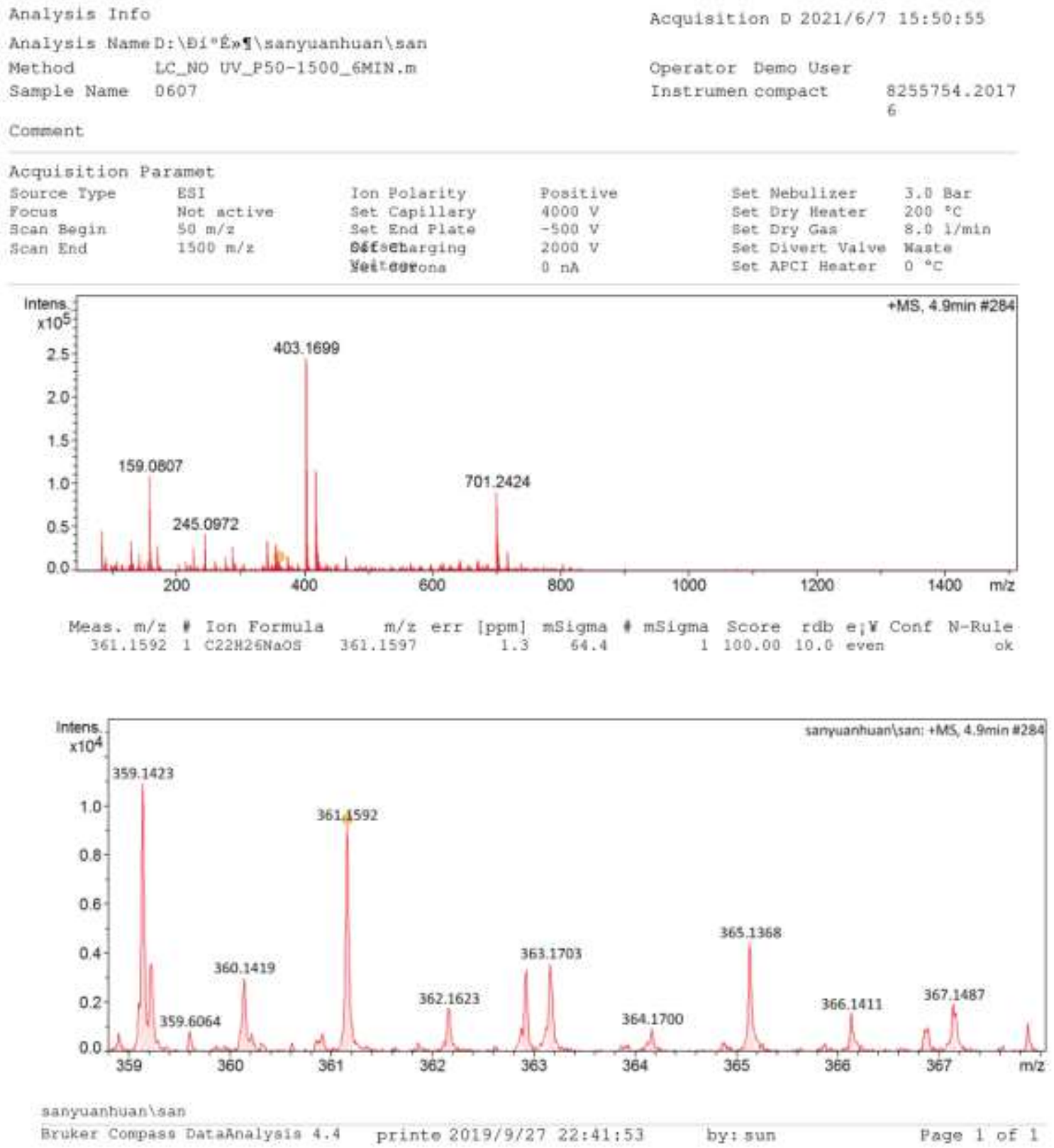


\section{References}

(1) Frisch, M. J.; Trucks, G. W.; Schlegel, H. B.; Scuseria, G. E.; Robb, M. A.; Cheeseman, J. R.; Scalmani, G.; Barone, V.; Petersson, G. A.; Nakatsuji, H.; Li, X.; Caricato, M.; Marenich, A. V.; Bloino, J.; Janesko, B. G.; Gomperts, R.; Mennucci, B.; Hratchian, H. P.; Ortiz, J. V.; Izmaylov, A. F.; Sonnenberg, J. L.; Williams; Ding, F.; Lipparini, F.; Egidi, F.; Goings, J.; Peng, B.; Petrone, A.; Henderson, T.; Ranasinghe, D.; Zakrzewski, V. G.; Gao, J.; Rega, N.; Zheng, G.; Liang, W.; Hada, M.; Ehara, M.; Toyota, K.; Fukuda, R.; Hasegawa, J.; Ishida, M.; Nakajima, T.; Honda, Y.; Kitao, O.; Nakai, H.; Vreven, T.; Throssell, K.; Montgomery Jr., J. A.; Peralta, J. E.; Ogliaro, F.; Bearpark, M. J.; Heyd, J. J.; Brothers, E. N.; Kudin, K. N.; Staroverov, V. N.; Keith, T. A.; Kobayashi, R.; Normand, J.; Raghavachari, K.; Rendell, A. P.; Burant, J. C.; Iyengar, S. S.; Tomasi, J.; Cossi, M.; Millam, J. M.; Klene, M.; Adamo, C.; Cammi, R.; Ochterski, J. W.; Martin, R. L.; Morokuma, K.; Farkas, O.; Foresman, J. B.; Fox, D. J. Wallingford, CT, Gaussian 16 Rev. A.01, 2016. 